\title{
Straightforward synthesis of highly functionalized indanes and tetralines through ene-cyclopropene rearrangement mediated by ruthenium.
}

\author{
Alejandro Puet, Gema Domínguez and Javier Pérez-Castells* \\ Department of Chemistry and Biochemistry Facultad de Farmacia, Universidad San \\ Pablo-CEU, CEU Universities Urbanización Montepríncipe, 28660 Boadilla del Monte, \\ Madrid, SPAIN.
}

E-mail:.jpercas@,ceu.es 
TABLE OF CONTENTS

\begin{tabular}{|c|c|}
\hline${ }^{1} \mathrm{H}$ and ${ }^{13} \mathrm{C}\left\{{ }^{1} \mathrm{H}\right\}$ of compound $\mathbf{1 b}$ & S1 \\
\hline${ }^{1} \mathrm{H}$ and ${ }^{13} \mathrm{C}\left\{{ }^{1} \mathrm{H}\right\}$ of compound $\mathbf{1 c}$ & S3 \\
\hline${ }^{1} \mathrm{H}$ and ${ }^{13} \mathrm{C}\left\{{ }^{1} \mathrm{H}\right\}$ of compound $1 \mathrm{e}$ & S5 \\
\hline${ }^{1} \mathrm{H}$ and ${ }^{13} \mathrm{C}\left\{{ }^{1} \mathrm{H}\right\}$ of compound $\mathbf{1 f}$ & S7 \\
\hline${ }^{1} \mathrm{H}$ and ${ }^{13} \mathrm{C}\left\{{ }^{1} \mathrm{H}\right\}$ of compound $\mathbf{1 g}$ & S9 \\
\hline${ }^{1} \mathrm{H}$ and ${ }^{13} \mathrm{C}\left\{{ }^{1} \mathrm{H}\right\}$ of compound $\mathbf{1 h}$ & S11 \\
\hline${ }^{1} \mathrm{H}$ and ${ }^{13} \mathrm{C}\left\{{ }^{1} \mathrm{H}\right\}$ of compound $\mathbf{1 i}$ & S13 \\
\hline${ }^{1} \mathrm{H}$ and ${ }^{13} \mathrm{C}\left\{{ }^{1} \mathrm{H}\right\}$ of compound $\mathbf{1 j}$ & S15 \\
\hline COSY of compound $\mathbf{1 j}$ & S17 \\
\hline HMQC of compound $\mathbf{1} \mathbf{j}$ & S18 \\
\hline${ }^{1} \mathrm{H}$ and ${ }^{13} \mathrm{C}\left\{{ }^{1} \mathrm{H}\right\}$ of compound $\mathbf{1 k}$ & S19 \\
\hline${ }^{1} \mathrm{H}$ and ${ }^{13} \mathrm{C}\left\{{ }^{1} \mathrm{H}\right\}$ of compound $\mathbf{1 m}$ & S21 \\
\hline${ }^{1} \mathrm{H}$ and ${ }^{13} \mathrm{C}\left\{{ }^{1} \mathrm{H}\right\}$ of compound $\mathbf{5 a}$ & S23 \\
\hline${ }^{1} \mathrm{H}$ and ${ }^{13} \mathrm{C}\left\{{ }^{1} \mathrm{H}\right\}$ of compound $\mathbf{5 b}$ & S25 \\
\hline${ }^{1} \mathrm{H}$ and ${ }^{13} \mathrm{C}\left\{{ }^{1} \mathrm{H}\right\}$ of compound $\mathbf{5 c}$ & S27 \\
\hline${ }^{1} \mathrm{H}$ and ${ }^{13} \mathrm{C}\left\{{ }^{1} \mathrm{H}\right\}$ of compound $\mathbf{5 d}$ & $\mathbf{S 2 9}$ \\
\hline${ }^{1} \mathrm{H}$ and ${ }^{13} \mathrm{C}\left\{{ }^{1} \mathrm{H}\right\}$ of compound $\mathbf{5 e}$ & S31 \\
\hline${ }^{1} \mathrm{H}$ and ${ }^{13} \mathrm{C}\left\{{ }^{1} \mathrm{H}\right\}$ of compound $\mathbf{5 f}$ & S33 \\
\hline${ }^{1} \mathrm{H}$ and ${ }^{13} \mathrm{C}\left\{{ }^{1} \mathrm{H}\right\}$ of compound $\mathbf{5 g}$ & S35 \\
\hline${ }^{1} \mathrm{H}$ and ${ }^{13} \mathrm{C}\left\{{ }^{1} \mathrm{H}\right\}$ of compound $\mathbf{5 h}$ & S37 \\
\hline${ }^{1} \mathrm{H}$ and ${ }^{13} \mathrm{C}\left\{{ }^{1} \mathrm{H}\right\}$ of compound $\mathbf{5 i}$ & S39 \\
\hline COSY of compound $\mathbf{5 i}$ & S41 \\
\hline HMQC of compound $\mathbf{5 i}$ & S42 \\
\hline${ }^{1} \mathrm{H}$ and ${ }^{13} \mathrm{C}\left\{{ }^{1} \mathrm{H}\right\}$ of compound $\mathbf{5} \mathbf{j}$ & S43 \\
\hline${ }^{1} \mathrm{H}$ and ${ }^{13} \mathrm{C}\left\{{ }^{1} \mathrm{H}\right\}$ of compound $\mathbf{5 k}$ & S45 \\
\hline${ }^{1} \mathrm{H}$ and ${ }^{13} \mathrm{C}\left\{{ }^{1} \mathrm{H}\right\}$ of compound $\mathbf{5 I}$ & S47 \\
\hline${ }^{1} \mathrm{H}$ and ${ }^{13} \mathrm{C}\left\{{ }^{1} \mathrm{H}\right\}$ of compound $\mathbf{5 m}$ & S49 \\
\hline${ }^{1} \mathrm{H}$ and ${ }^{13} \mathrm{C}\left\{{ }^{1} \mathrm{H}\right\}$ of compound $\mathbf{5 q}$ & S51 \\
\hline${ }^{1} \mathrm{H}$ and ${ }^{13} \mathrm{C}\left\{{ }^{1} \mathrm{H}\right\}$ of compound 6 & S53 \\
\hline${ }^{1} \mathrm{H}$ and ${ }^{13} \mathrm{C}\left\{{ }^{1} \mathrm{H}\right\}$ of compound 7 & S55 \\
\hline HMBC of compound 7 & S57 \\
\hline${ }^{1} \mathrm{H}$ and ${ }^{13} \mathrm{C}\left\{{ }^{1} \mathrm{H}\right\}$ of compo & S58 \\
\hline
\end{tabular}




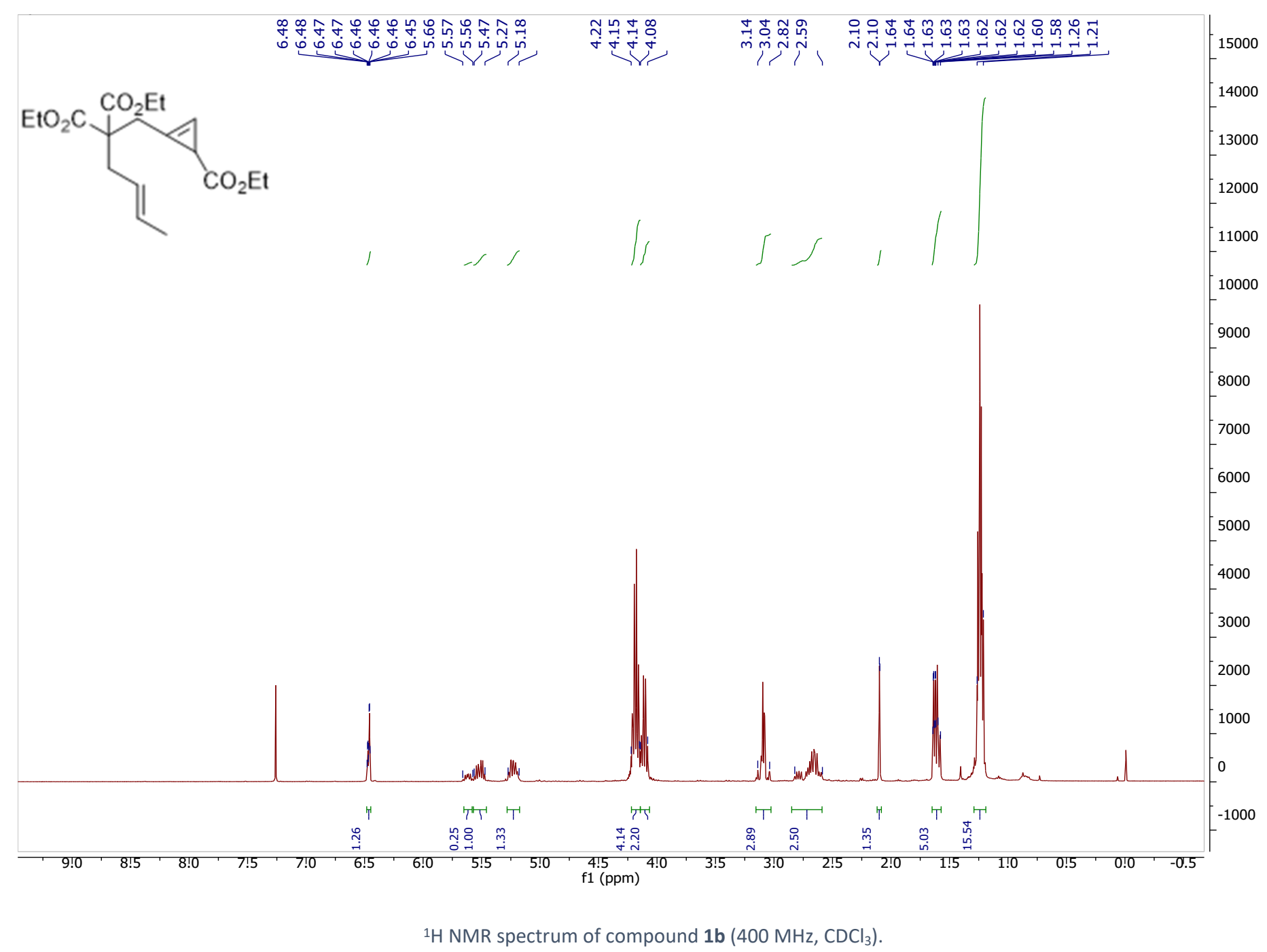




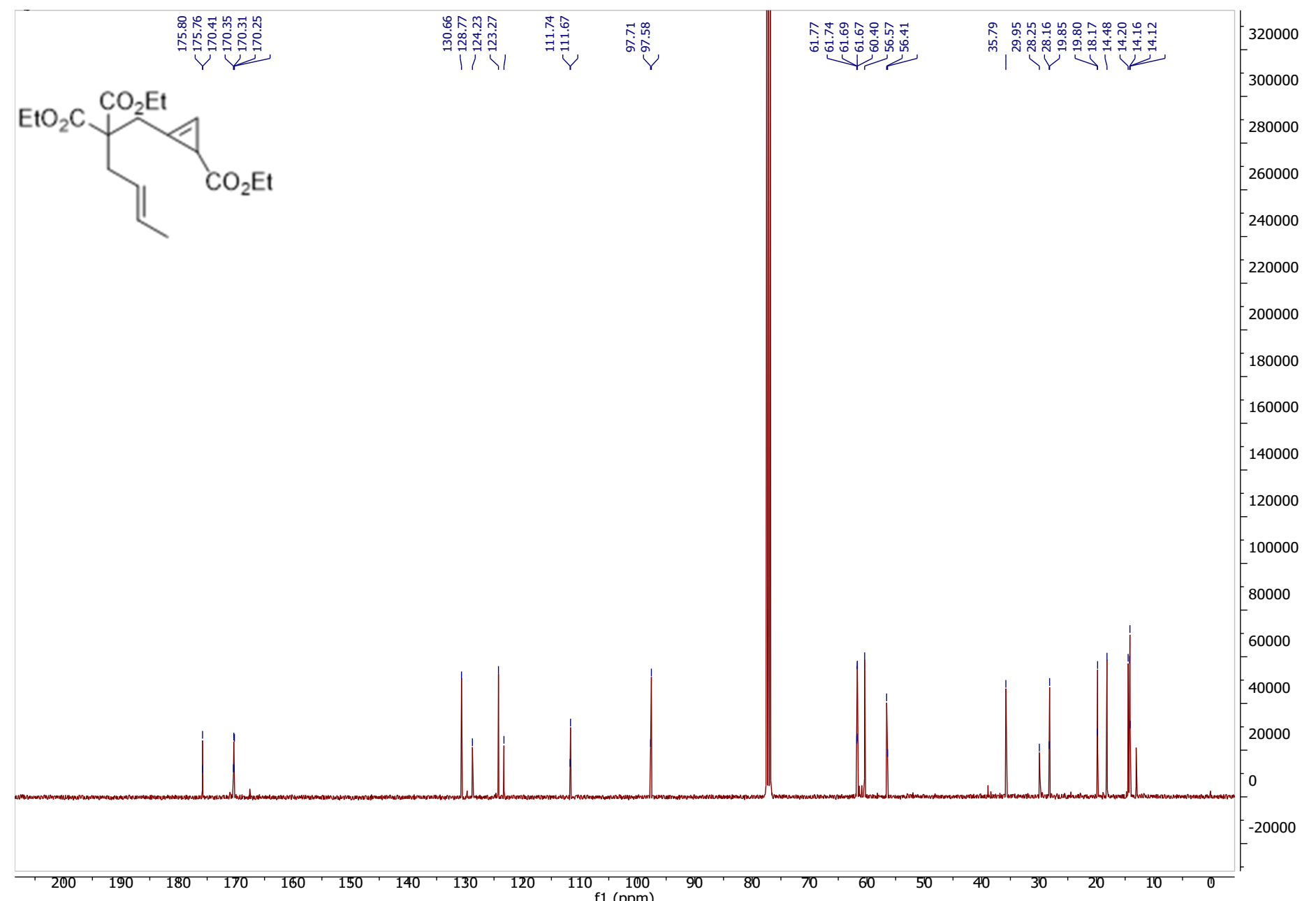

${ }^{13} \mathrm{C}\left\{{ }^{1} \mathrm{H}\right\}$ NMR spectrum of compound $\mathbf{1 b}\left(100 \mathrm{MHz}, \mathrm{CDCl}_{3}\right)$ 


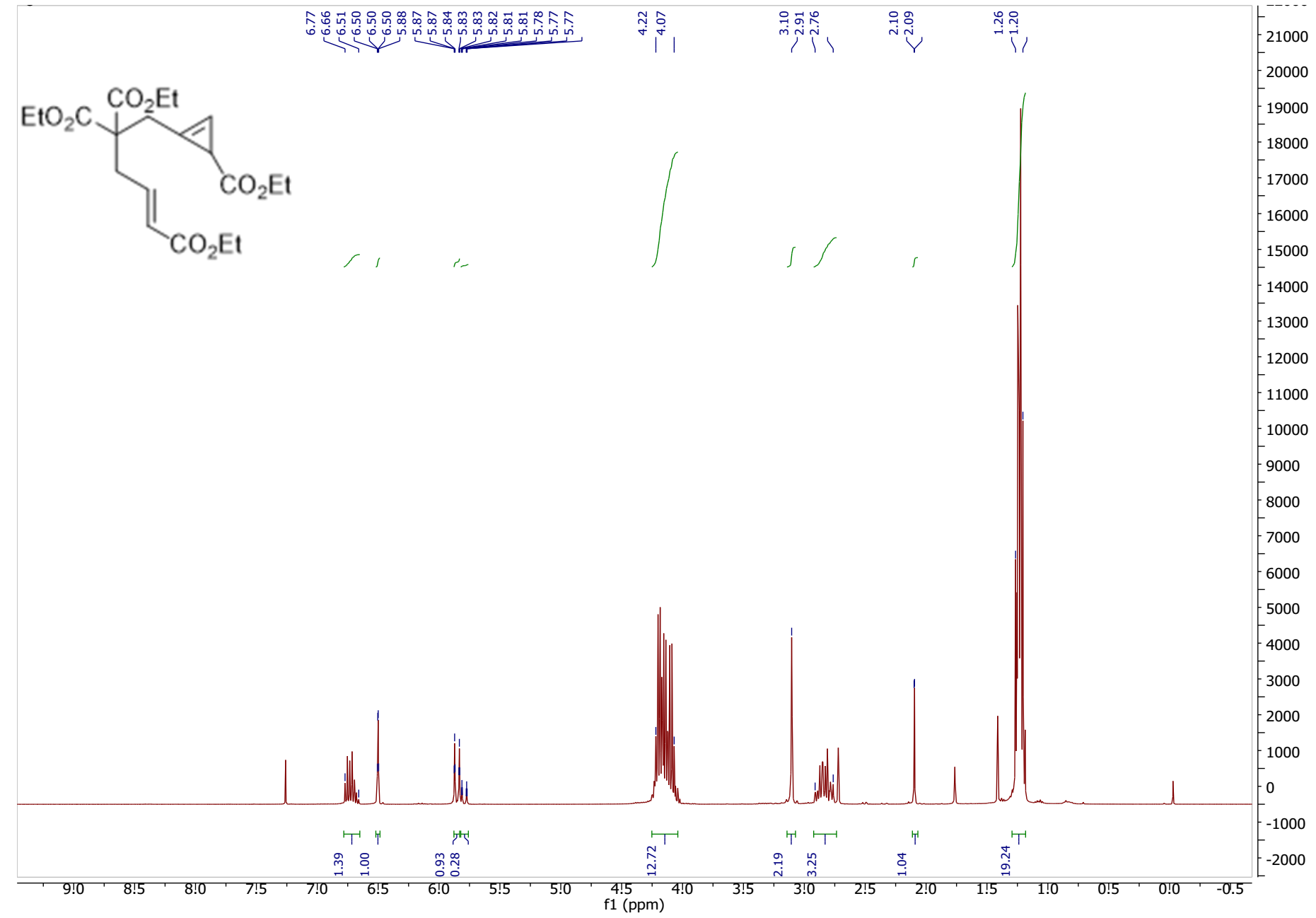

${ }^{1} \mathrm{H}$ NMR spectrum of compound $1 \mathrm{c}\left(400 \mathrm{MHz}, \mathrm{CDCl}_{3}\right)$. 


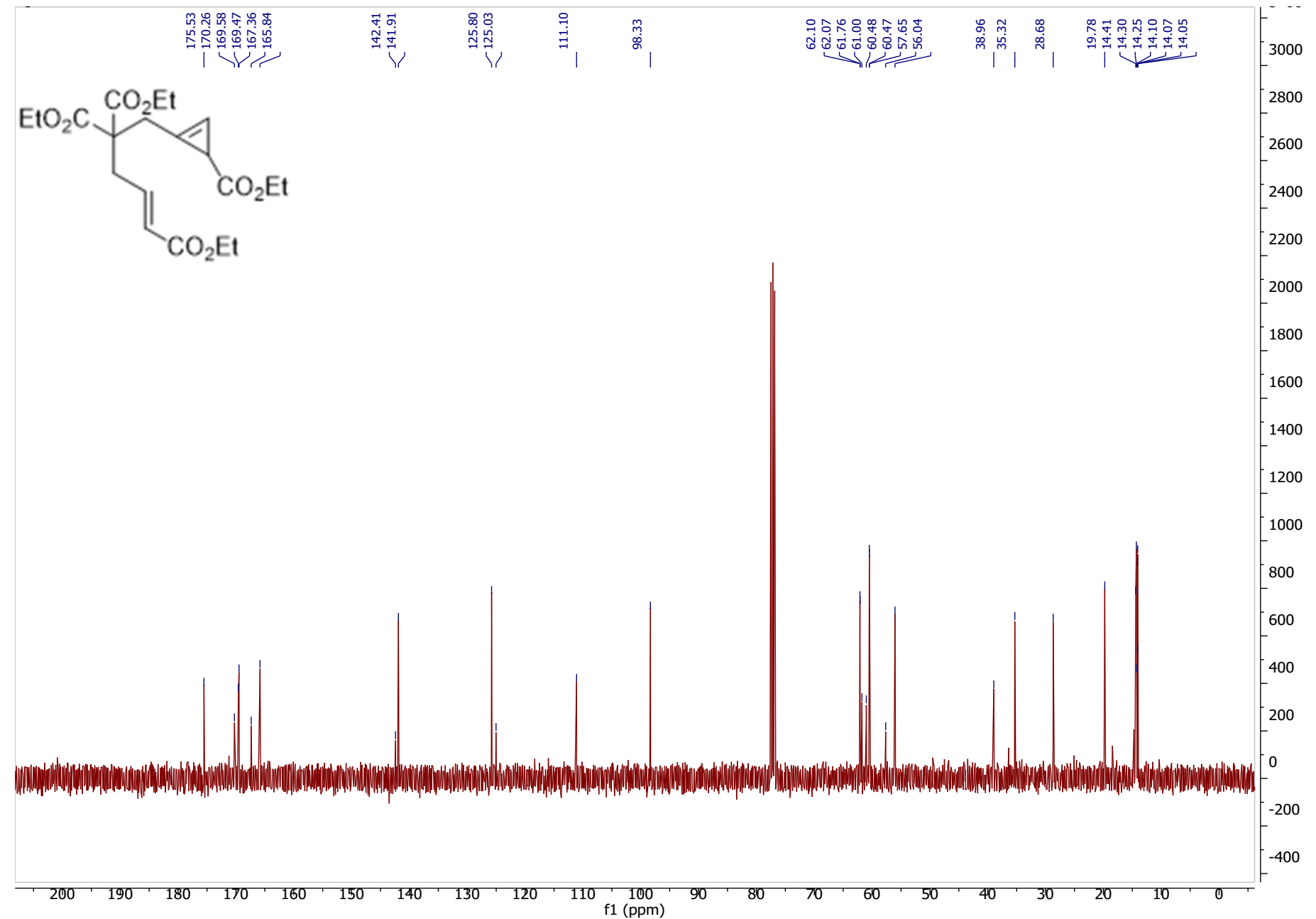

${ }^{13} \mathrm{C}\left\{{ }^{1} \mathrm{H}\right\}$ NMR spectrum of compound $1 \mathrm{c}\left(100 \mathrm{MHz}, \mathrm{CDCl}_{3}\right)$. 


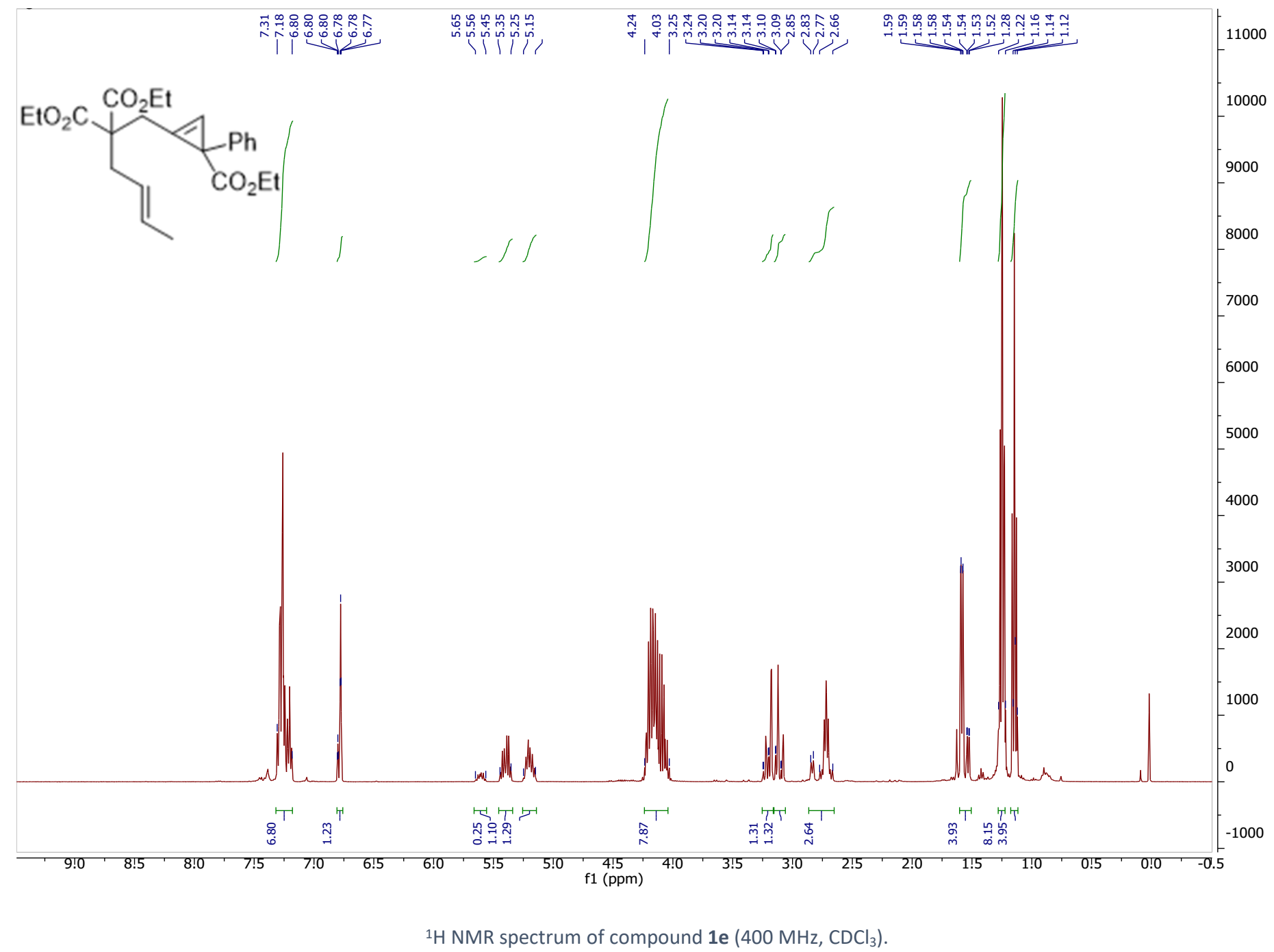




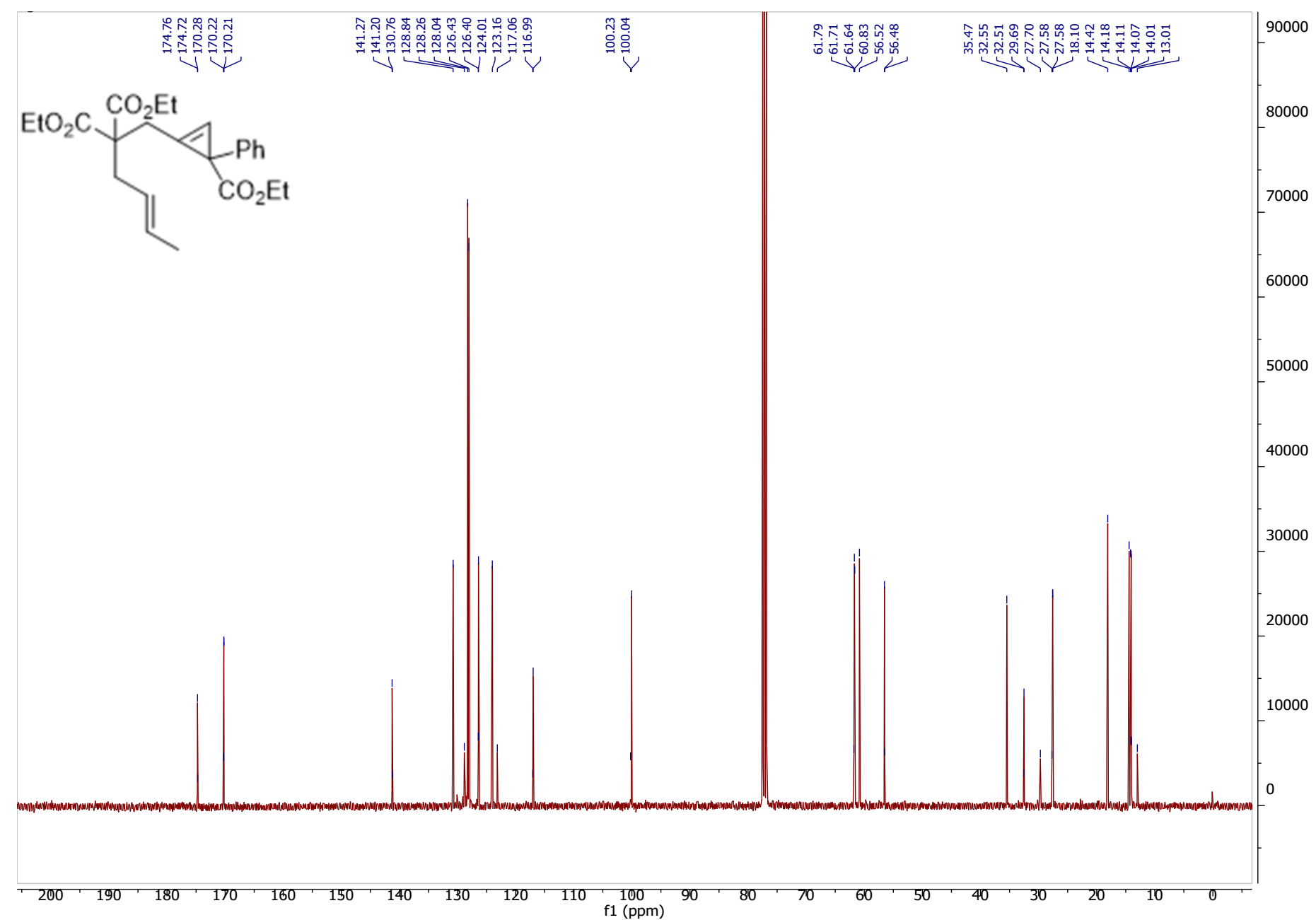

${ }^{13} \mathrm{C}\left\{{ }^{1} \mathrm{H}\right\}$ NMR spectrum of compound $1 \mathrm{e}\left(100 \mathrm{MHz}, \mathrm{CDCl}_{3}\right)$. 


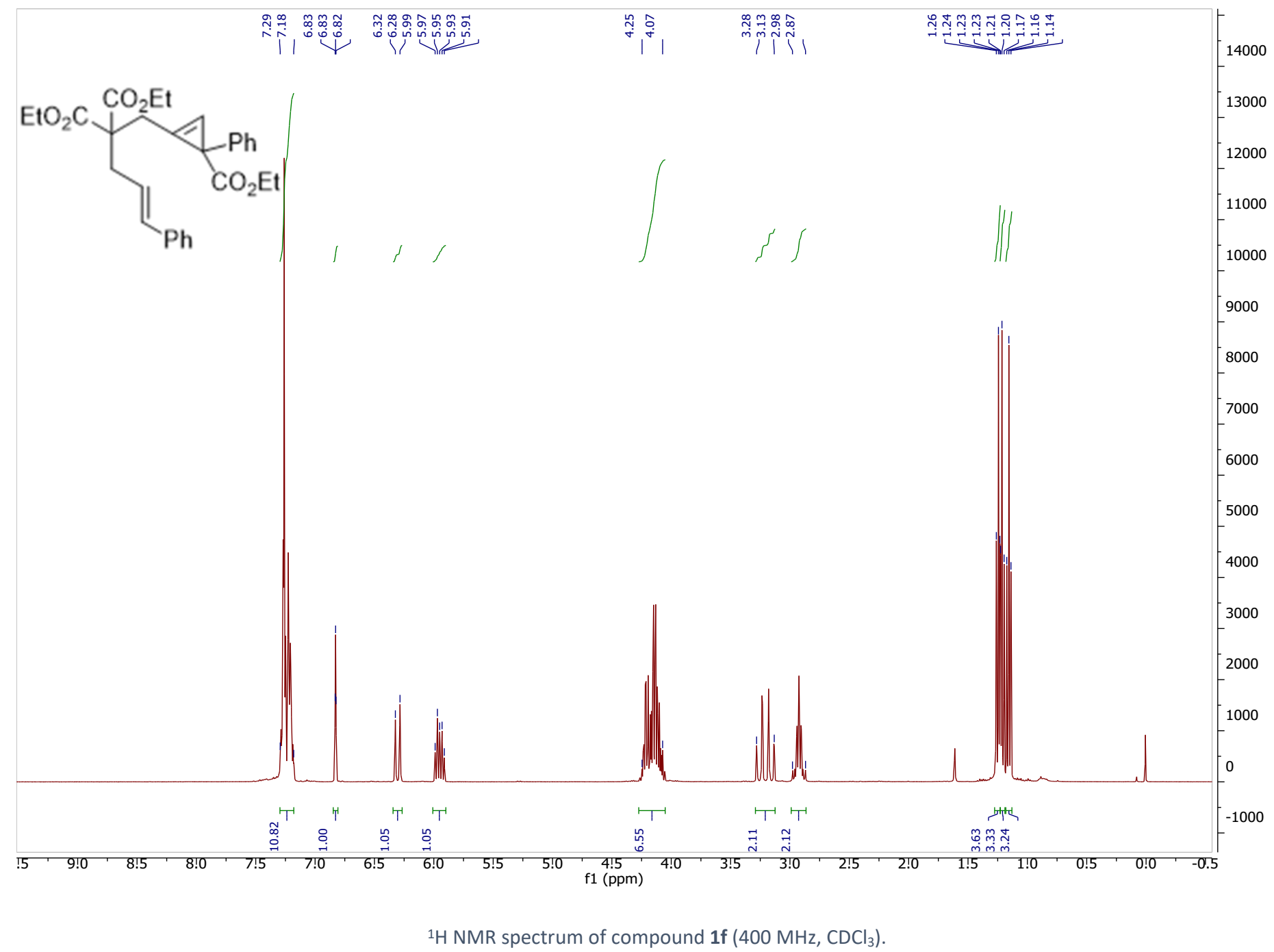




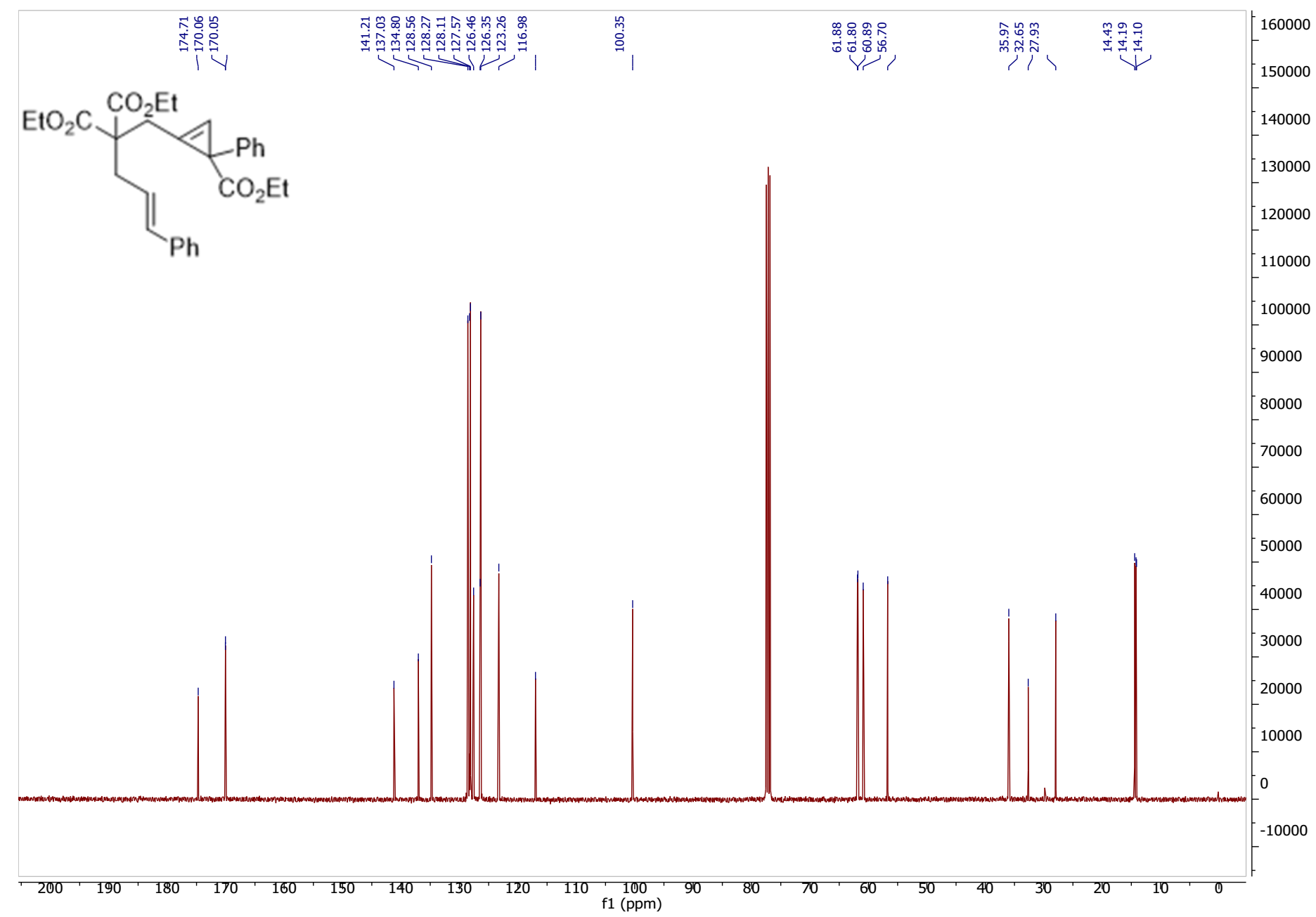

${ }^{13} \mathrm{C}\left\{{ }^{1} \mathrm{H}\right\}$ NMR spectrum of compound $\mathbf{1 f}\left(100 \mathrm{MHz}, \mathrm{CDCl}_{3}\right)$. 


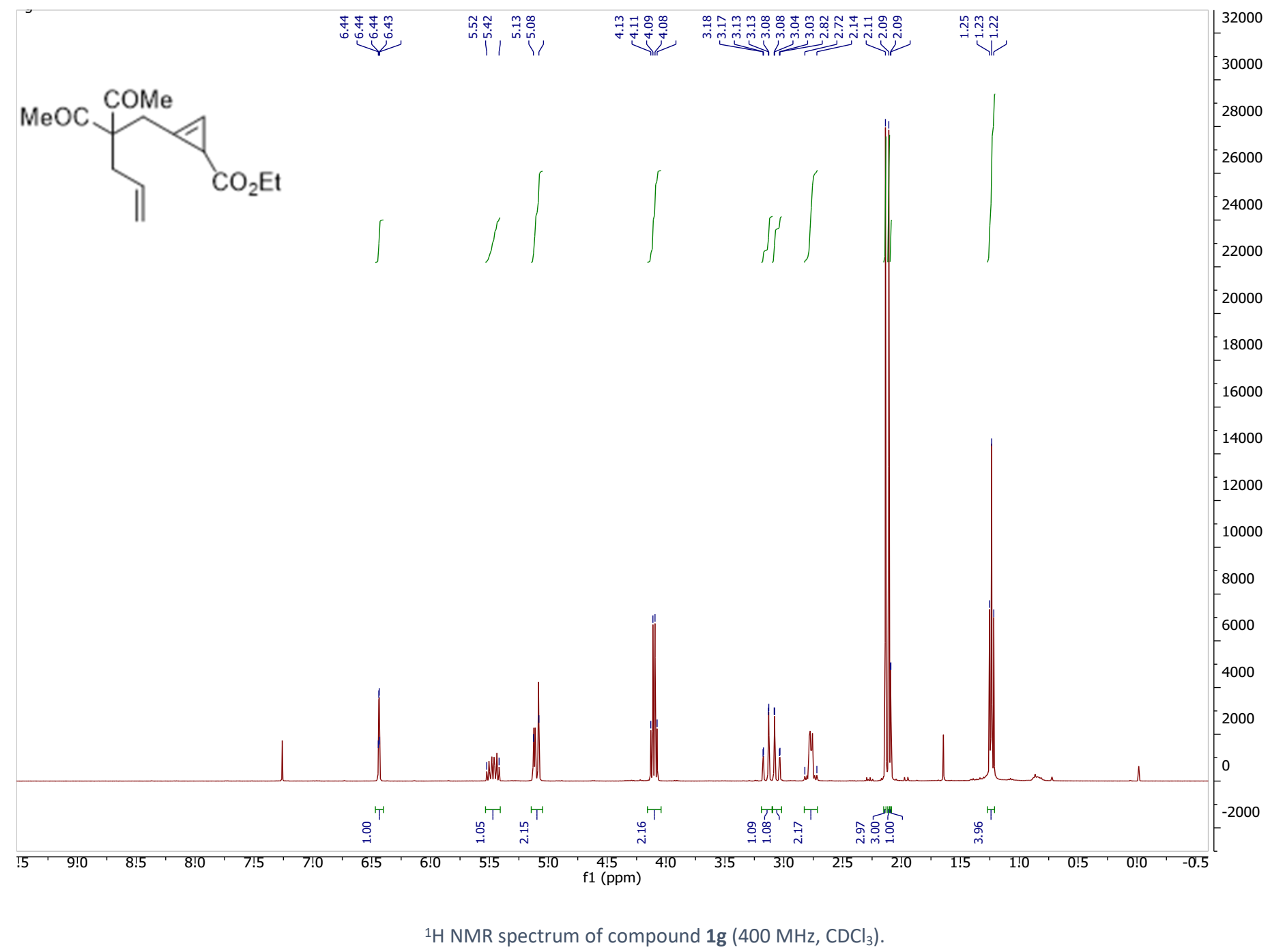




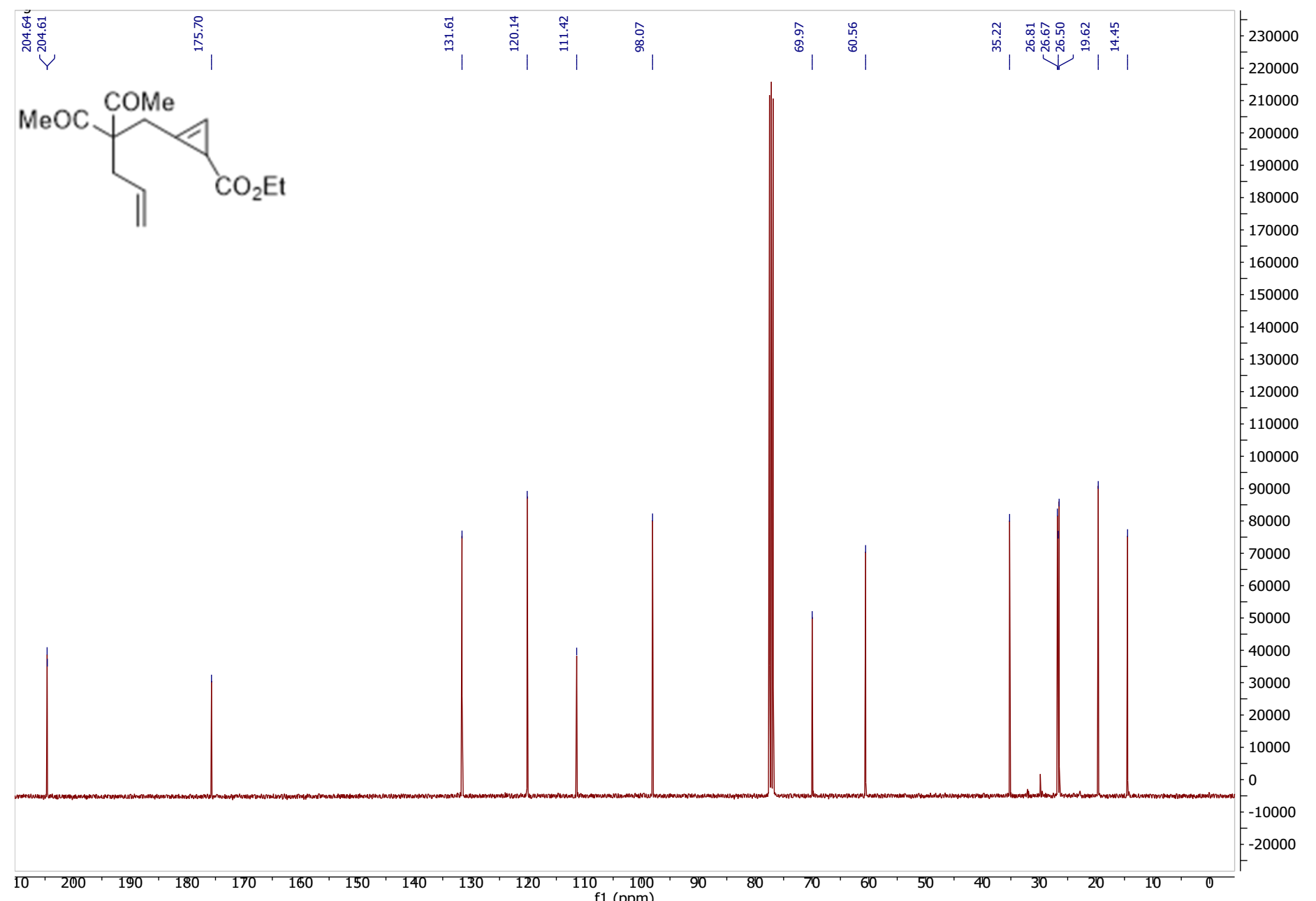

${ }^{13} \mathrm{C}\left\{{ }^{1} \mathrm{H}\right\}$ NMR spectrum of compound $1 \mathrm{~g}\left(100 \mathrm{MHz}, \mathrm{CDCl}_{3}\right)$. 


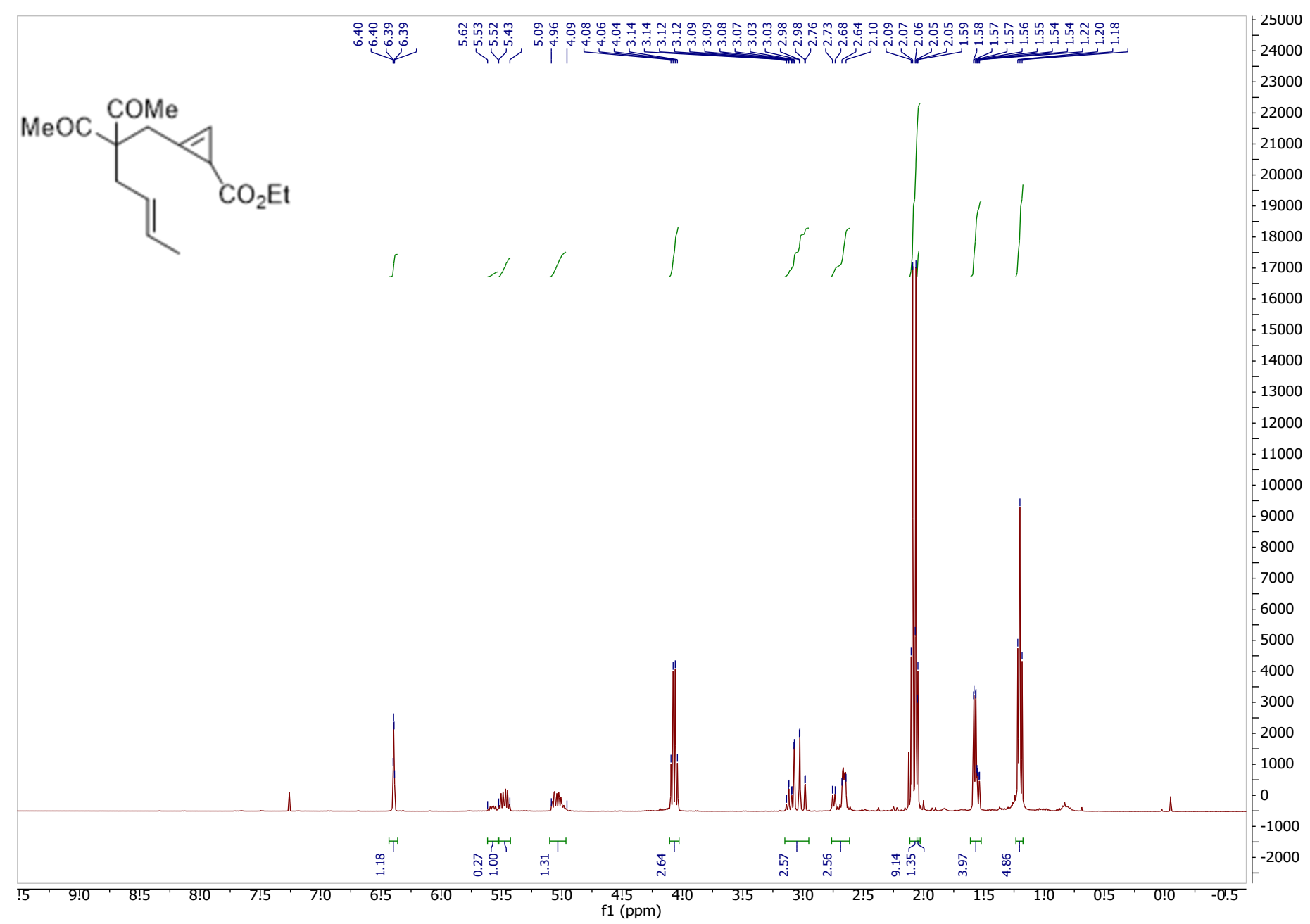

${ }^{1} \mathrm{H}$ NMR spectrum of compound $1 \mathrm{~h}\left(400 \mathrm{MHz}, \mathrm{CDCl}_{3}\right)$. 


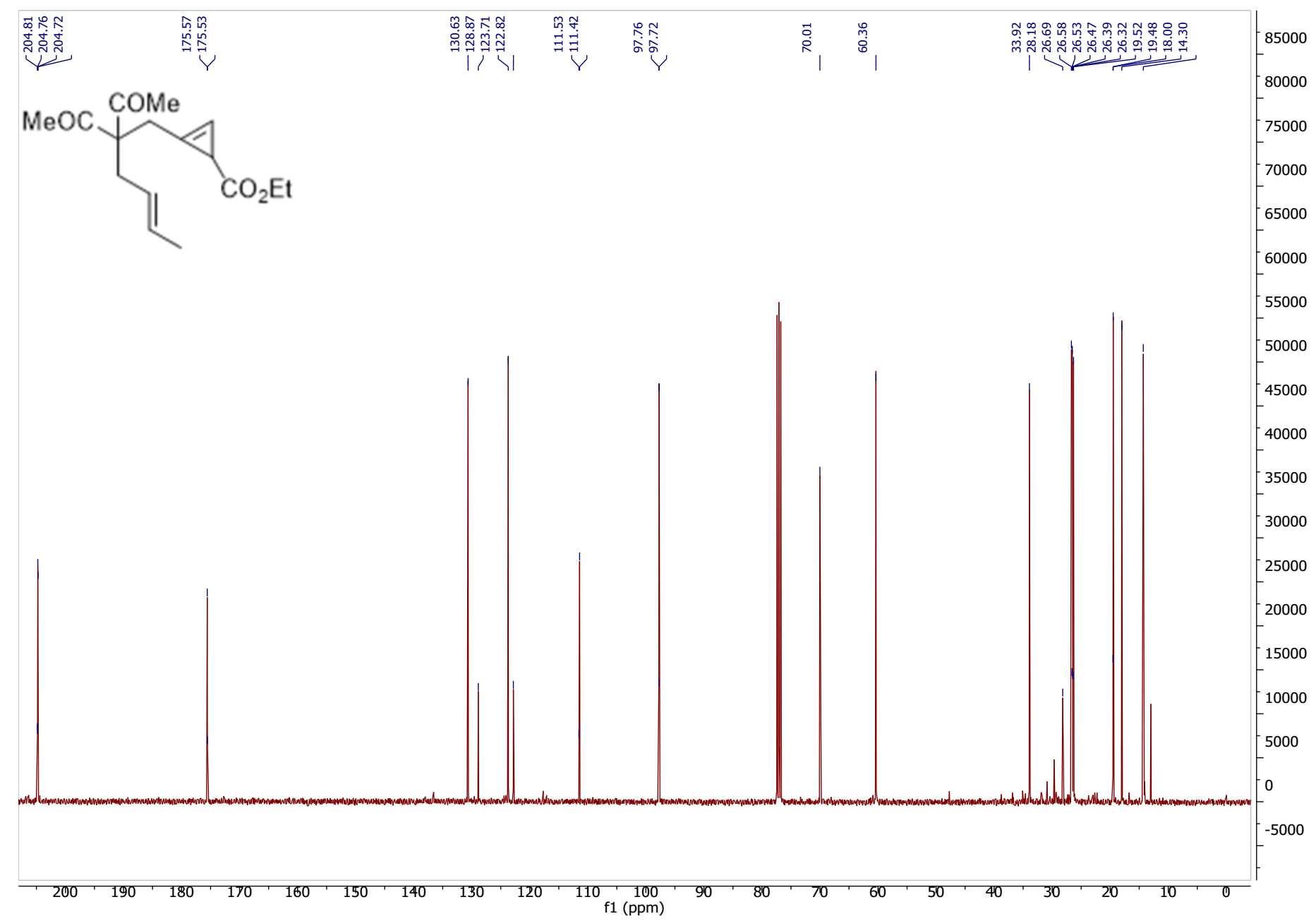

${ }^{13} \mathrm{C}\left\{{ }^{1} \mathrm{H}\right\}$ NMR spectrum of compound $\mathbf{1 h}\left(100 \mathrm{MHz}, \mathrm{CDCl}_{3}\right)$. 


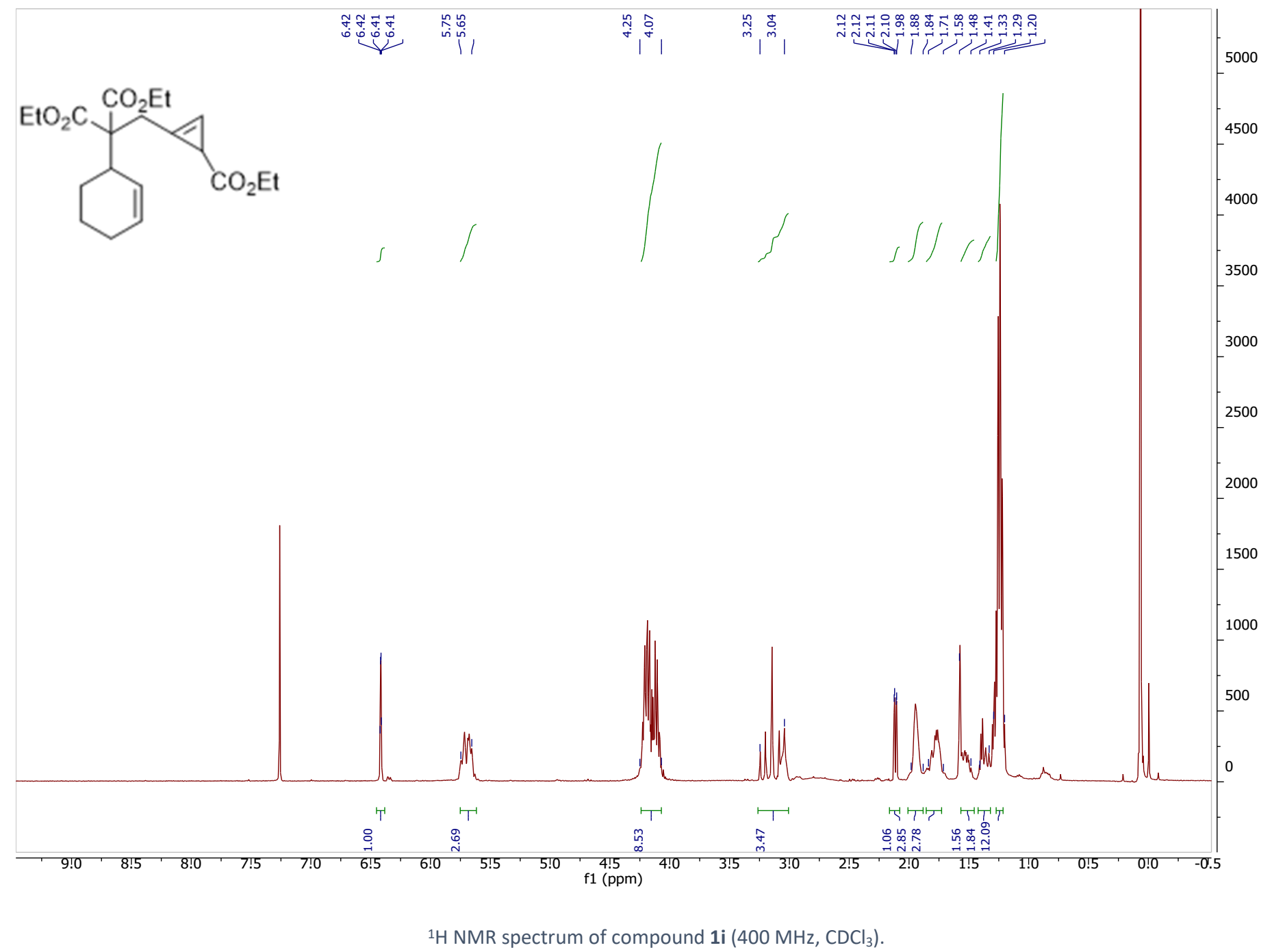




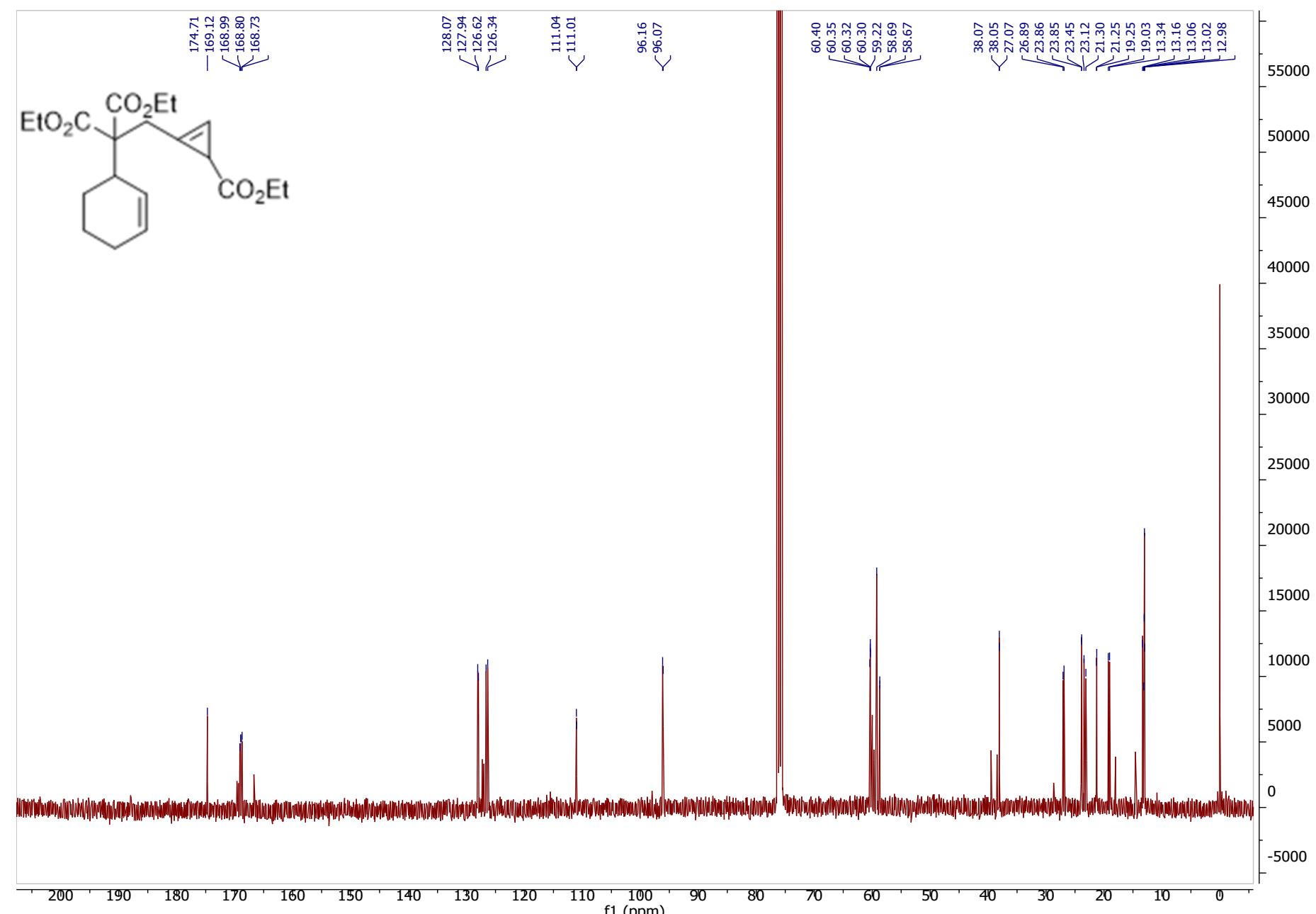

${ }^{13} \mathrm{C}\left\{{ }^{1} \mathrm{H}\right\}$ NMR spectrum of compound $1 \mathbf{i}\left(100 \mathrm{MHz}, \mathrm{CDCl}_{3}\right)$. 


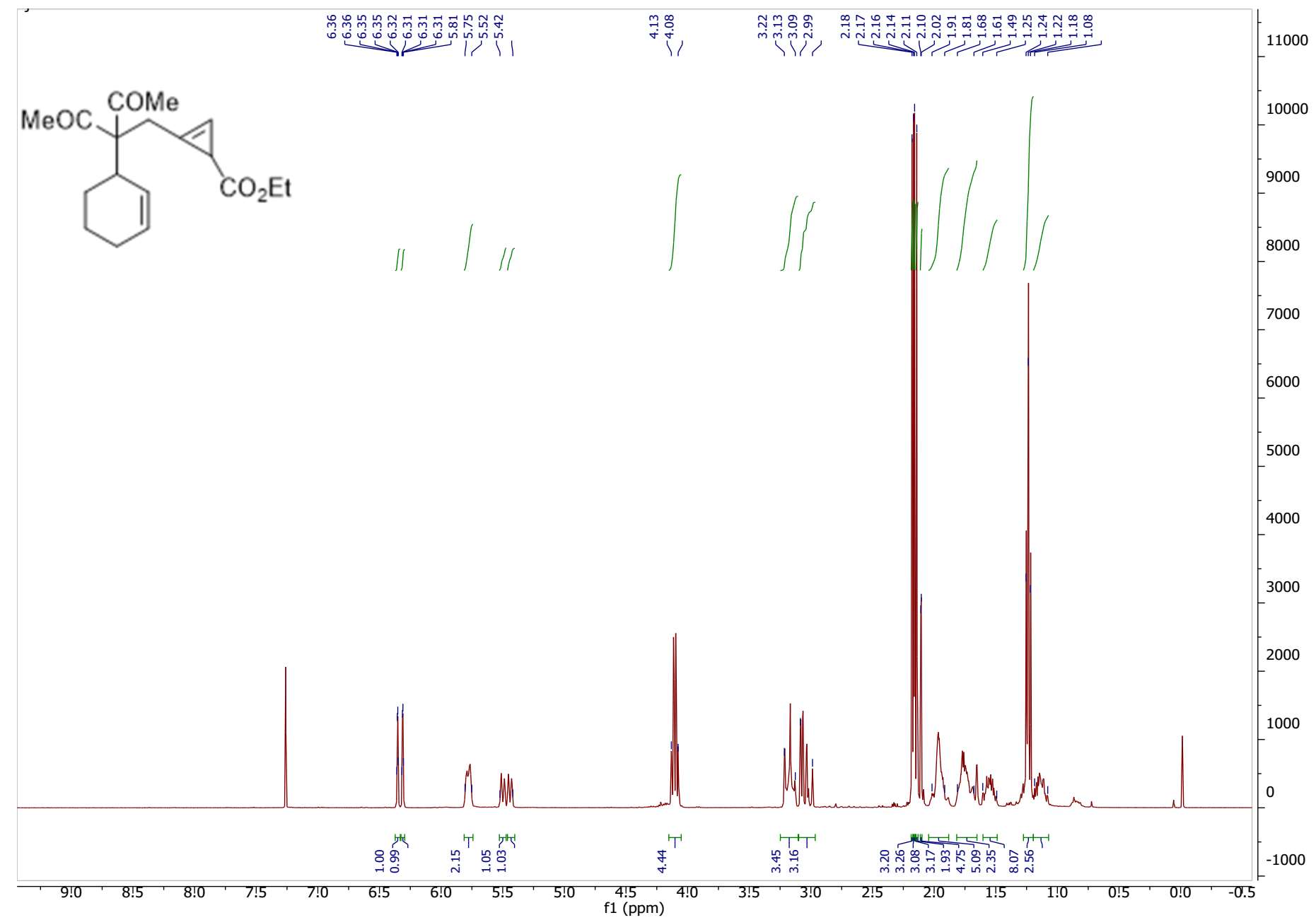

${ }^{1} \mathrm{H}$ NMR spectrum of compound $1 \mathrm{j}\left(400 \mathrm{MHz}, \mathrm{CDCl}_{3}\right)$. 


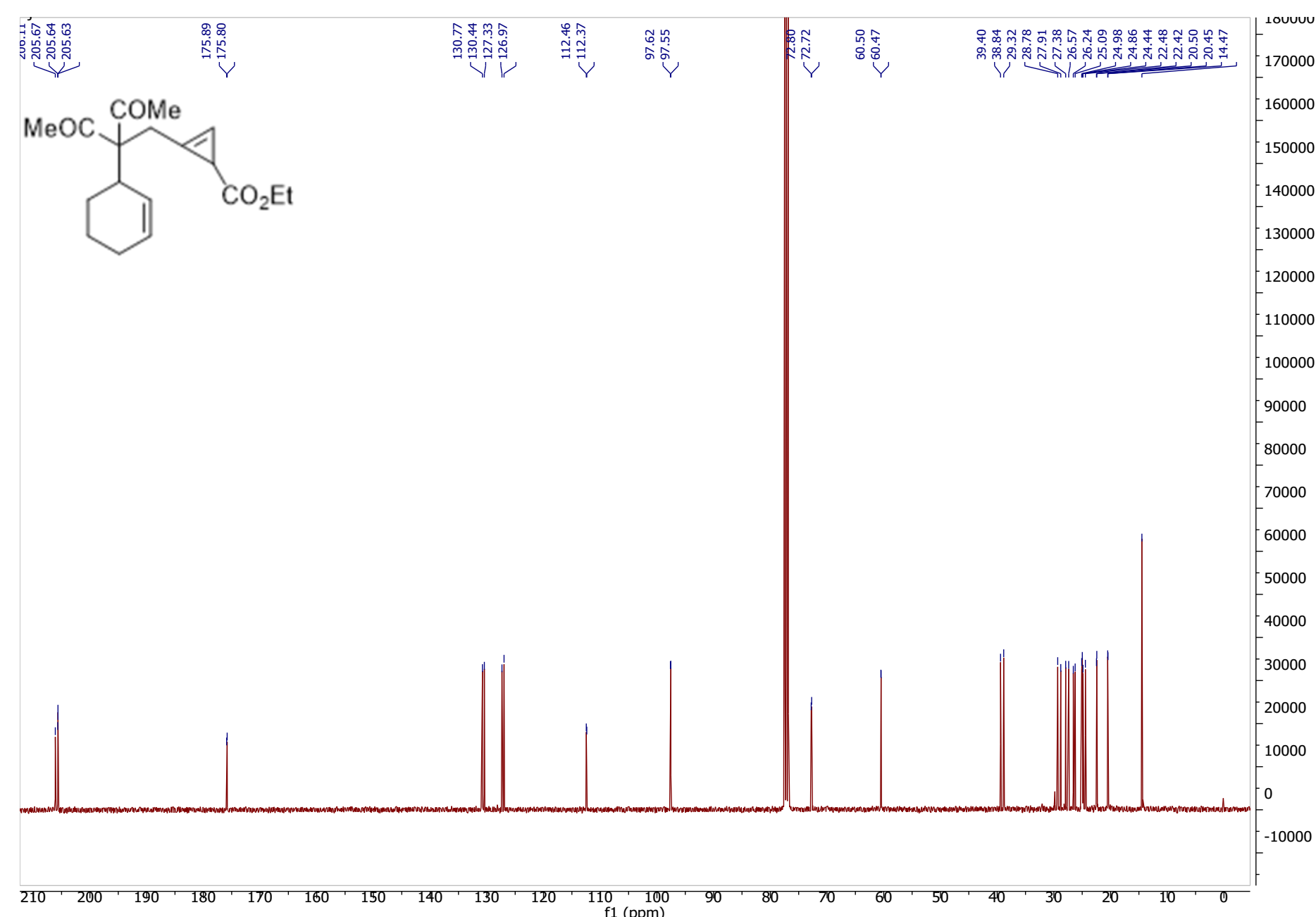

${ }^{13} \mathrm{C}\left\{{ }^{1} \mathrm{H}\right\}$ NMR spectrum of compound $\mathbf{1 j}\left(100 \mathrm{MHz}, \mathrm{CDCl}_{3}\right)$. 


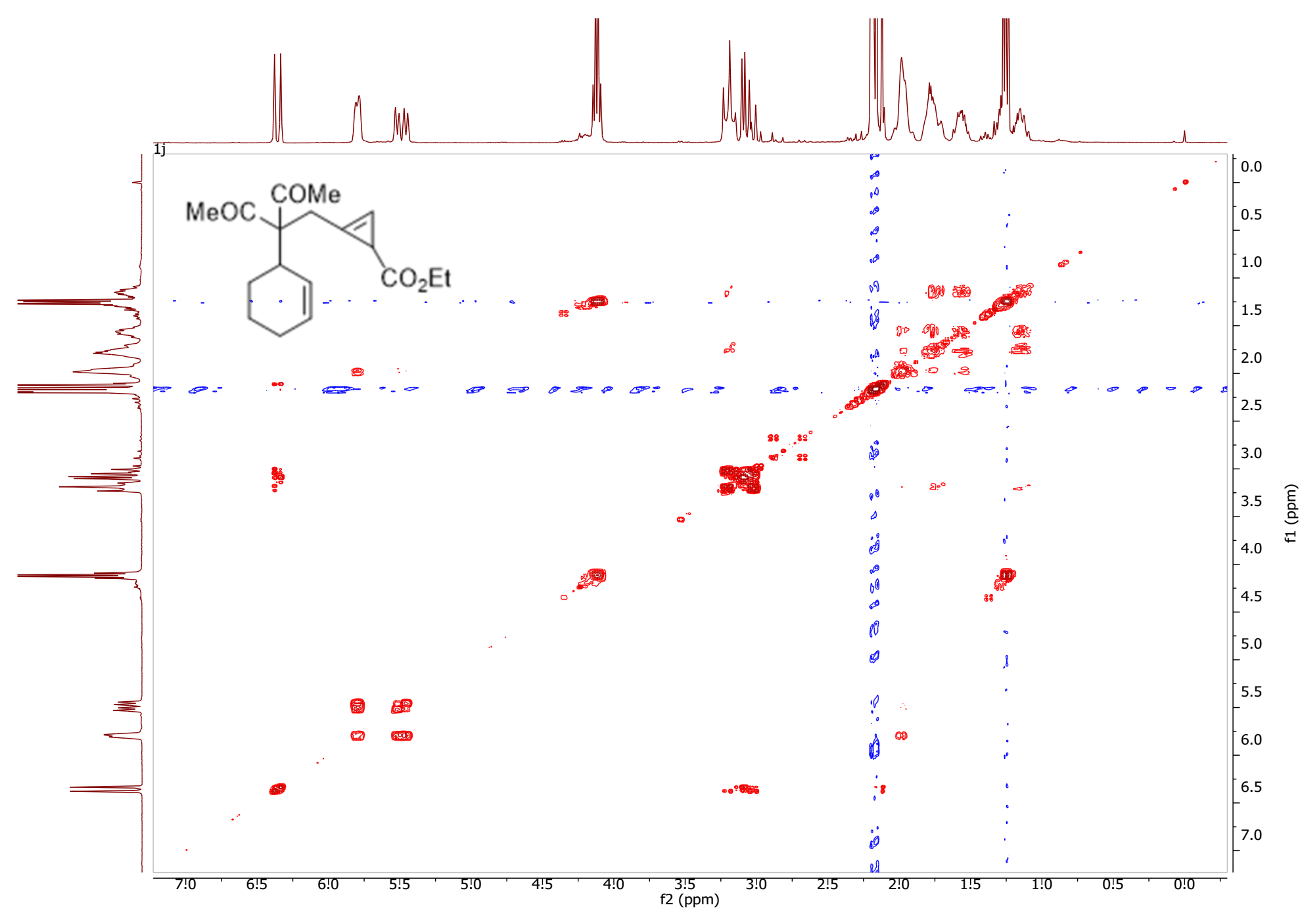

COSY spectra of compound $\mathbf{1} \mathbf{j}$ 


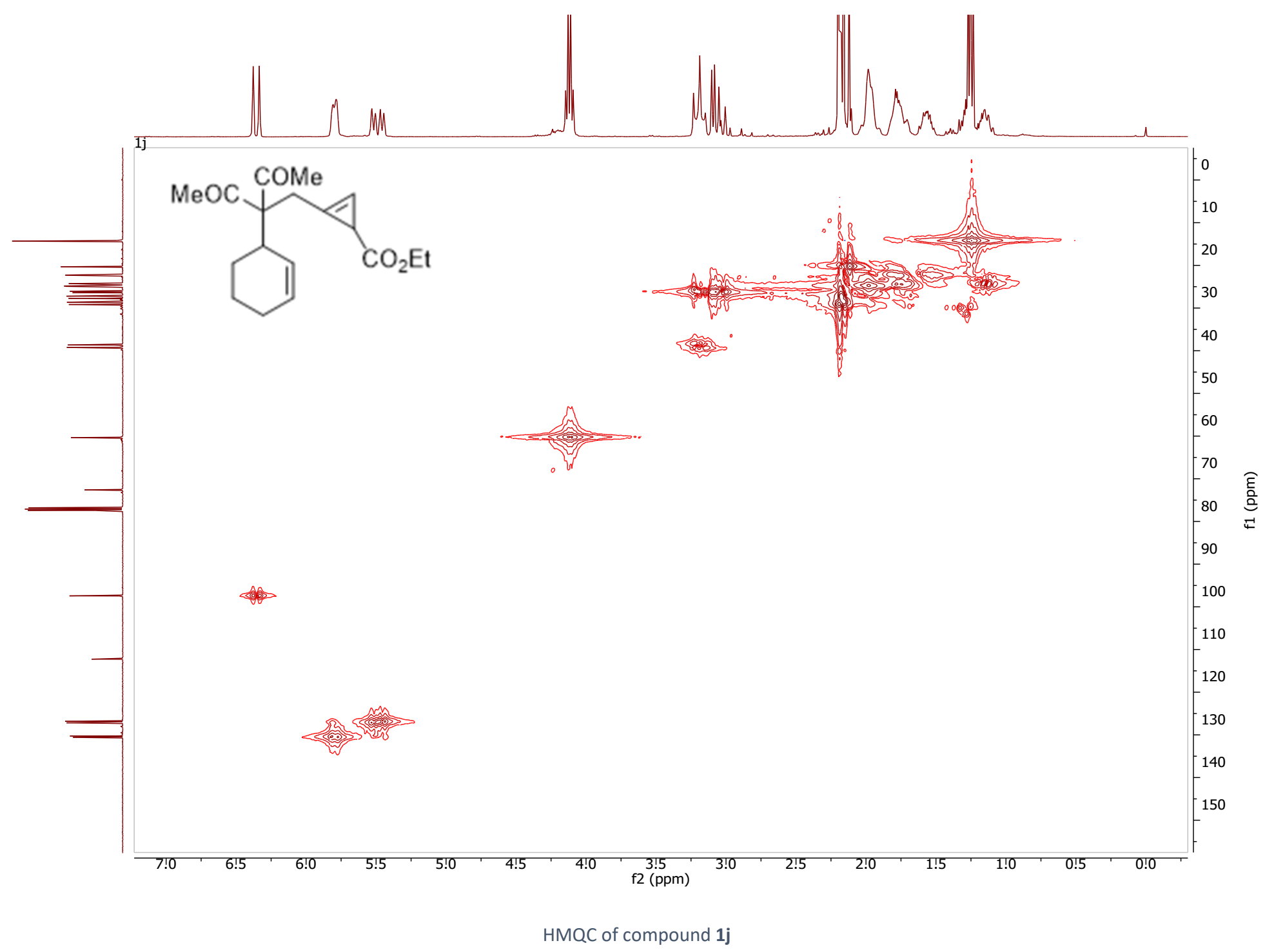




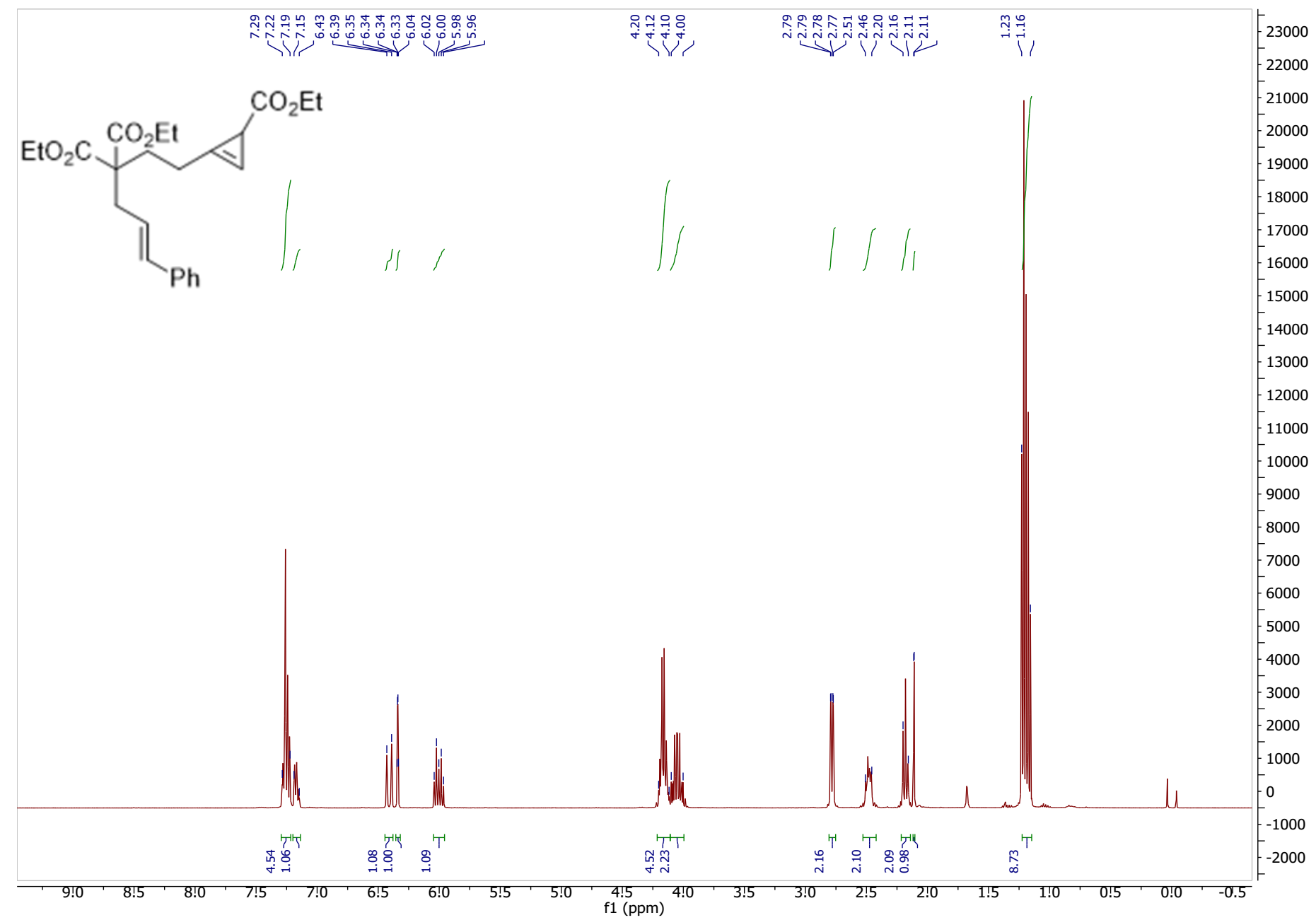

${ }^{1} \mathrm{H}$ NMR spectrum of compound $\mathbf{1} \mathbf{k}\left(400 \mathrm{MHz}, \mathrm{CDCl}_{3}\right)$. 


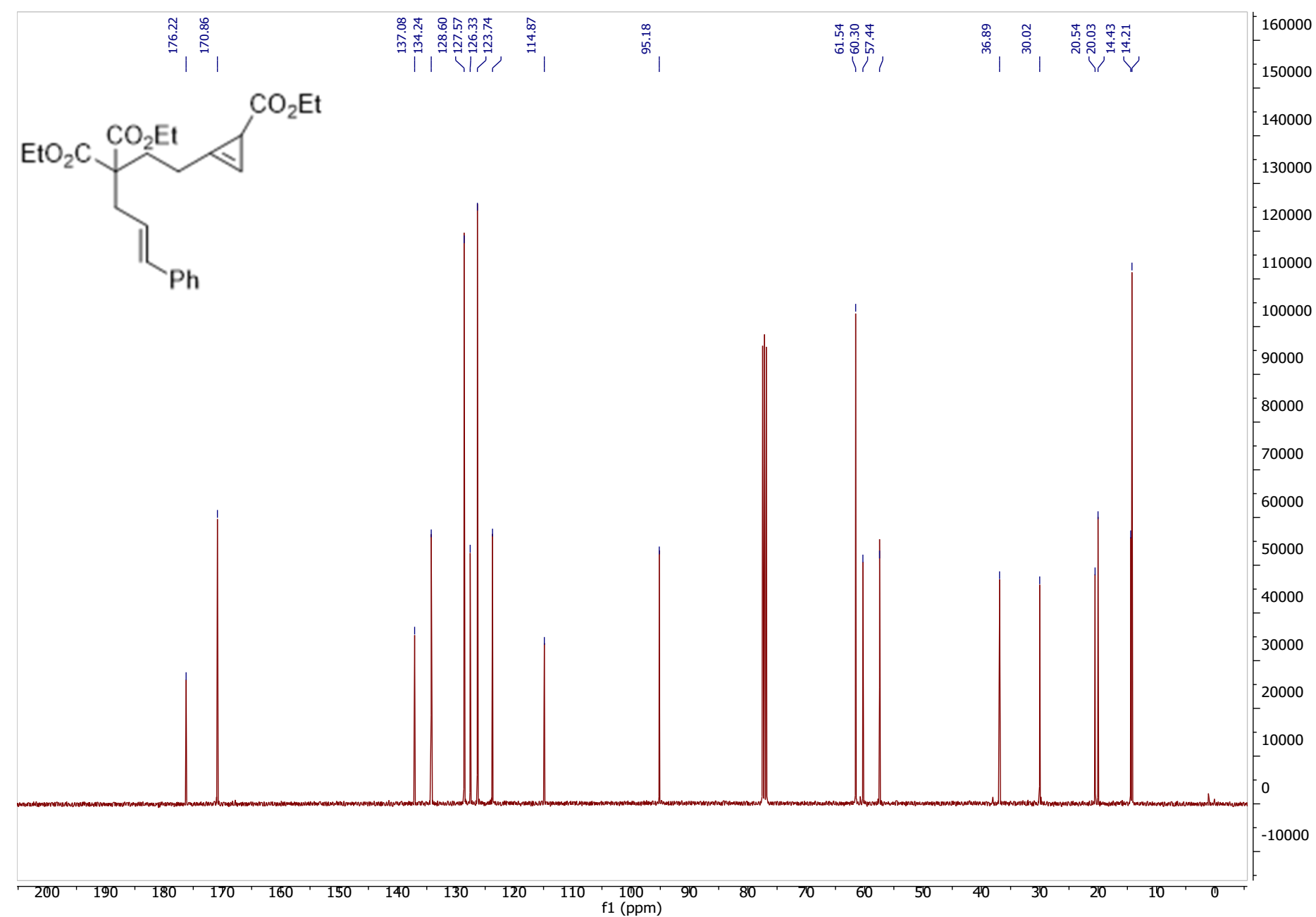

${ }^{13} \mathrm{C}\left\{{ }^{1} \mathrm{H}\right\}$ NMR spectrum of compound $\mathbf{1} \mathbf{k}\left(100 \mathrm{MHz}, \mathrm{CDCl}_{3}\right)$ 


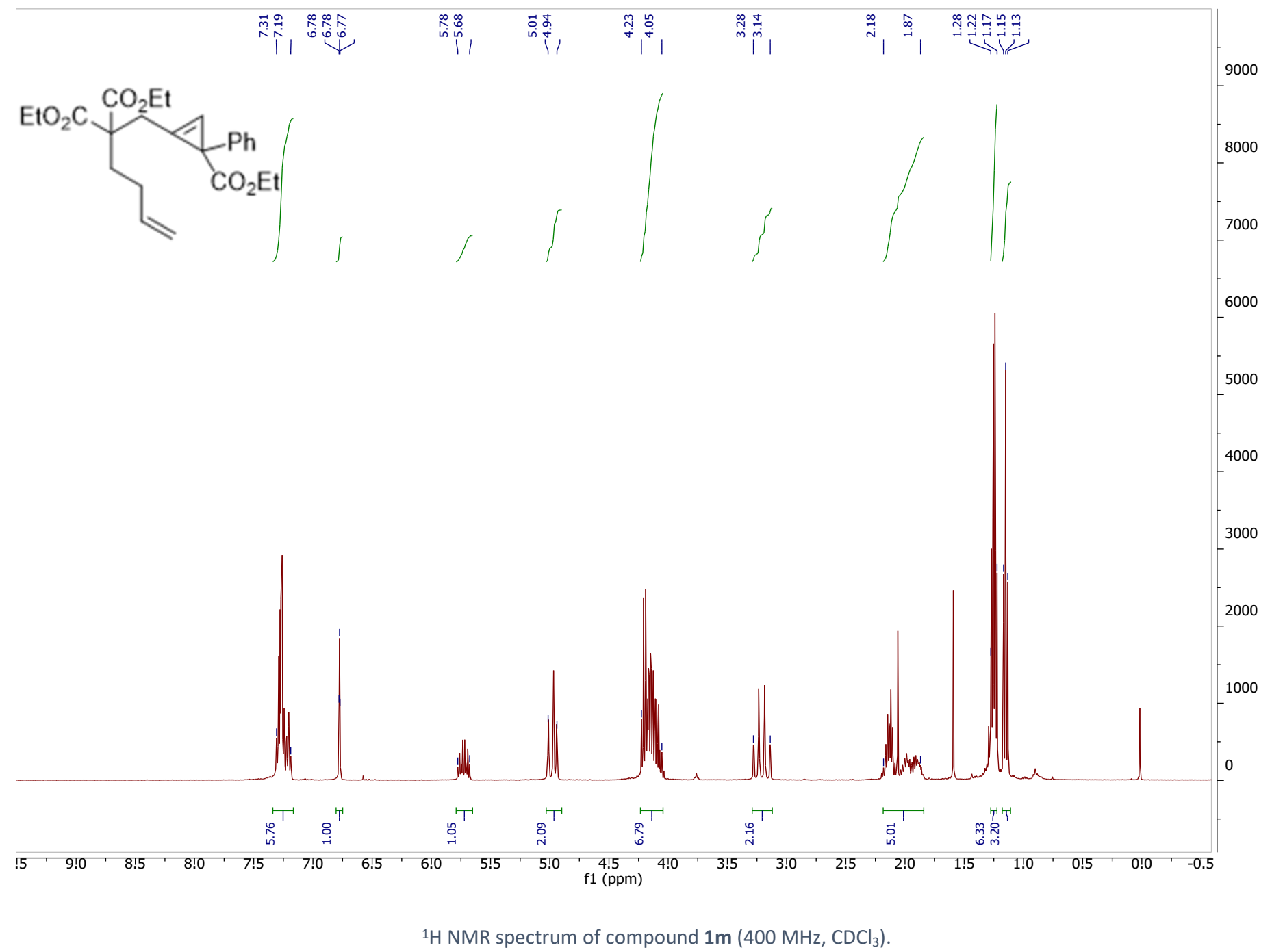




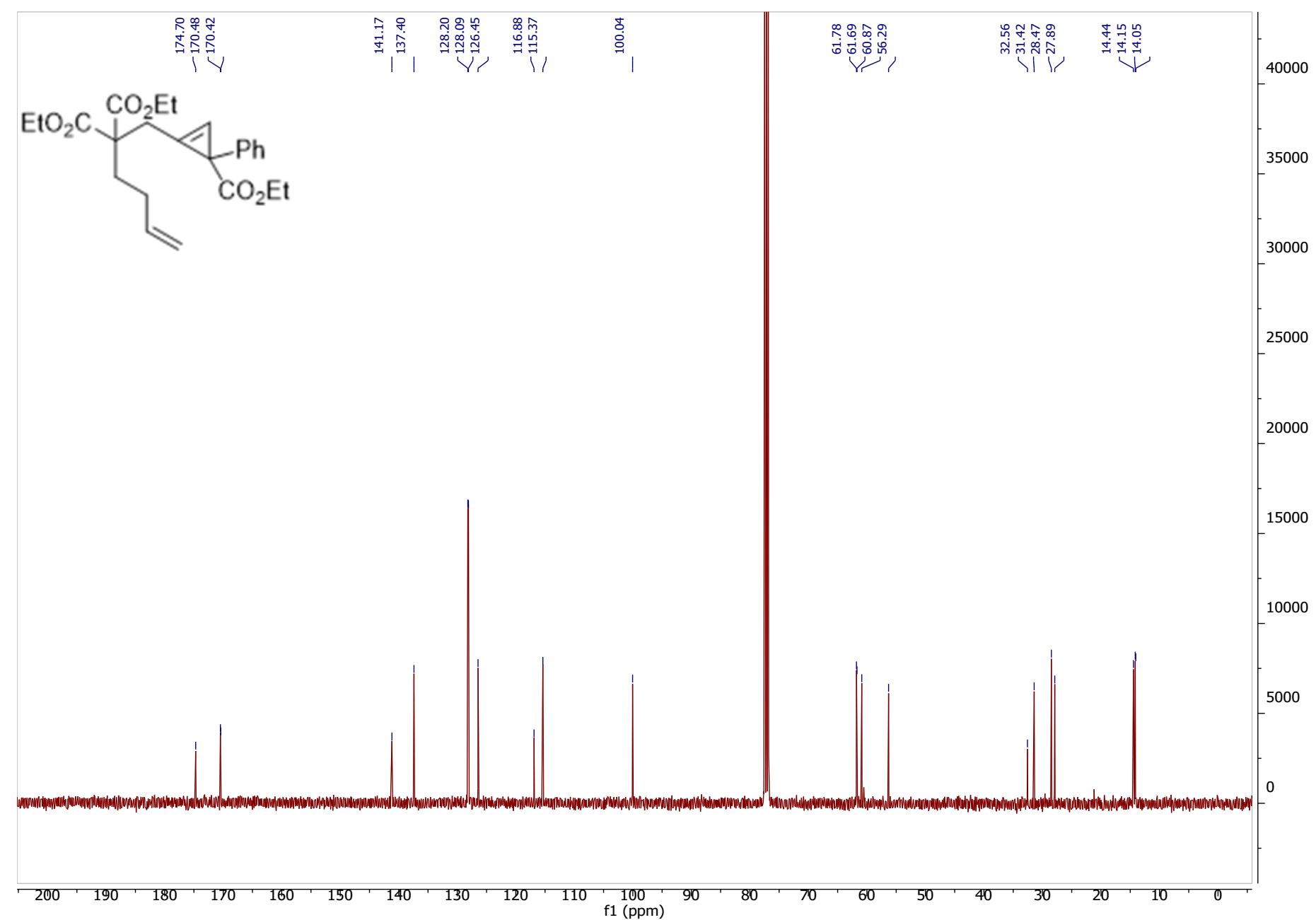

${ }^{13} \mathrm{C}\left\{{ }^{1} \mathrm{H}\right\}$ NMR spectrum of compound $1 \mathrm{~m}\left(100 \mathrm{MHz}, \mathrm{CDCl}_{3}\right)$. 


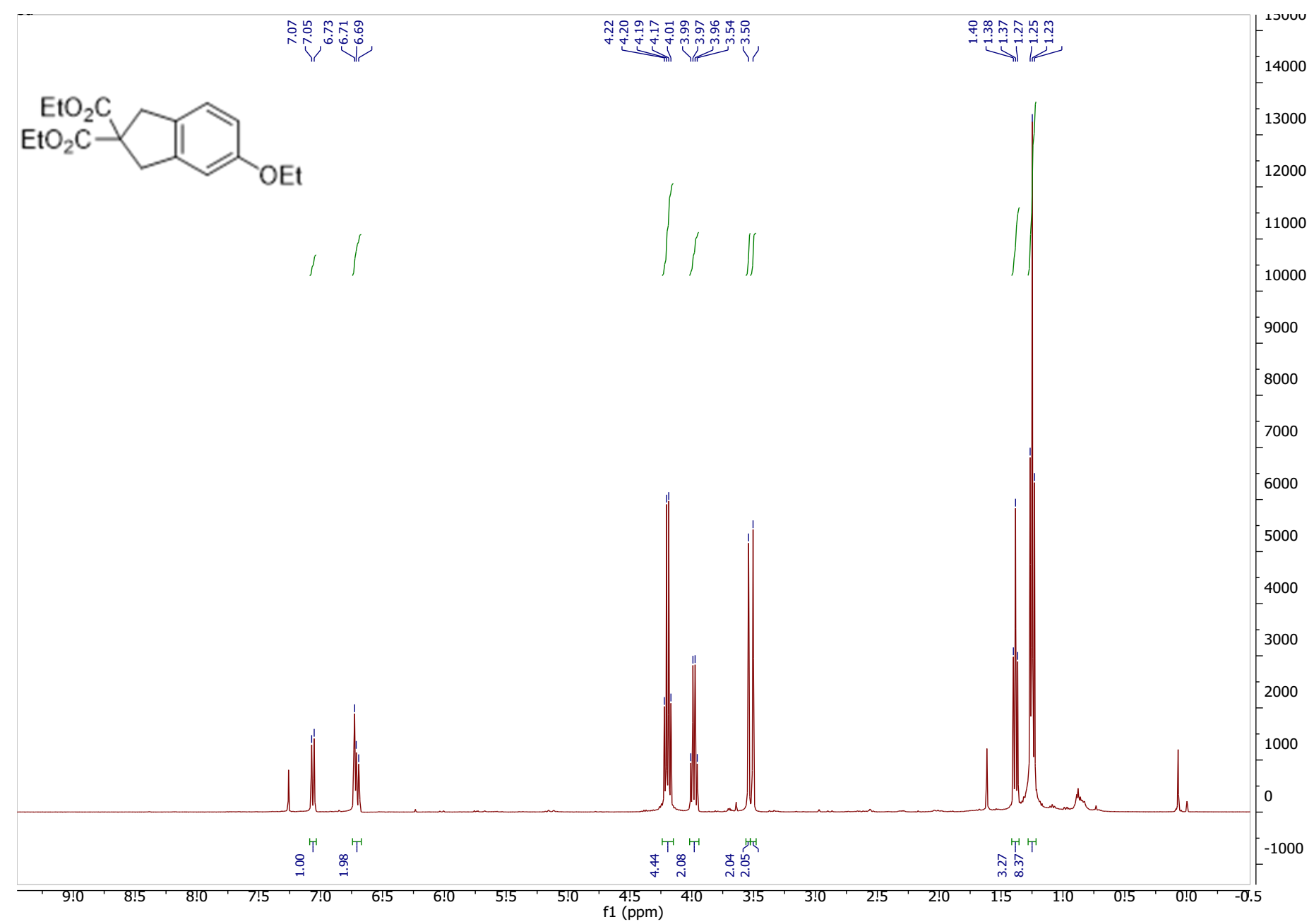

${ }^{1} \mathrm{H}$ NMR spectrum of compound $\mathbf{5 a}\left(400 \mathrm{MHz}, \mathrm{CDCl}_{3}\right)$. 


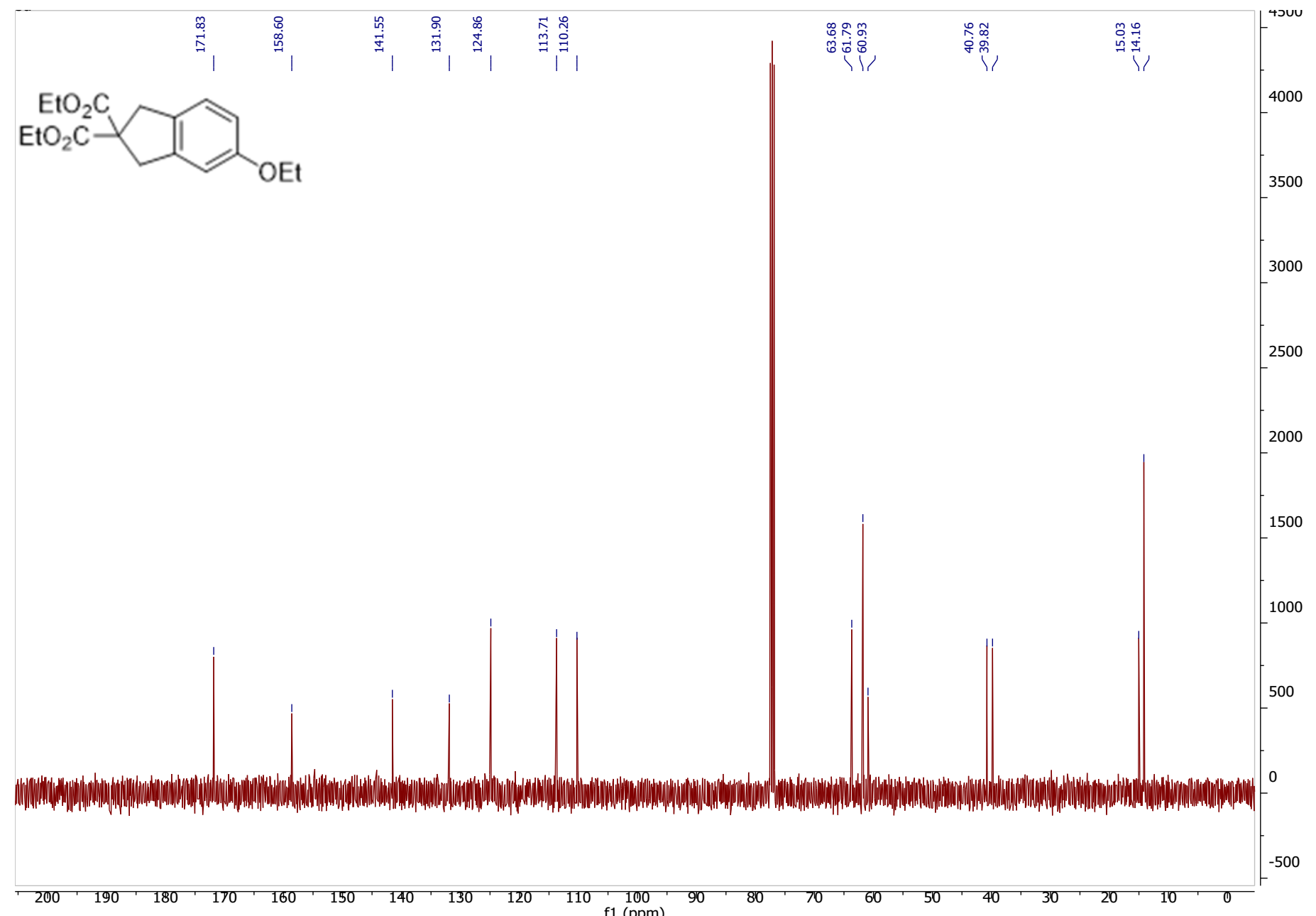

${ }^{13} \mathrm{C}\left\{{ }^{1} \mathrm{H}\right\}$ NMR spectrum of compound $\mathbf{5 a}\left(100 \mathrm{MHz}, \mathrm{CDCl}_{3}\right)$. 


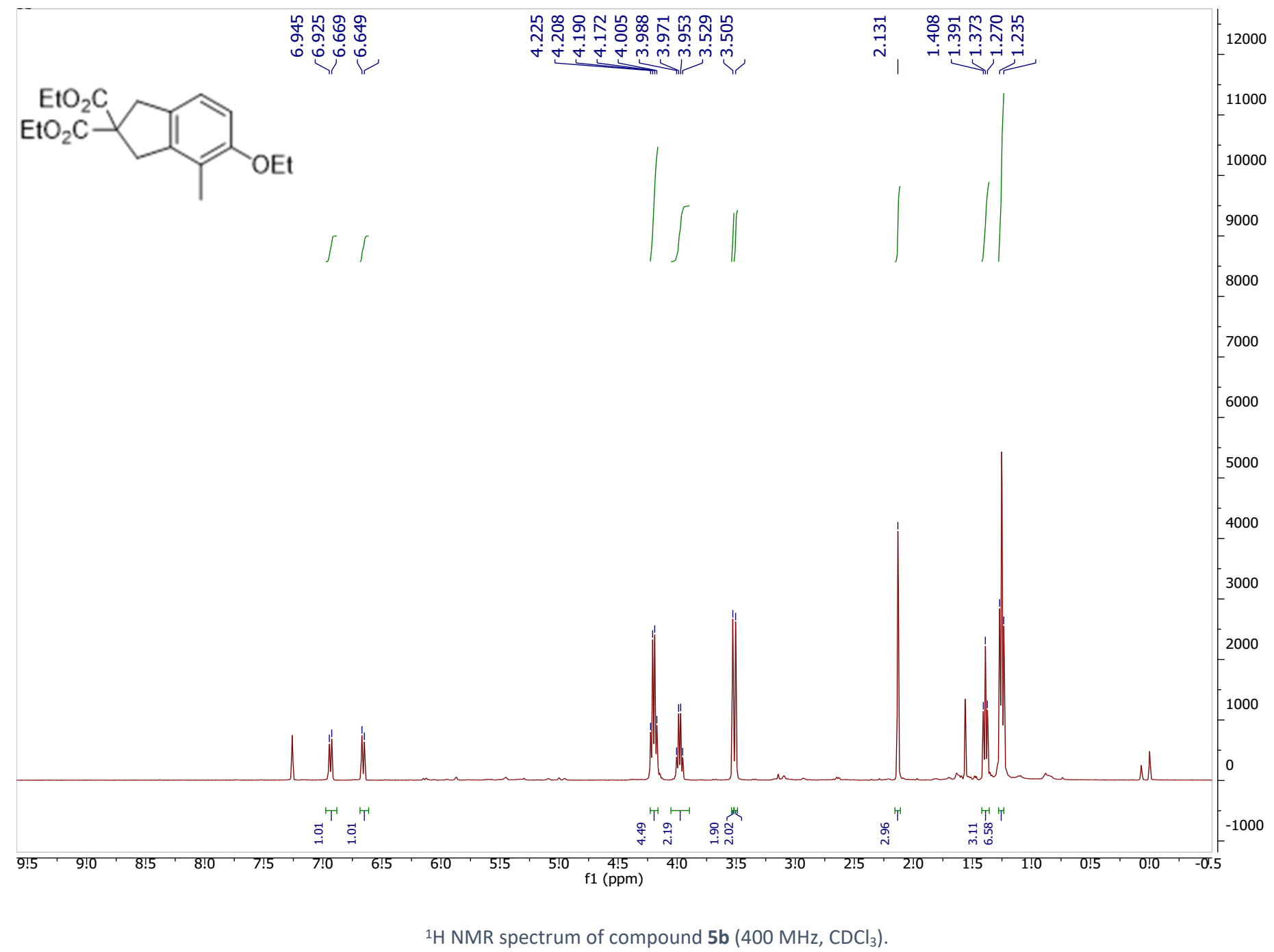




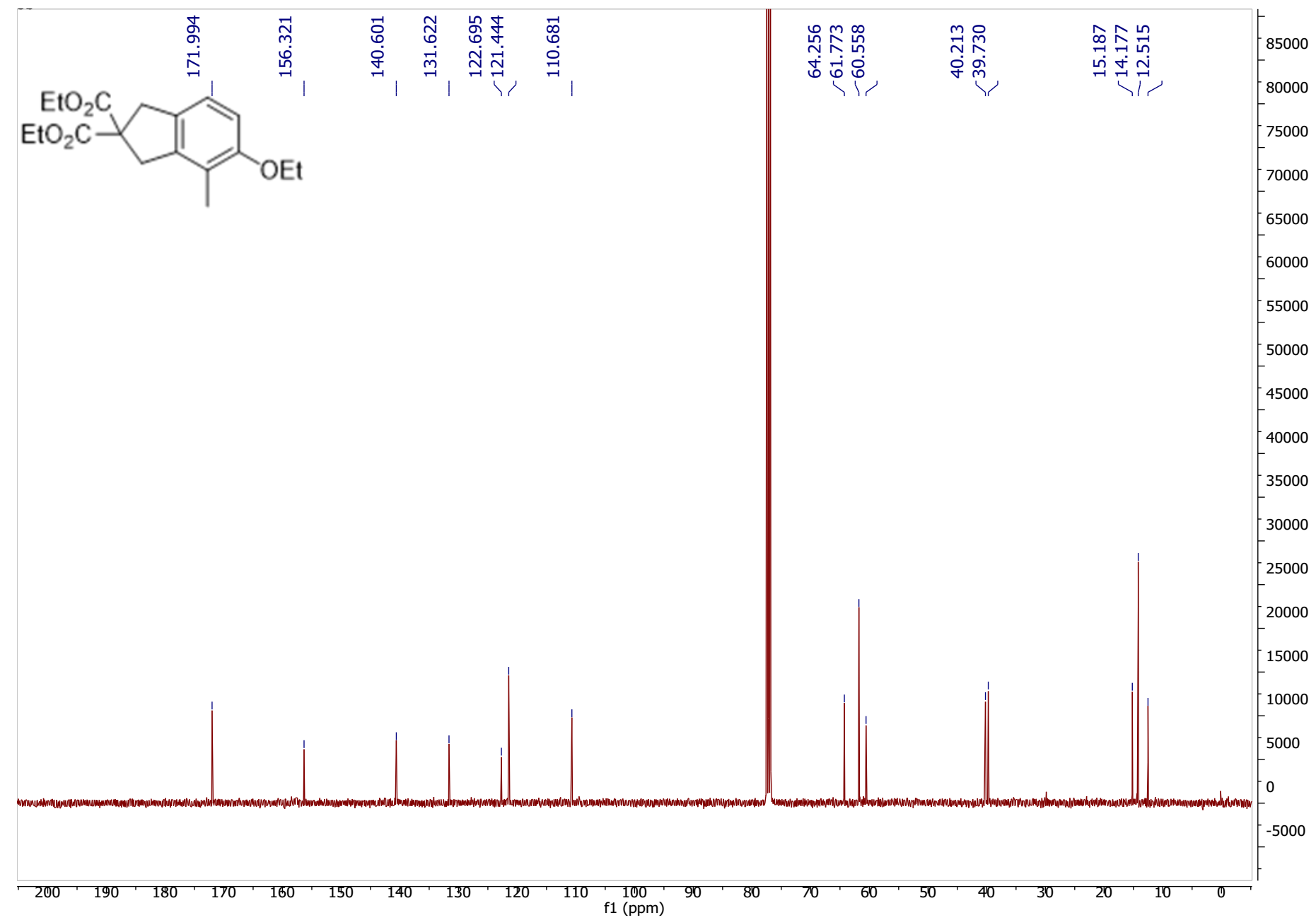

${ }^{13} \mathrm{C}\left\{{ }^{1} \mathrm{H}\right\}$ NMR spectrum of compound $\mathbf{5 b}\left(100 \mathrm{MHz}, \mathrm{CDCl}_{3}\right)$. 


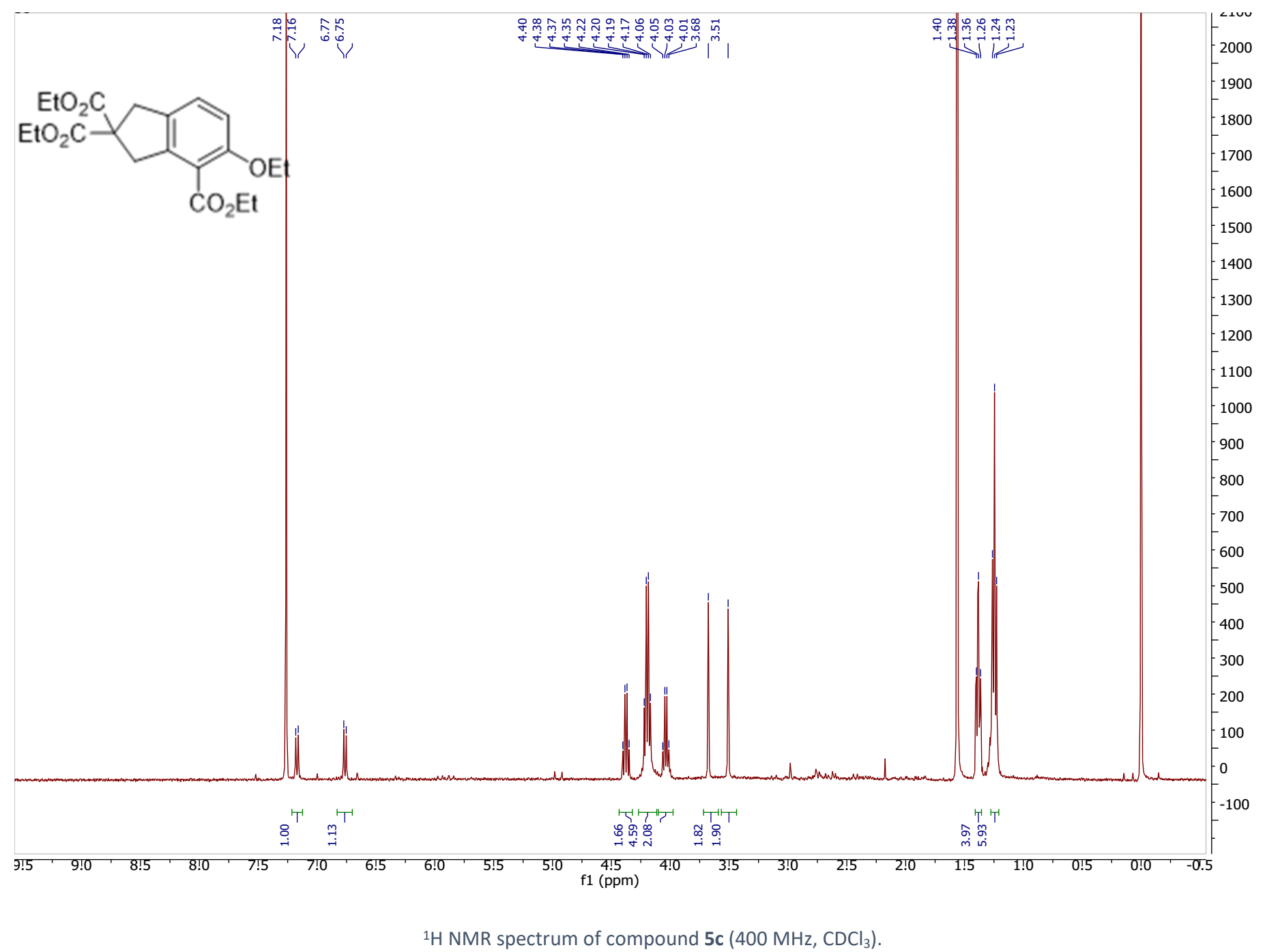




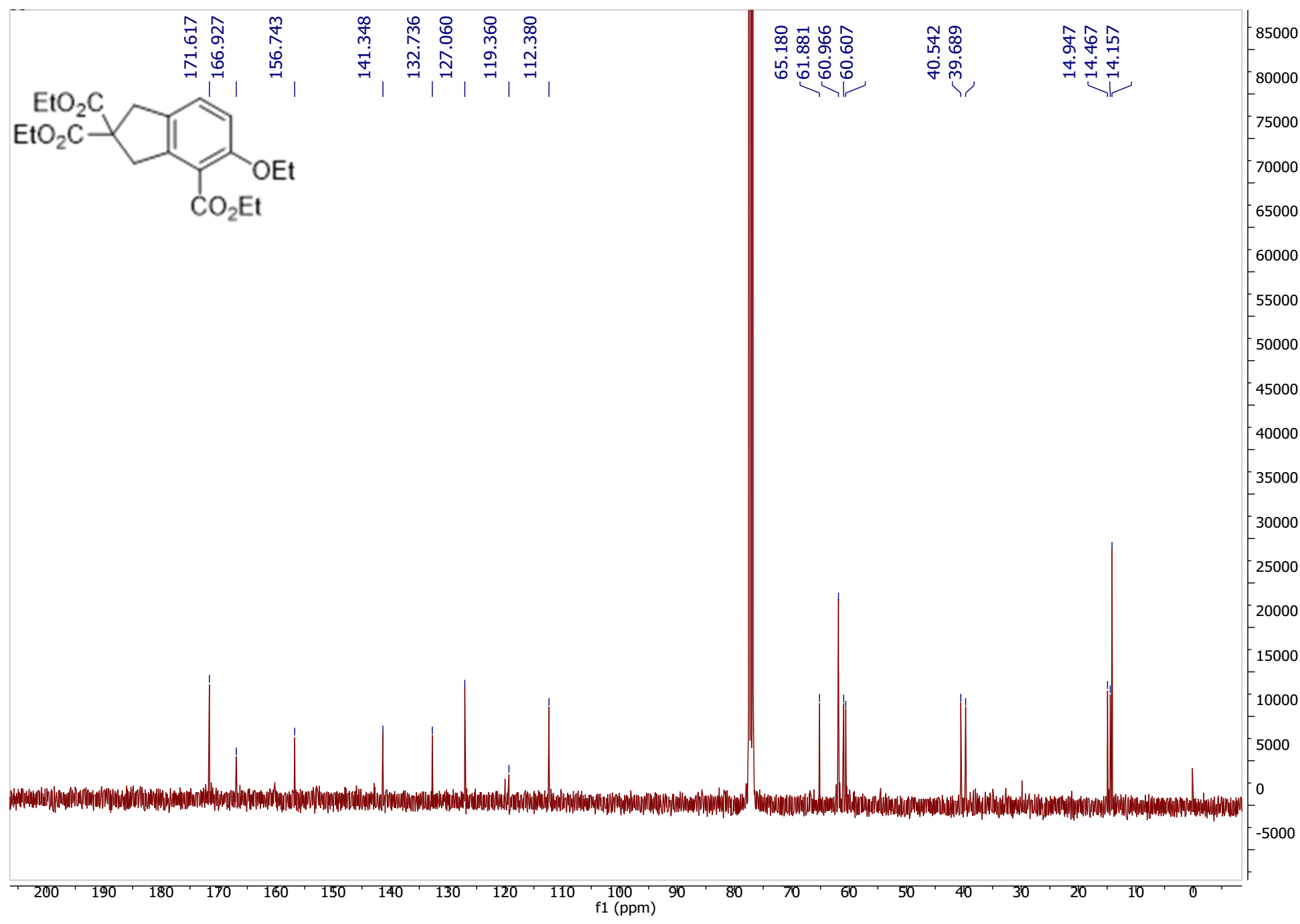

${ }^{13} \mathrm{C}\left\{{ }^{1} \mathrm{H}\right\}$ NMR spectrum of compound $\mathbf{5 c}\left(100 \mathrm{MHz}, \mathrm{CDCl}_{3}\right)$. 


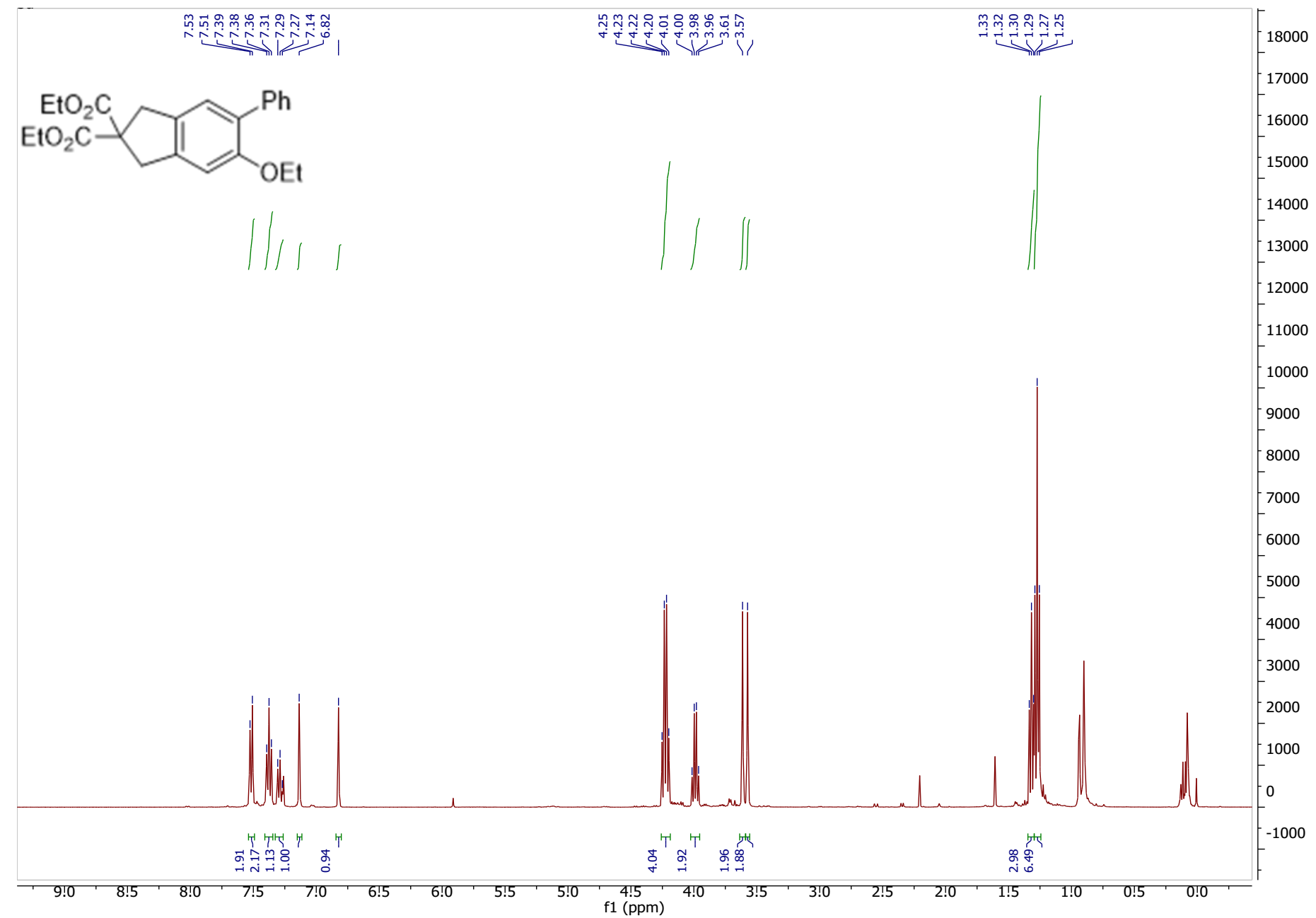

${ }^{1} \mathrm{H}$ NMR spectrum of compound $\mathbf{5 d}\left(400 \mathrm{MHz}, \mathrm{CDCl}_{3}\right)$. 


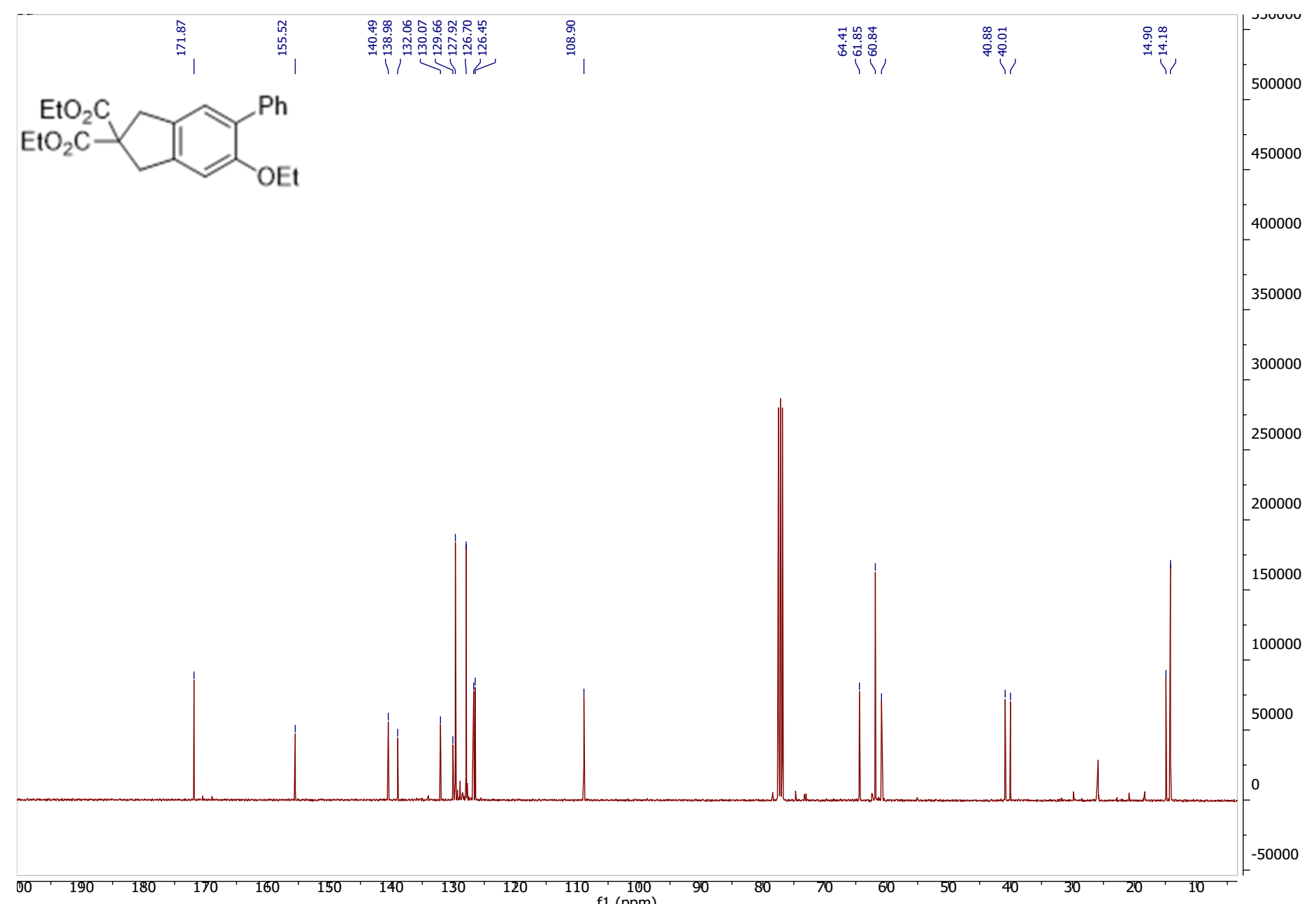

${ }^{13} \mathrm{C}\left\{{ }^{1} \mathrm{H}\right\}$ NMR spectrum of compound $\mathbf{5 d}\left(100 \mathrm{MHz}, \mathrm{CDCl}_{3}\right)$. 


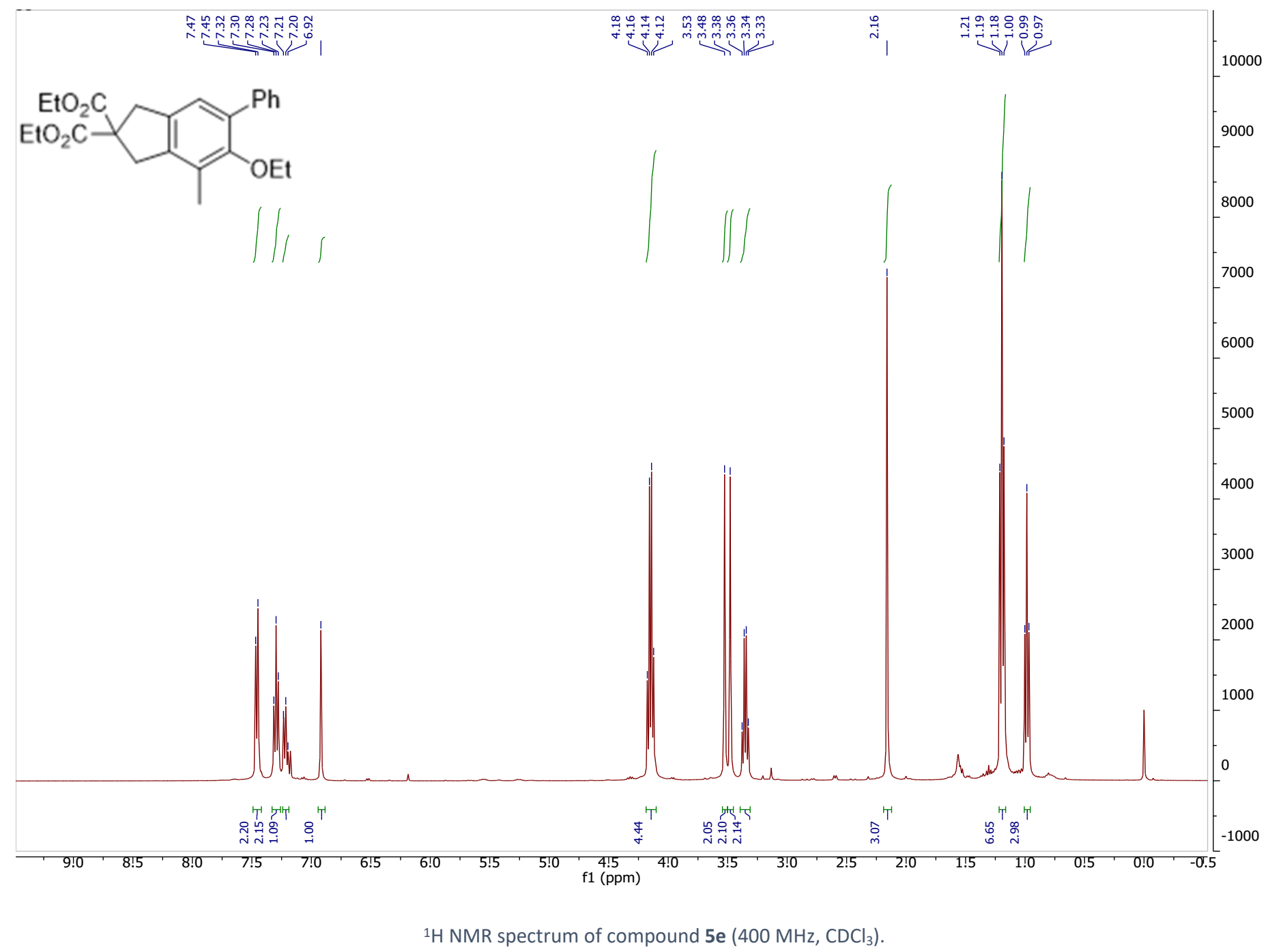




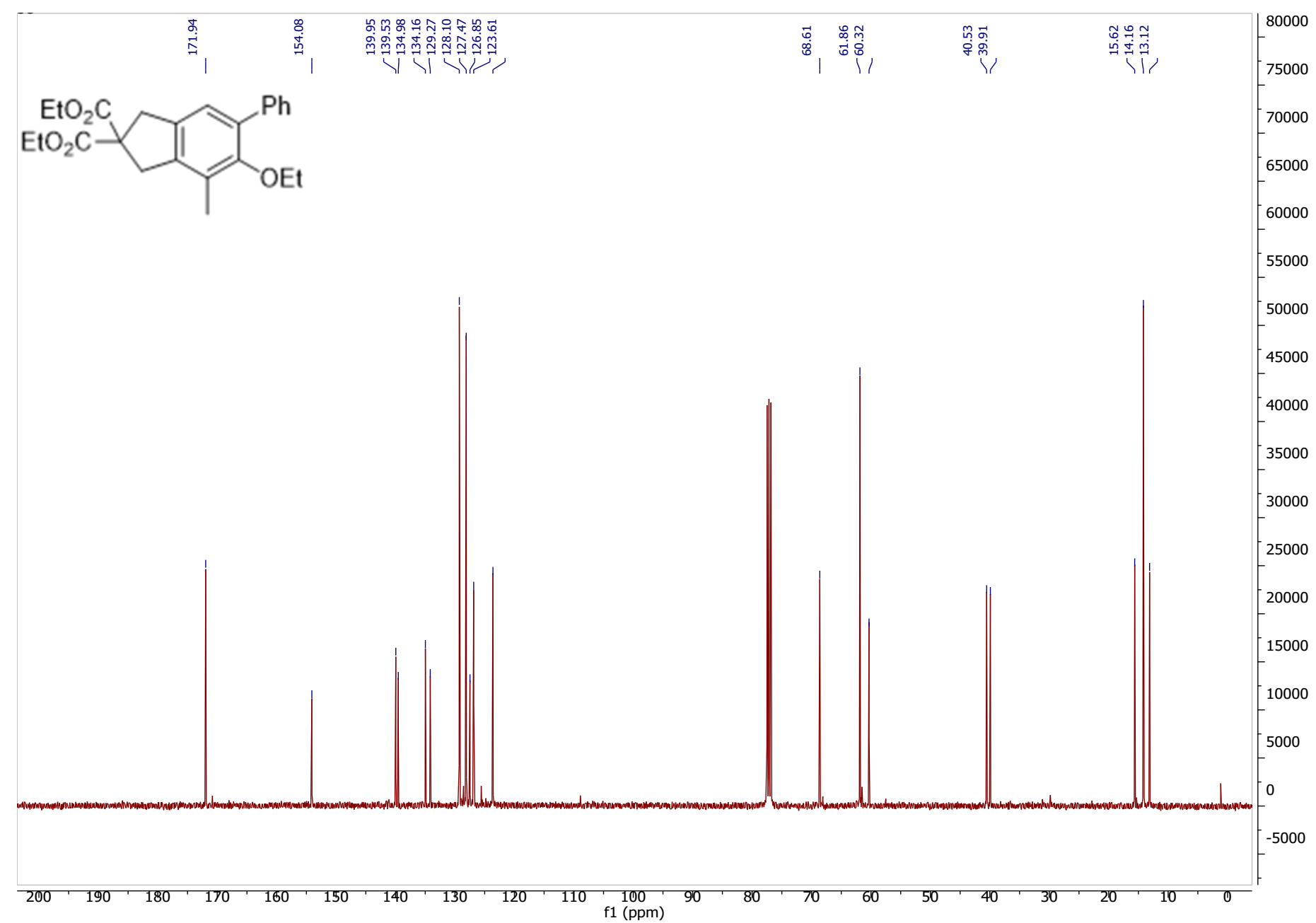

${ }^{13} \mathrm{C}\left\{{ }^{1} \mathrm{H}\right\}$ NMR spectrum of compound $5 e\left(100 \mathrm{MHz}, \mathrm{CDCl}_{3}\right)$. 


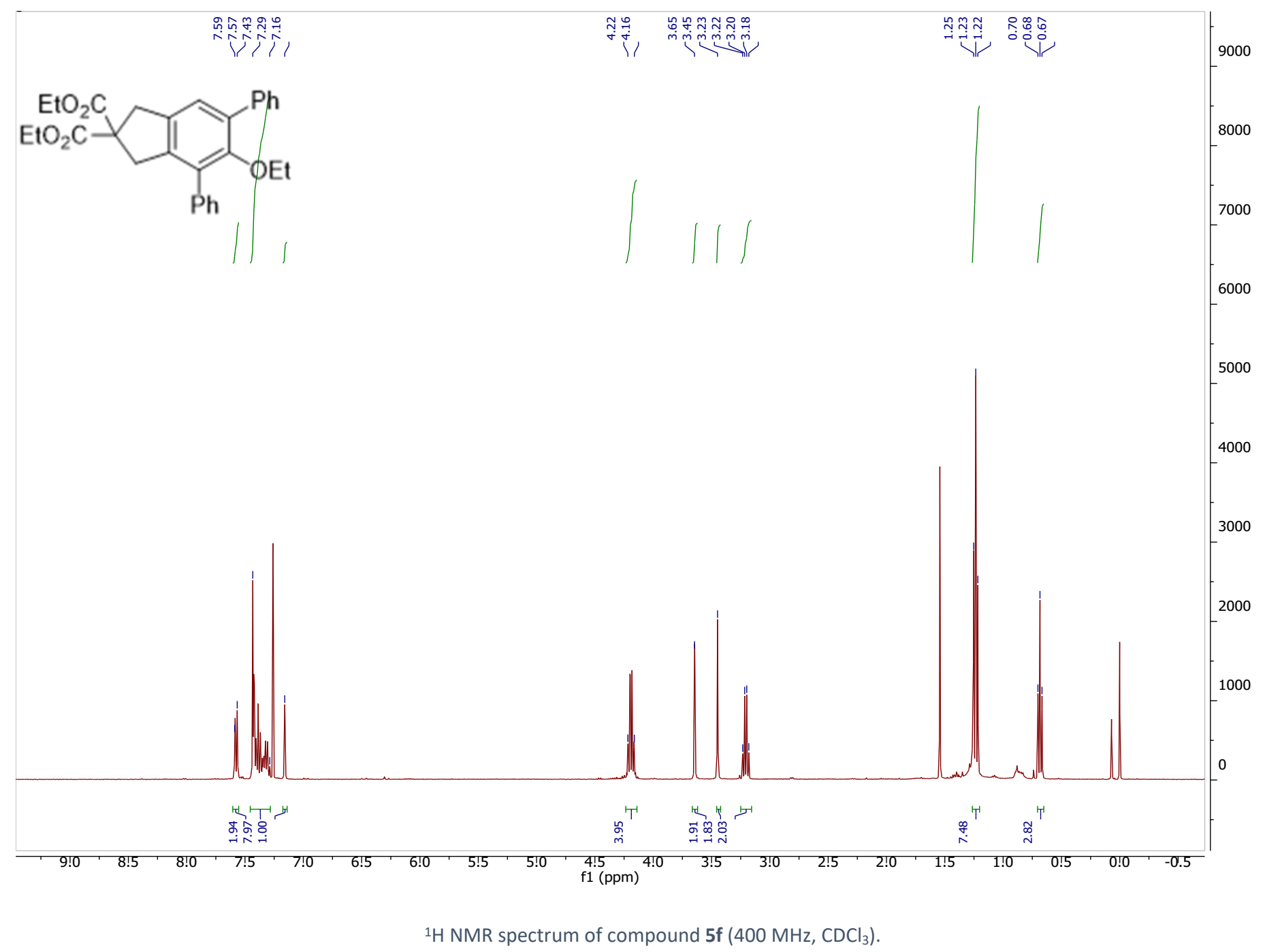




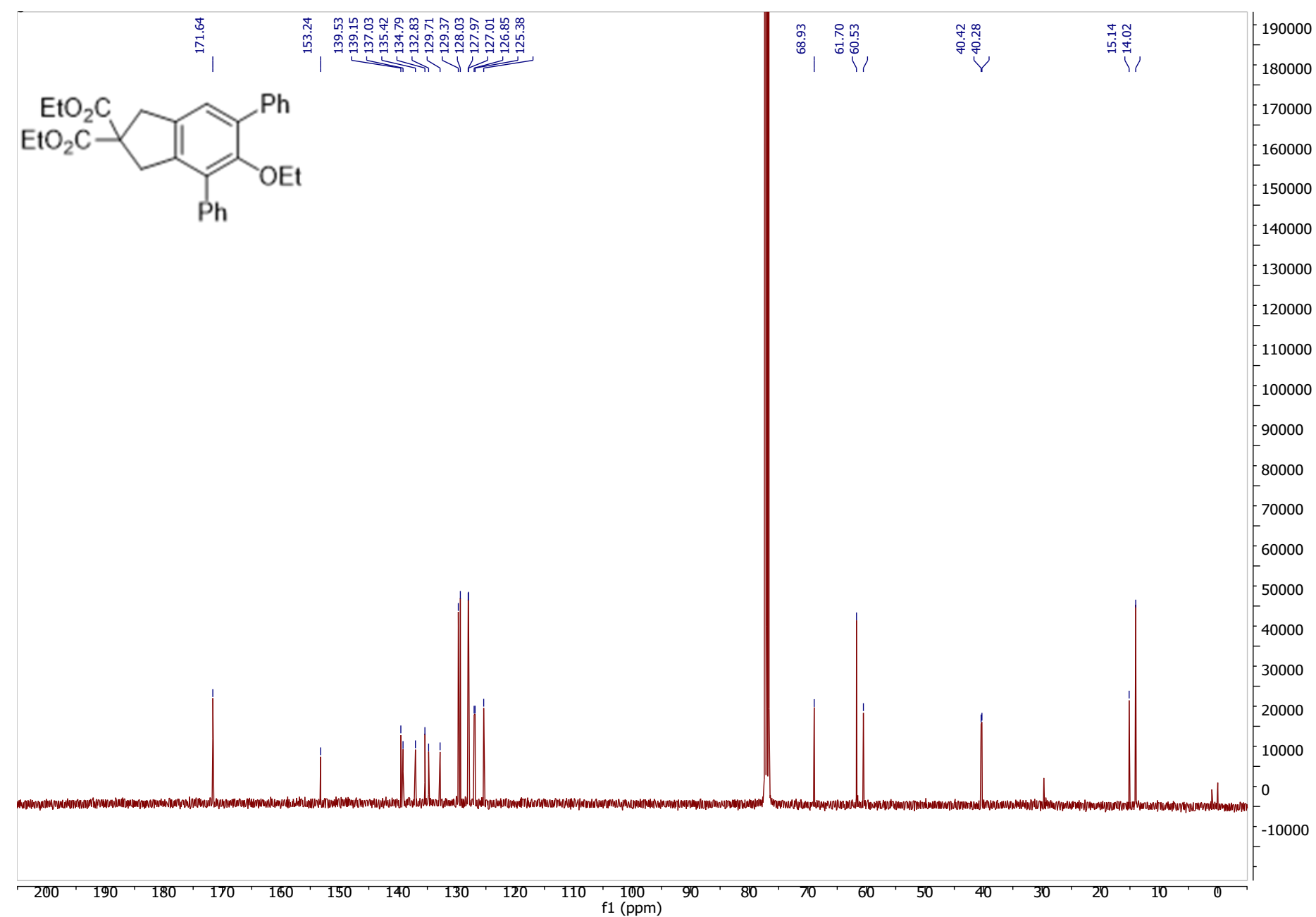

${ }^{13} \mathrm{C}\left\{{ }^{1} \mathrm{H}\right\}$ NMR spectrum of compound $\mathbf{5 f}\left(100 \mathrm{MHz}, \mathrm{CDCl}_{3}\right)$. 


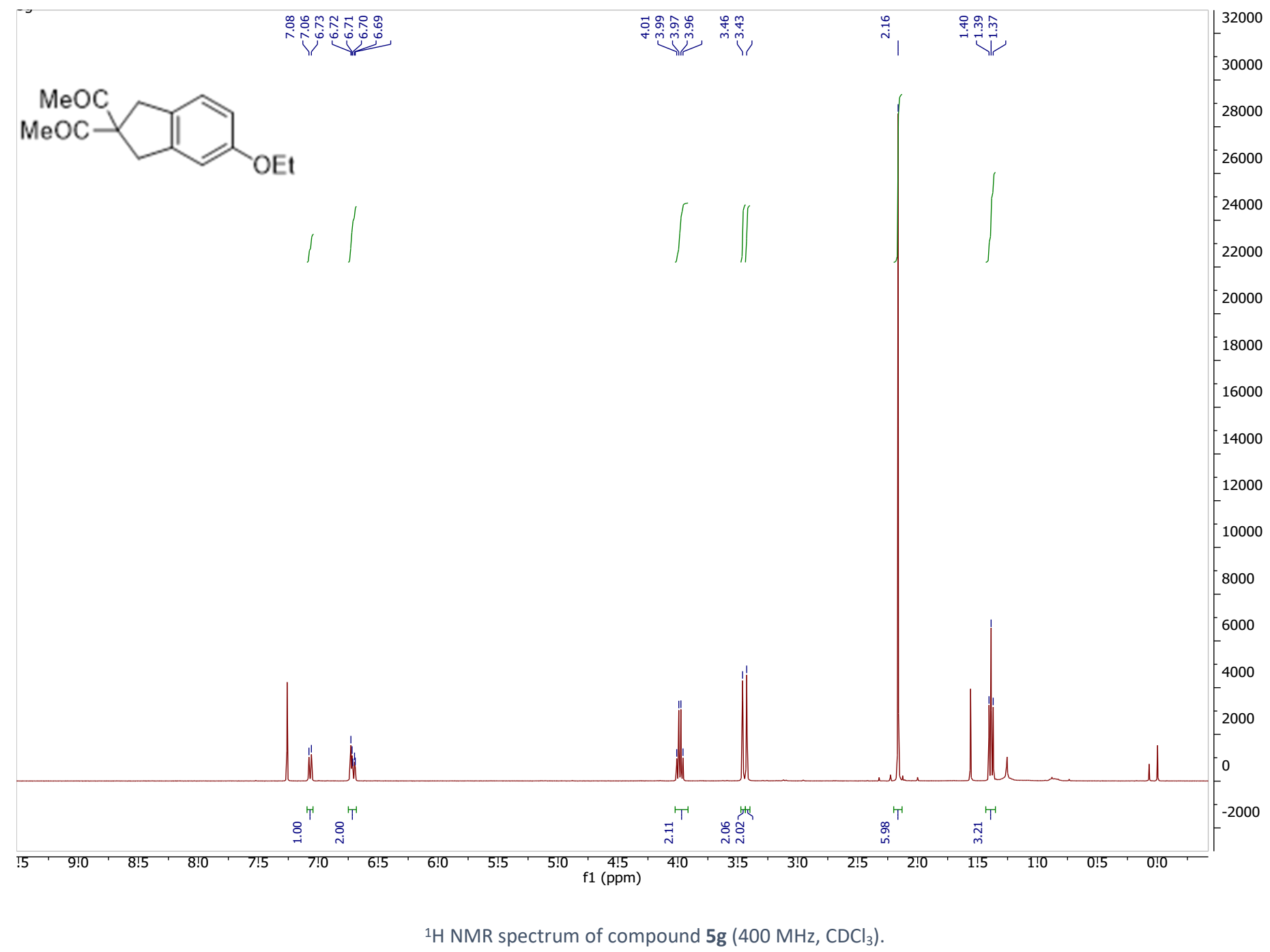




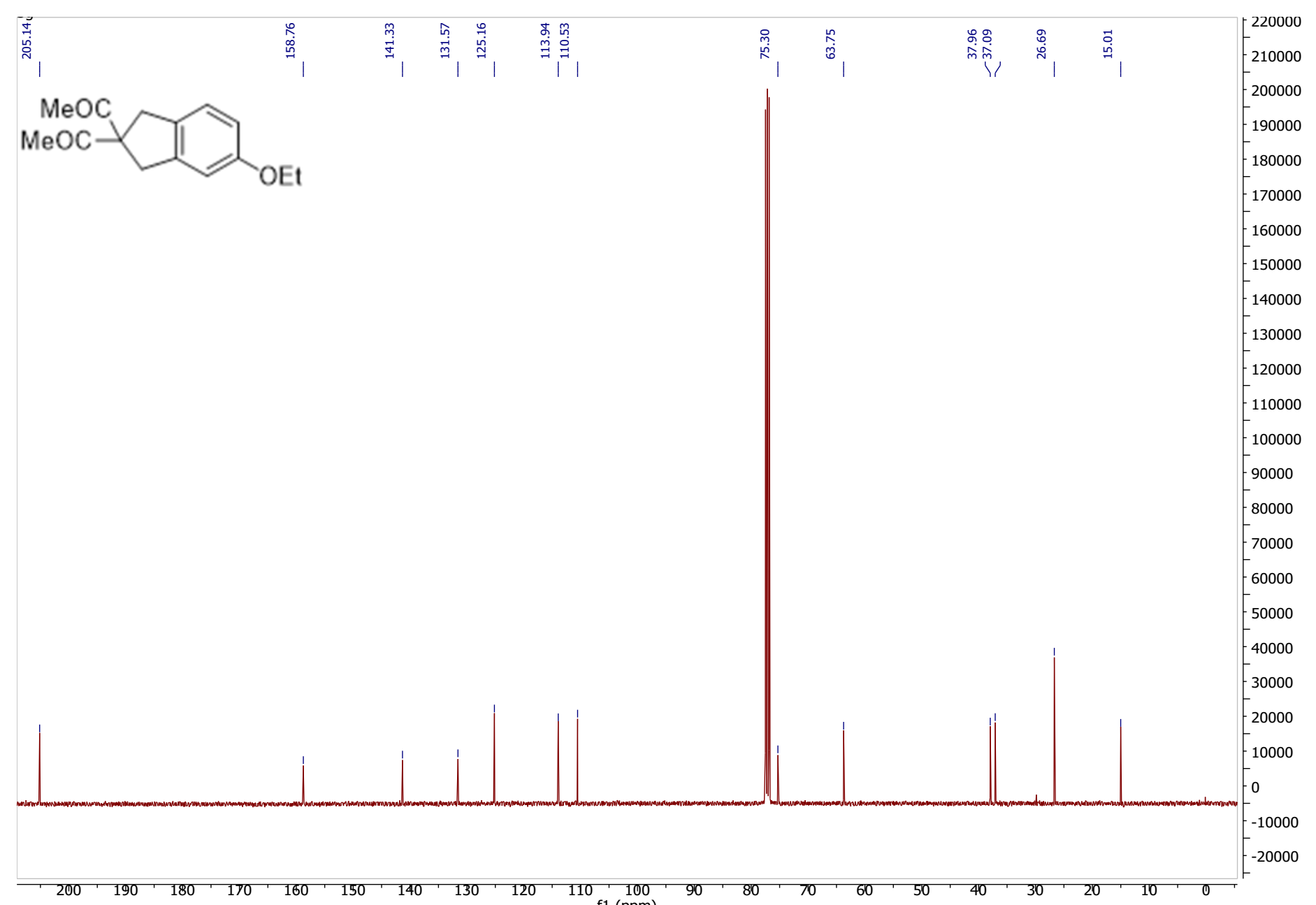

${ }^{13} \mathrm{C}\left\{{ }^{1} \mathrm{H}\right\}$ NMR spectrum of compound $\mathbf{5 g}\left(100 \mathrm{MHz}, \mathrm{CDCl}_{3}\right)$. 


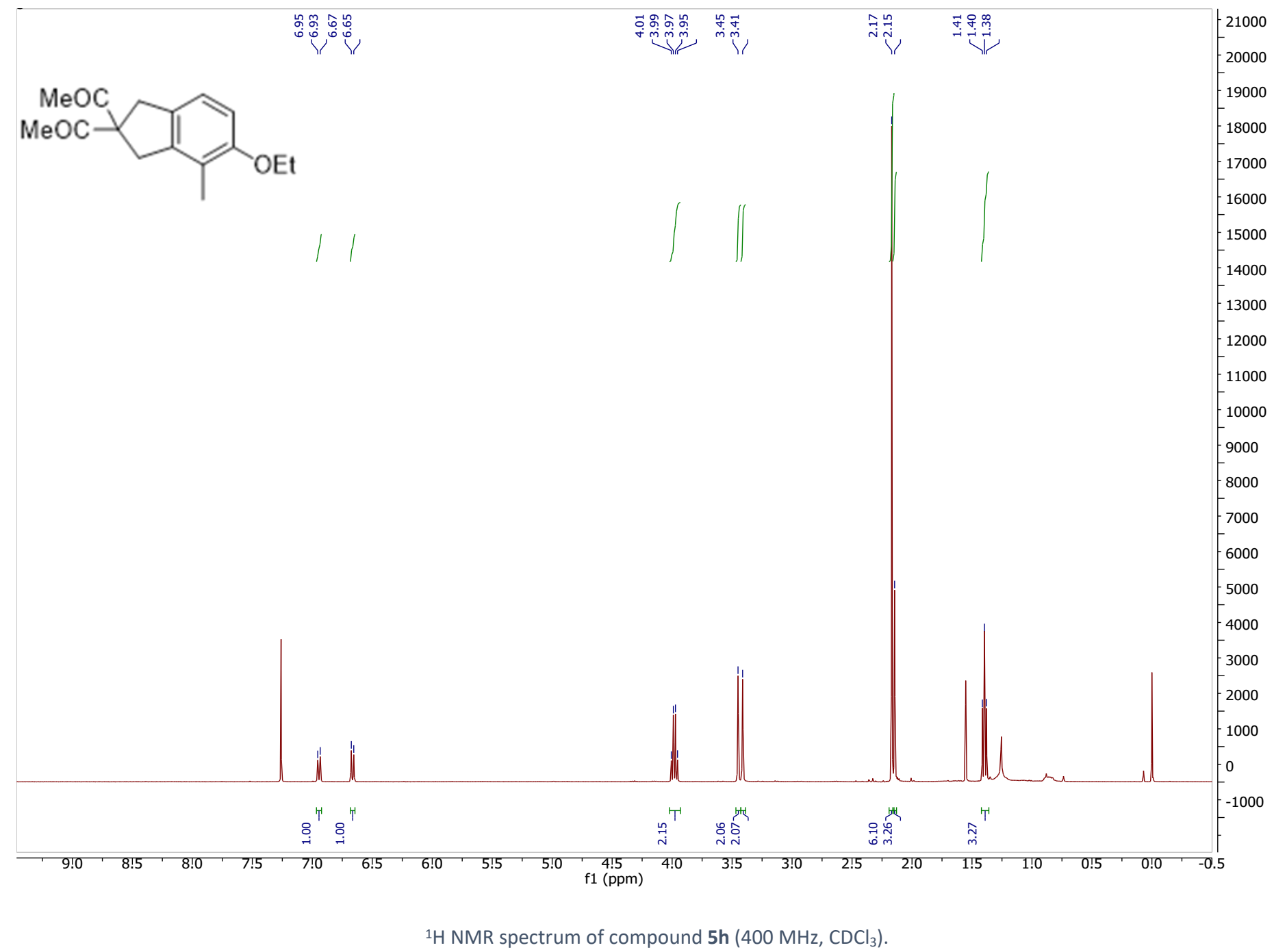




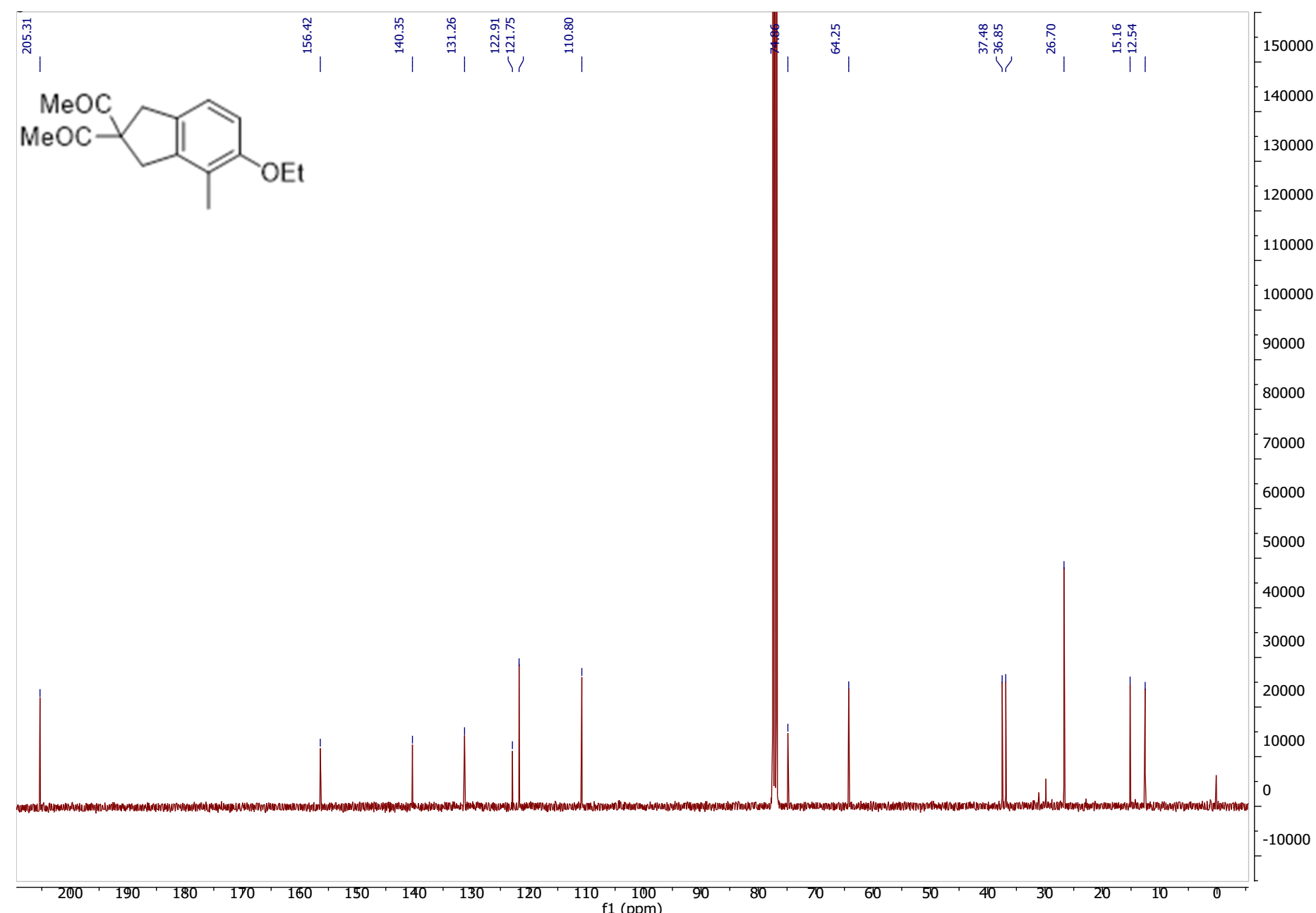

${ }^{13} \mathrm{C}\left\{{ }^{1} \mathrm{H}\right\}$ NMR spectrum of compound $\mathbf{5} \boldsymbol{h}\left(100 \mathrm{MHz}, \mathrm{CDCl}_{3}\right)$. 


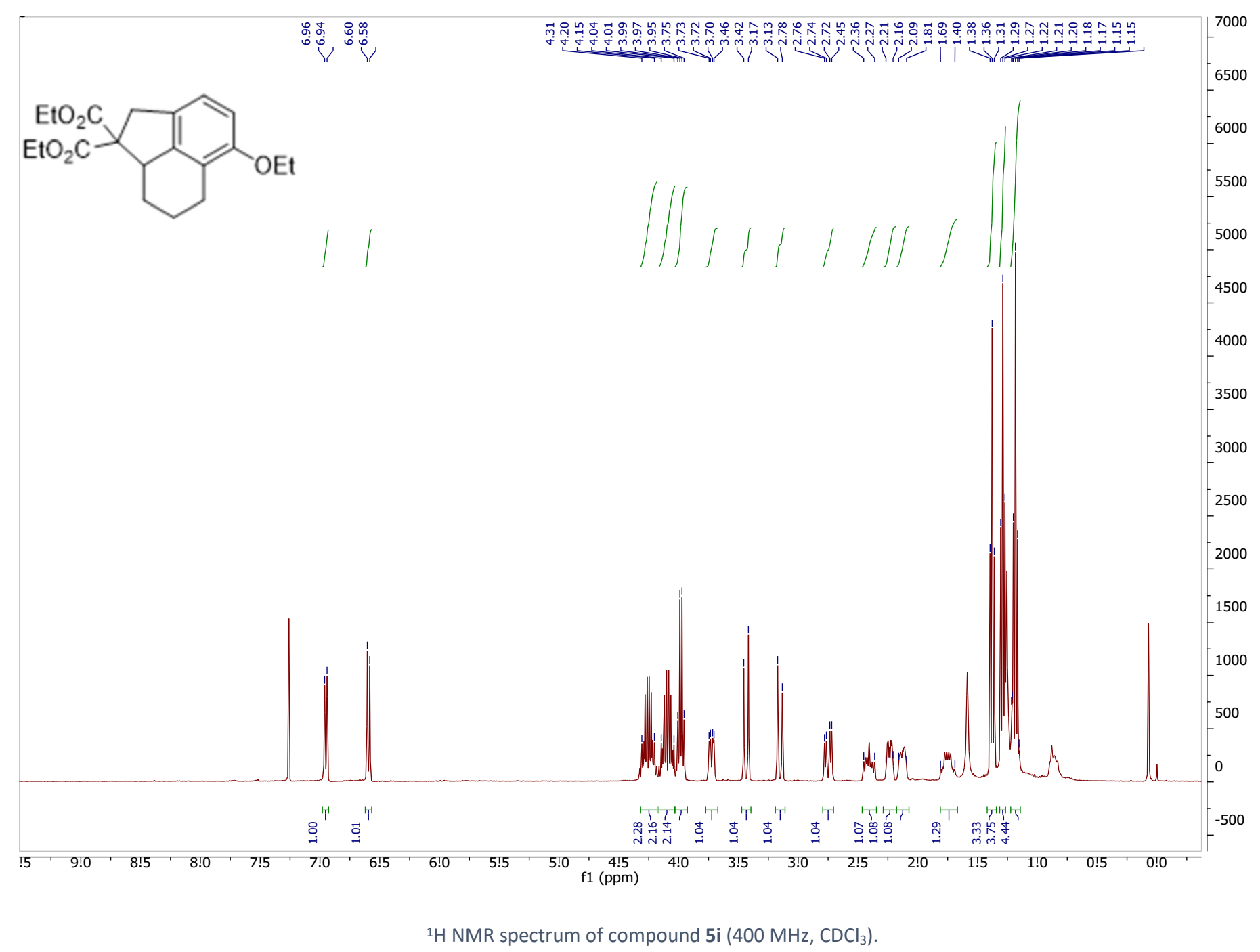




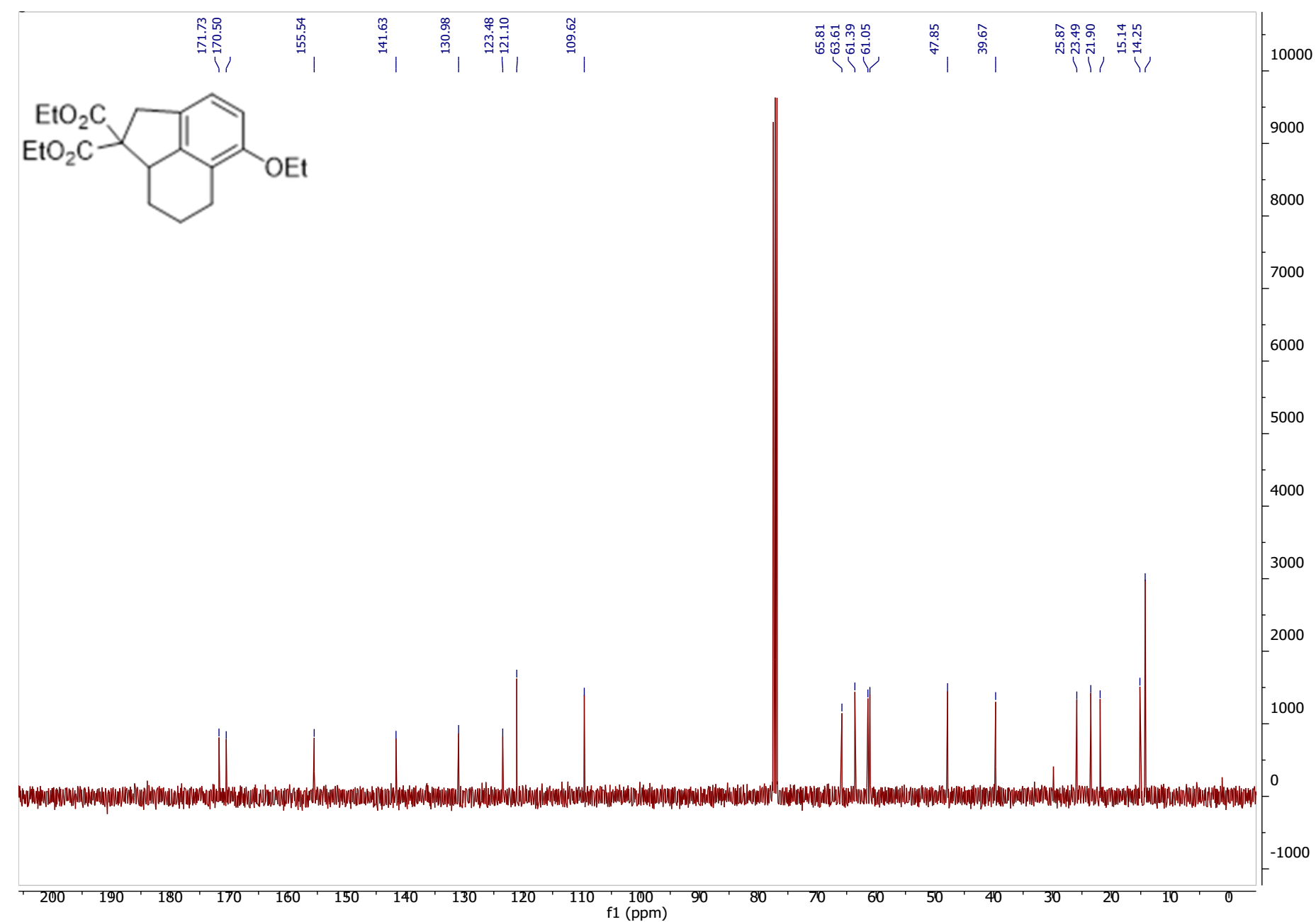

${ }^{13} \mathrm{C}\left\{{ }^{1} \mathrm{H}\right\}$ NMR spectrum of compound $\mathbf{5 i}\left(100 \mathrm{MHz}, \mathrm{CDCl}_{3}\right)$. 


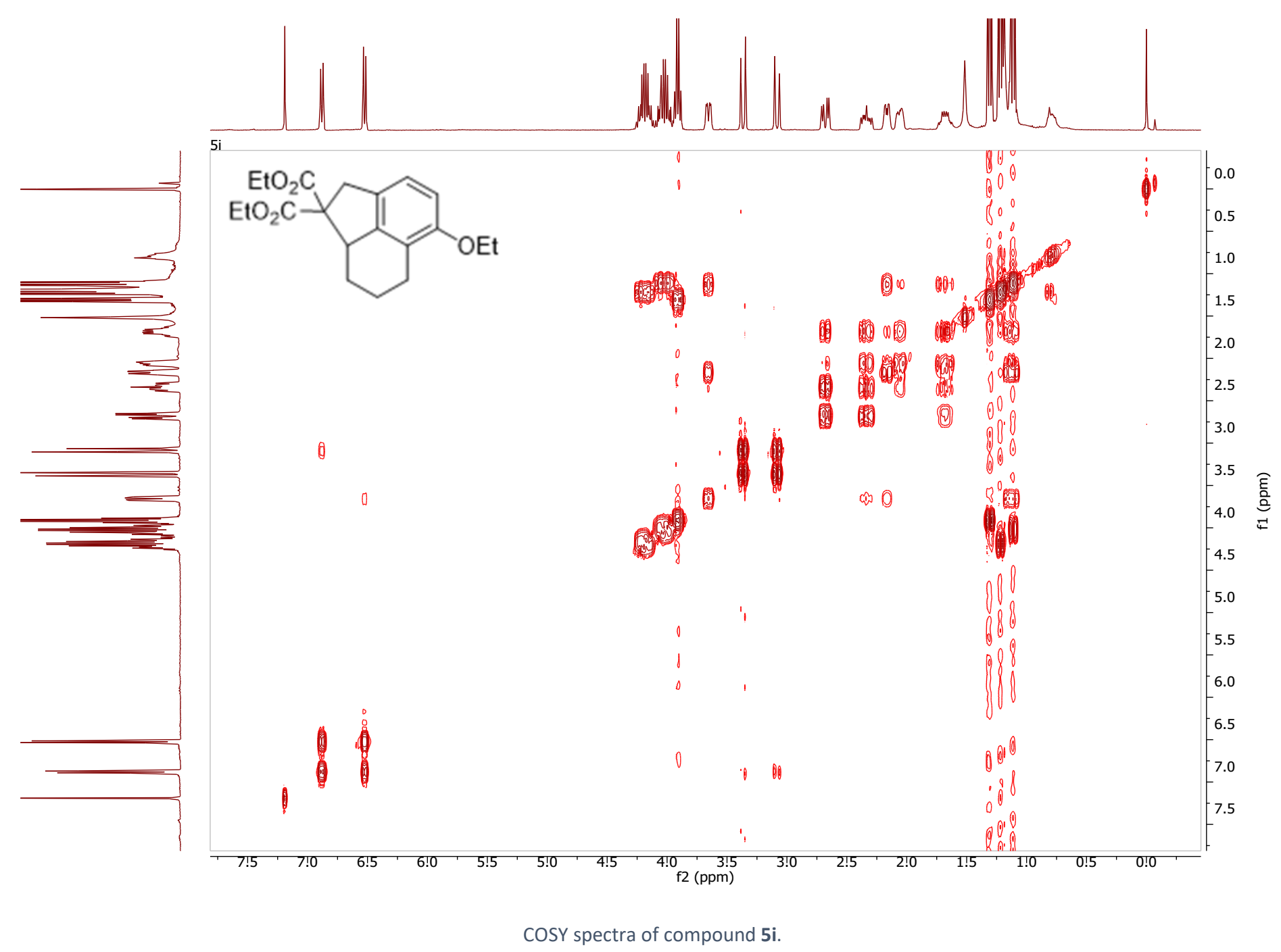




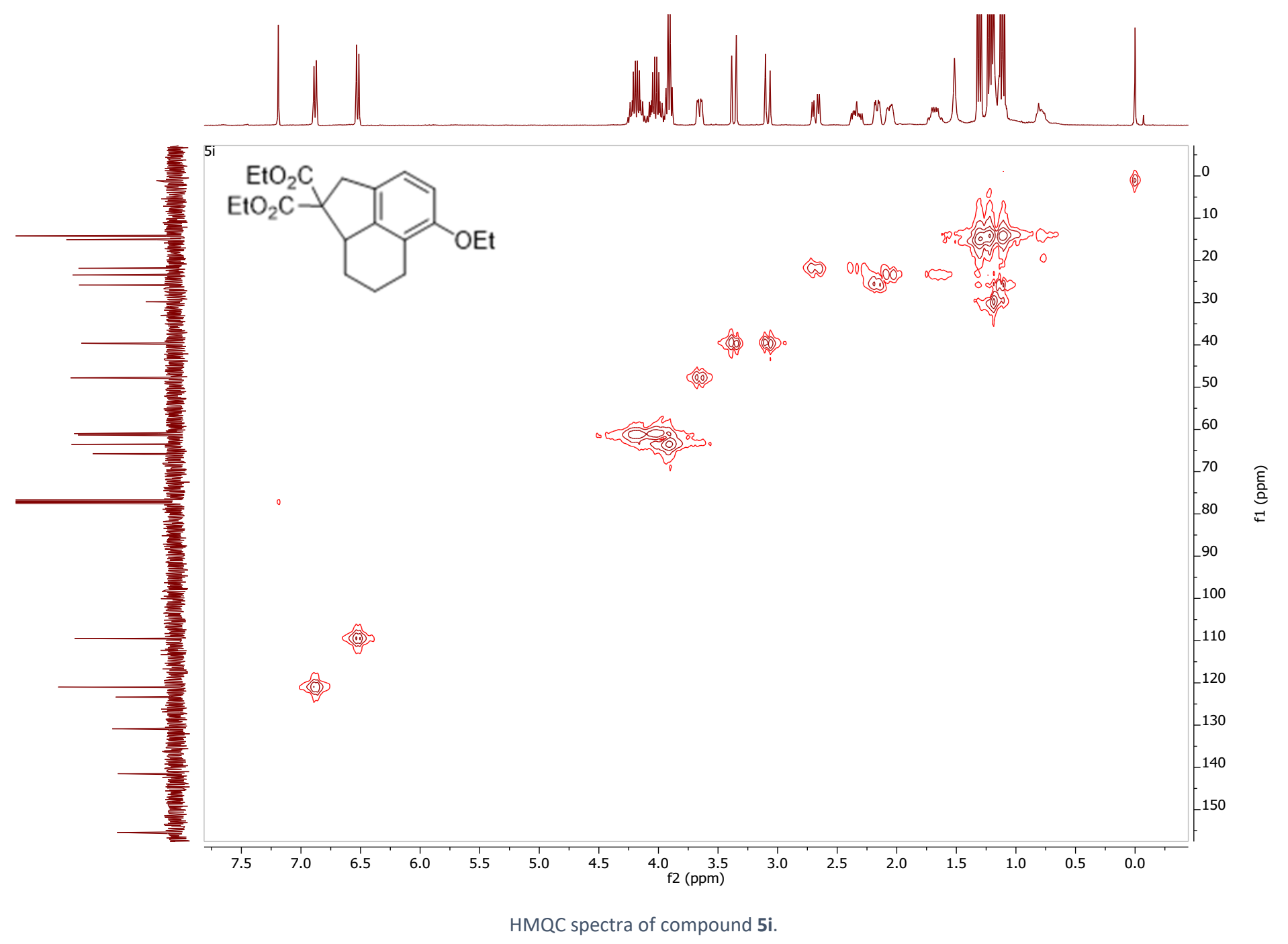




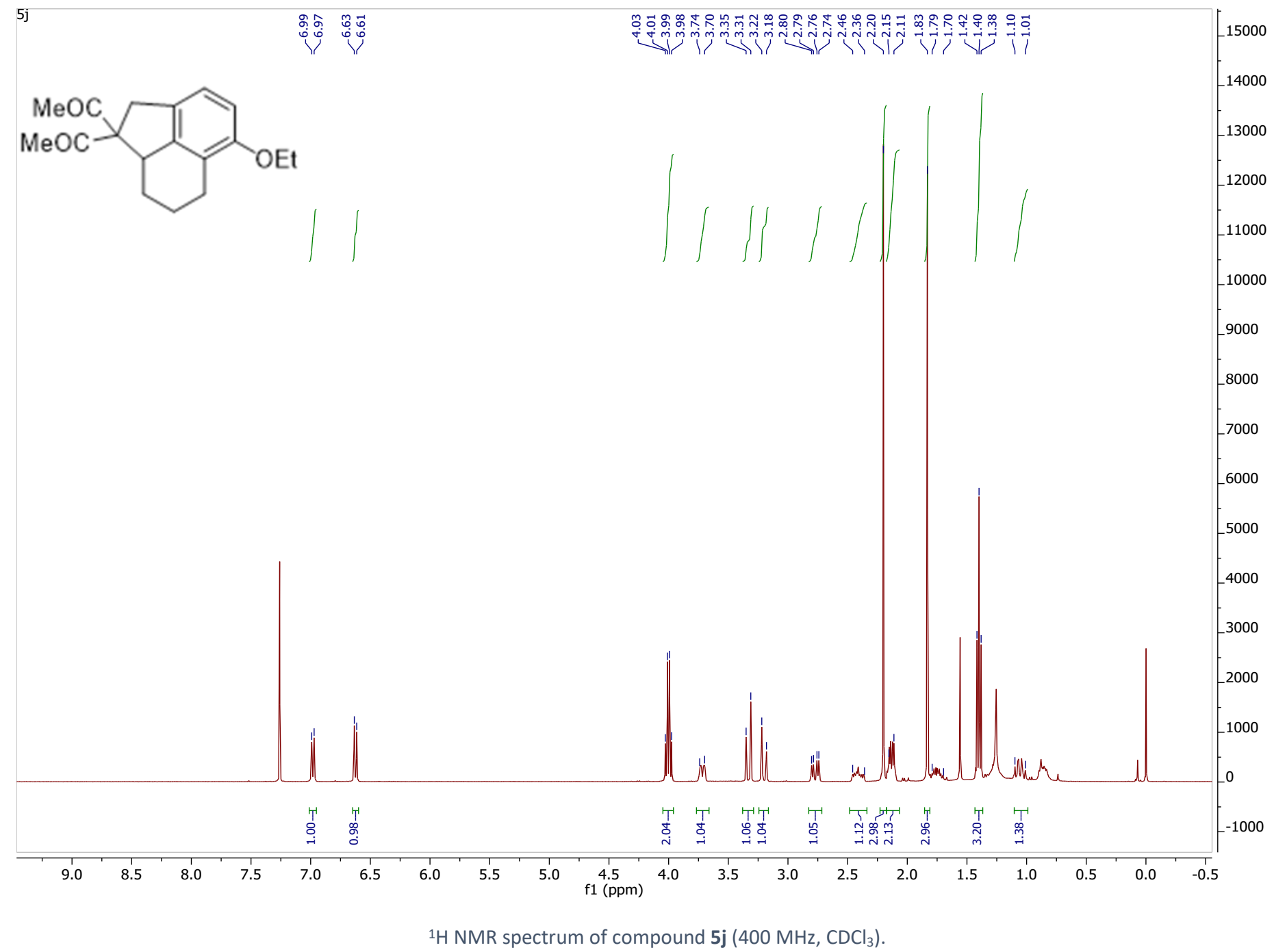




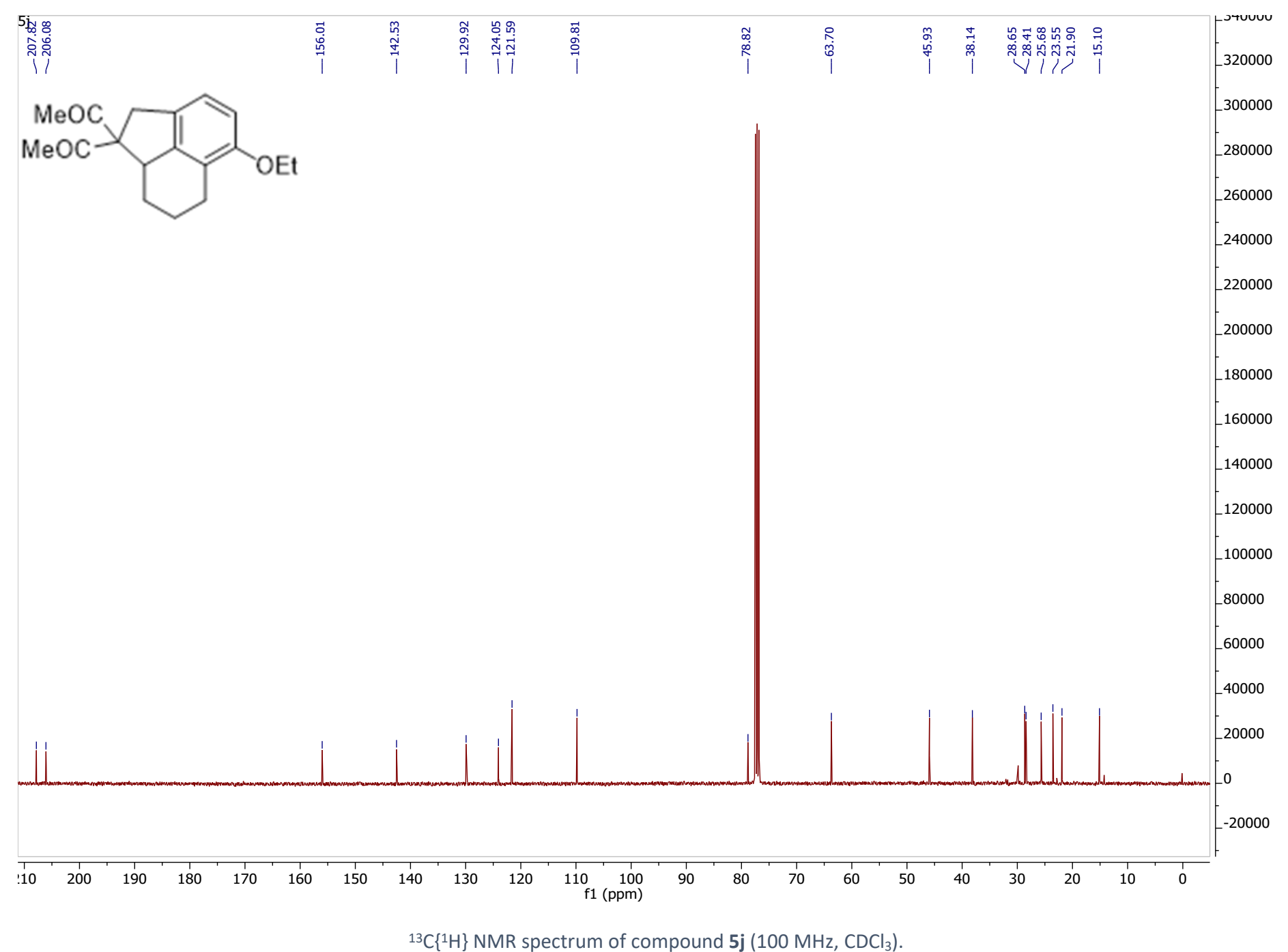




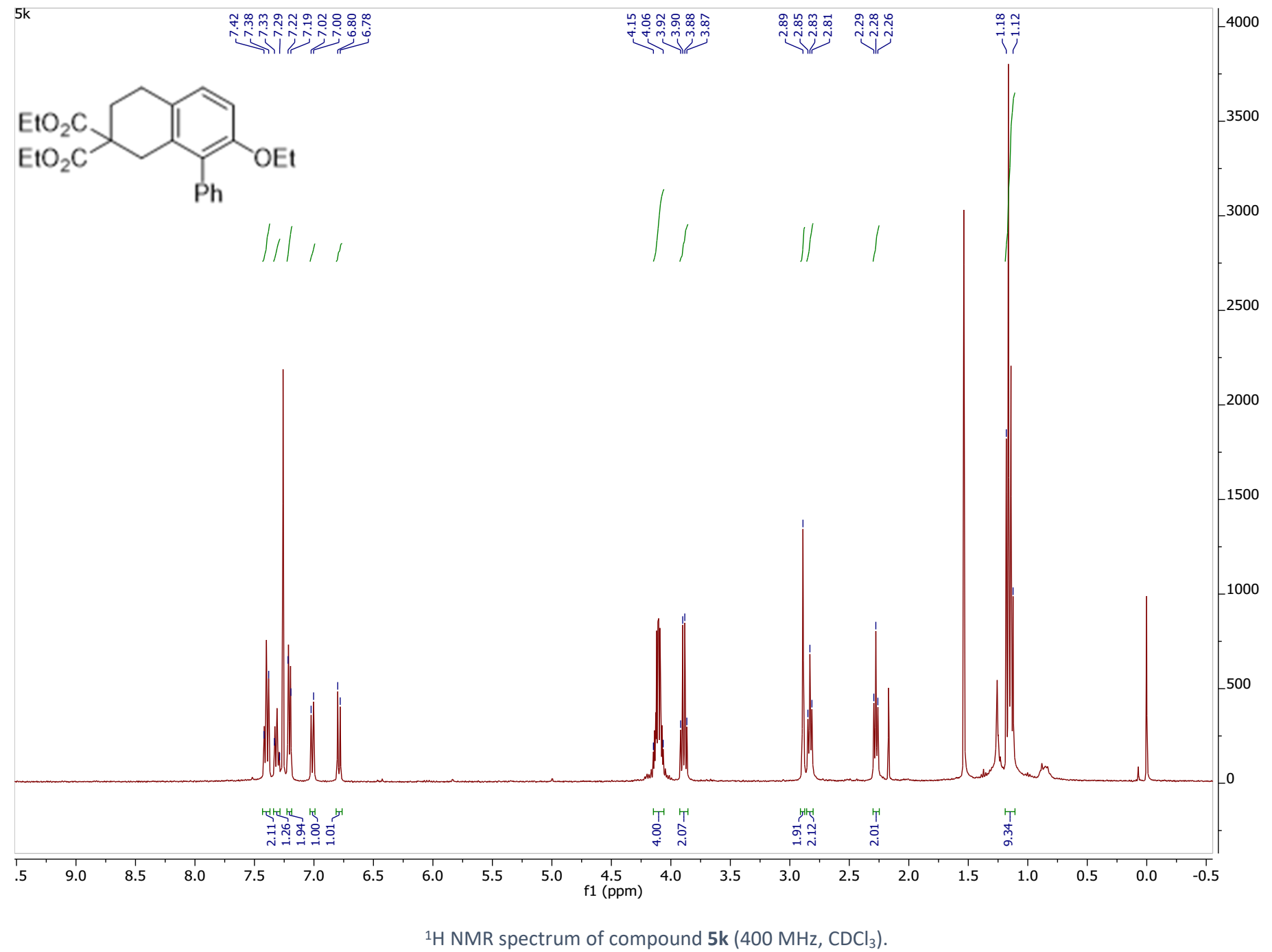




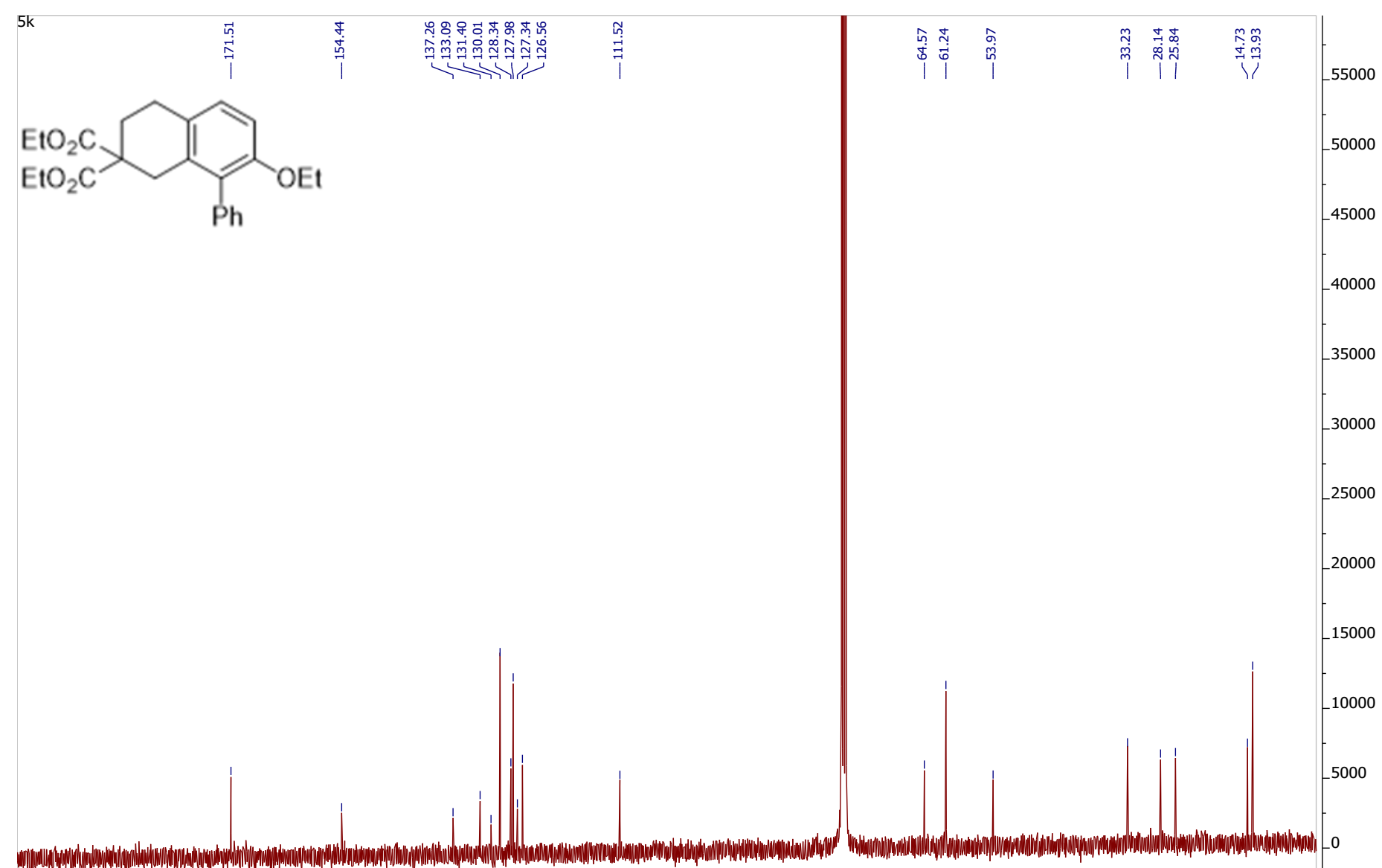

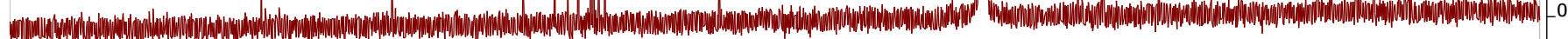

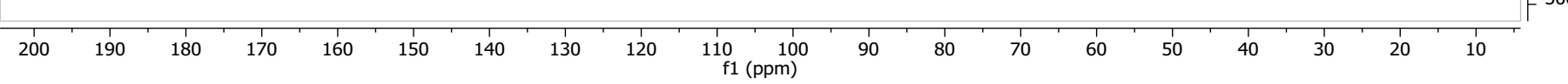

${ }^{13} \mathrm{C}\left\{{ }^{1} \mathrm{H}\right\} \mathrm{NMR}$ spectrum of compound $5 \mathrm{k}\left(100 \mathrm{MHz}, \mathrm{CDCl}_{3}\right)$. 


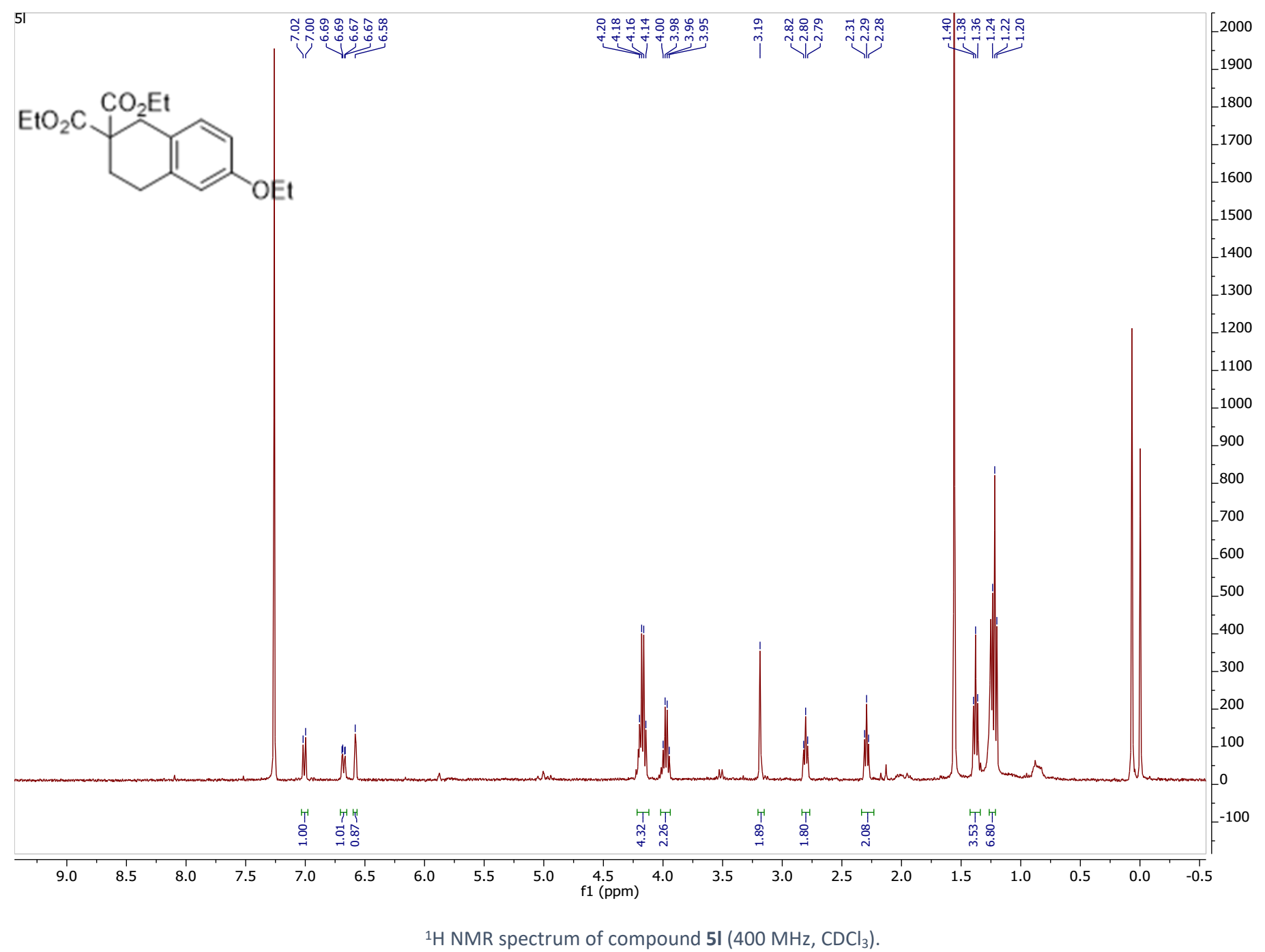




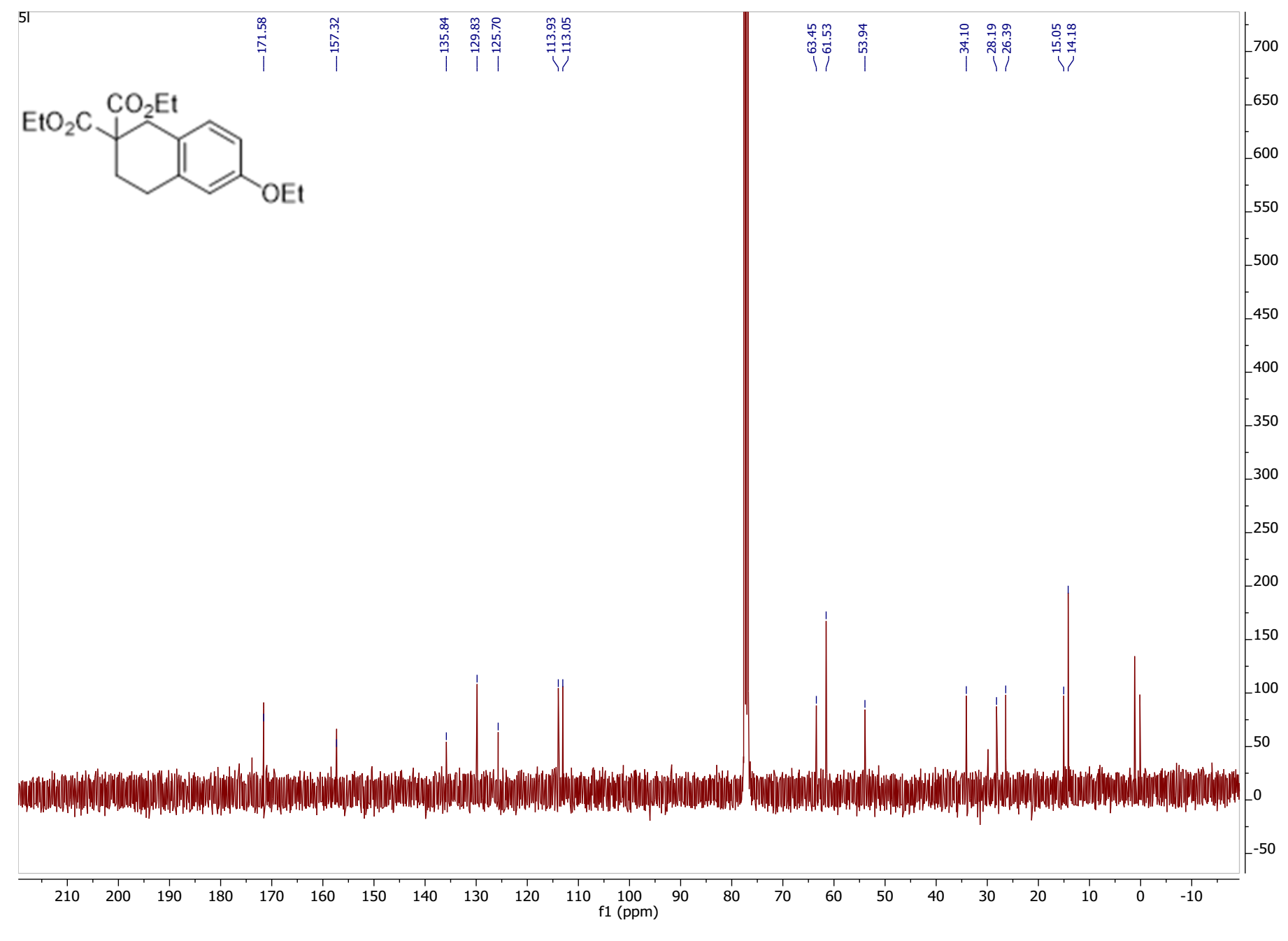

${ }^{13} \mathrm{C}\left\{{ }^{1} \mathrm{H}\right\}$ NMR spectrum of compound $5 \mathbf{5}\left(100 \mathrm{MHz}, \mathrm{CDCl}_{3}\right)$. 


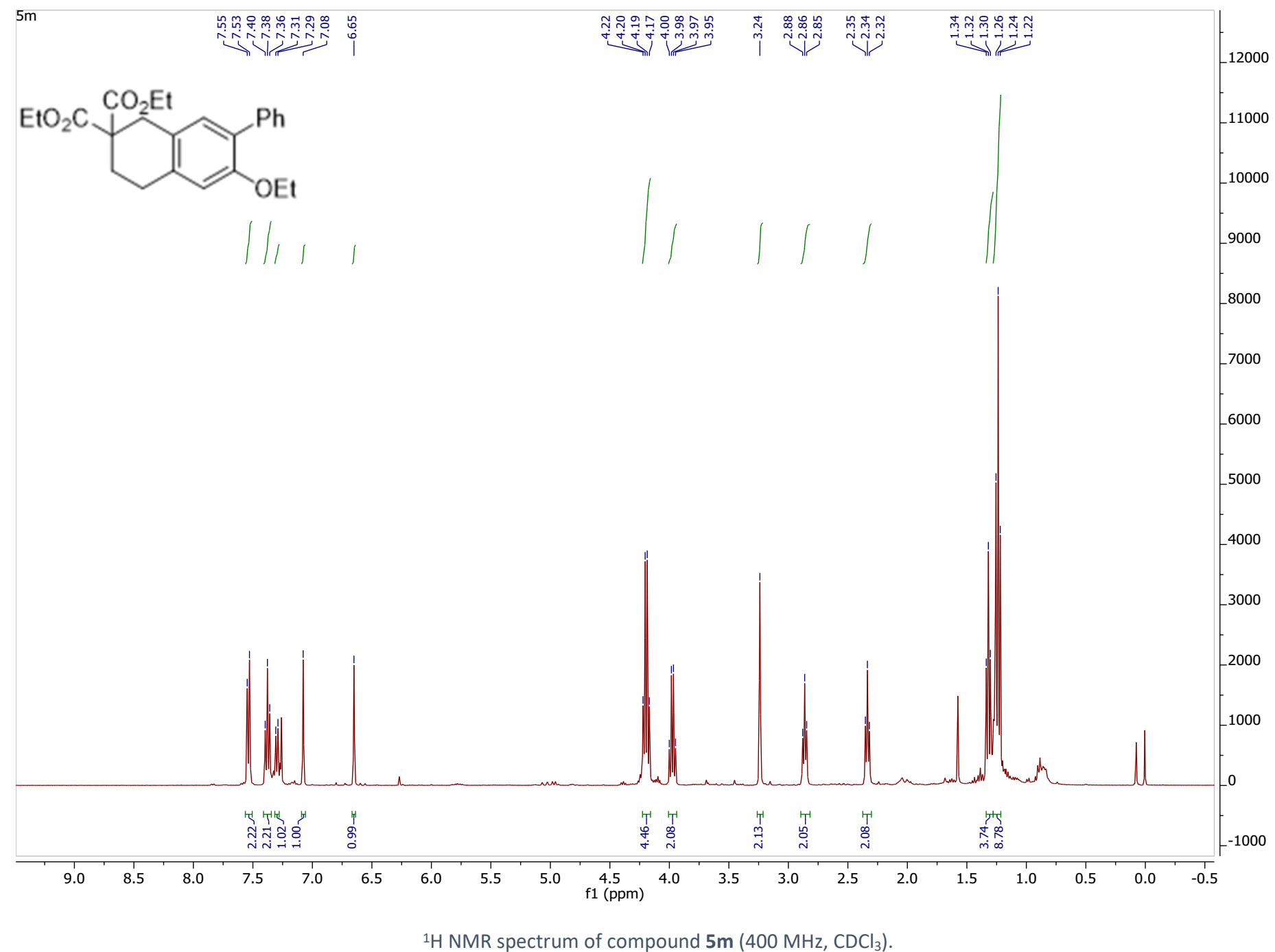




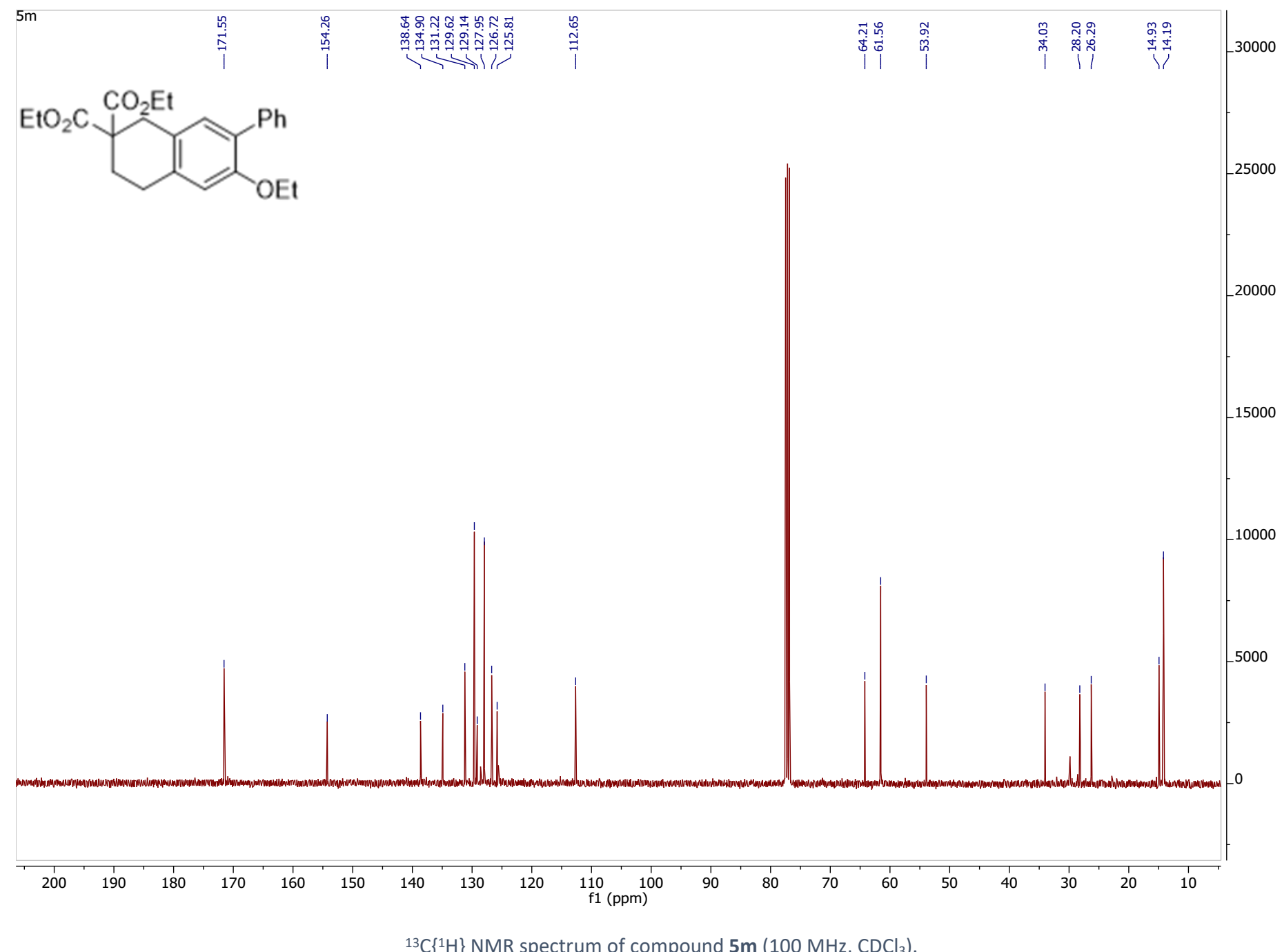




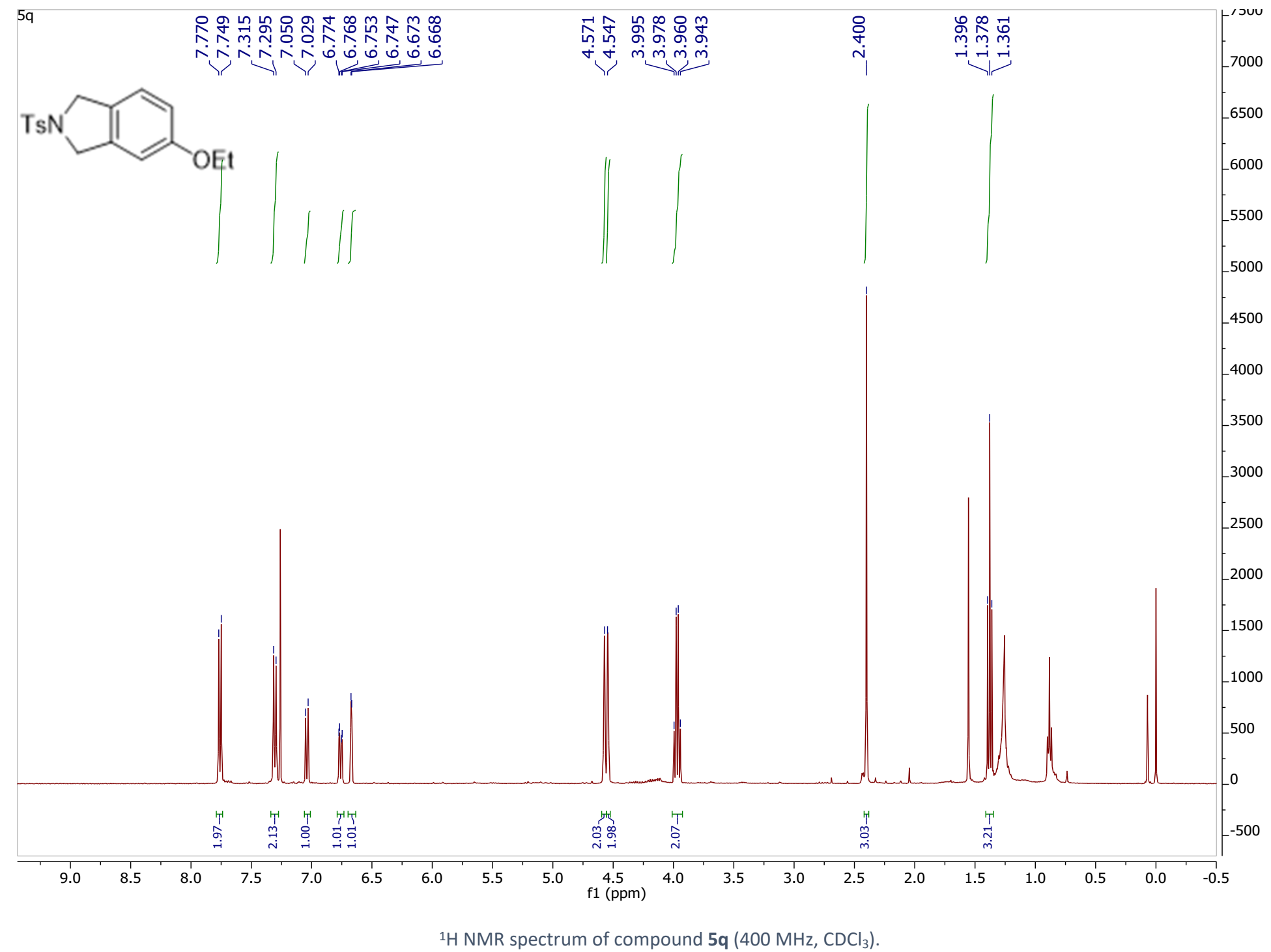




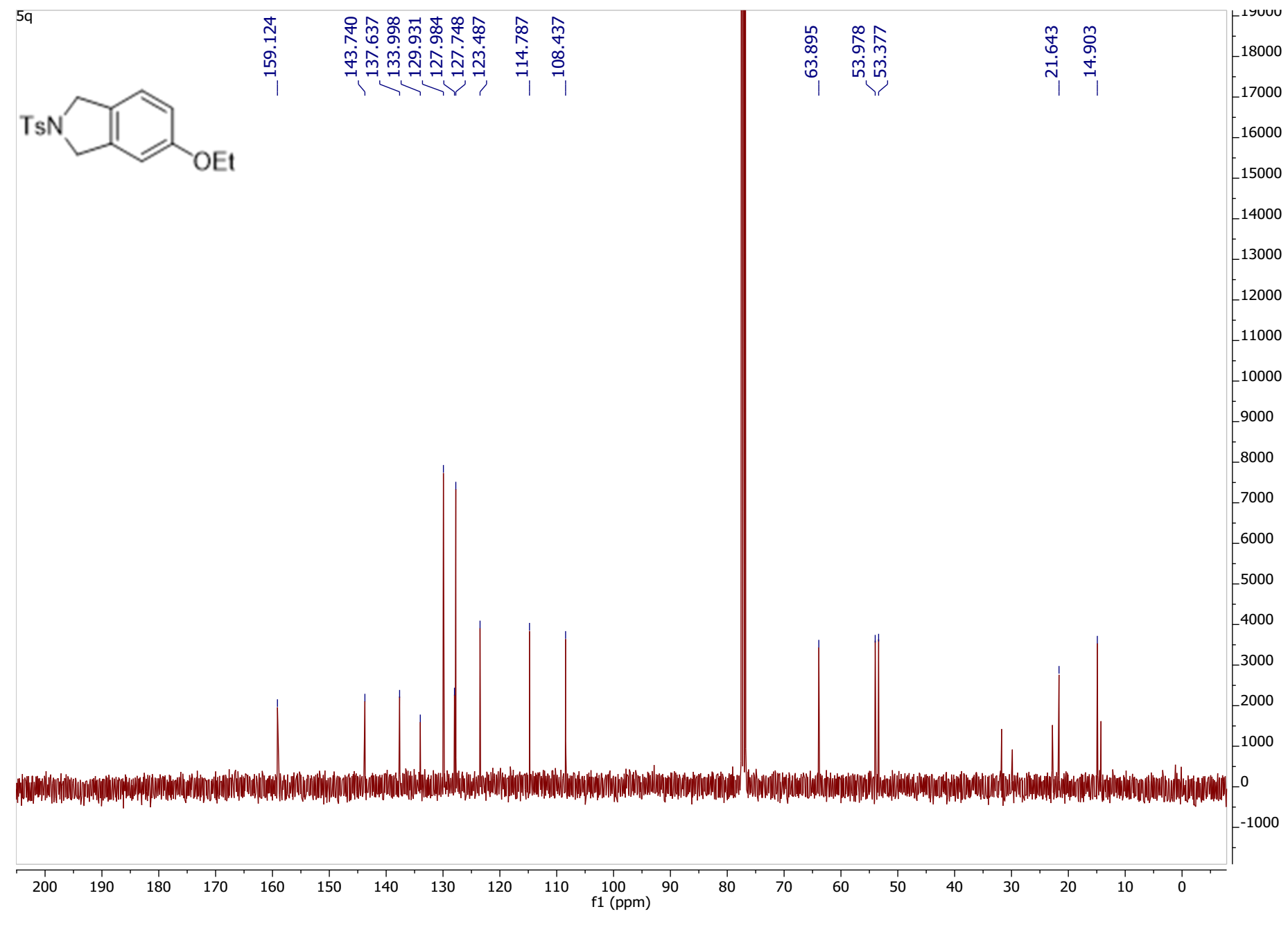

${ }^{13} \mathrm{C}\left\{{ }^{1} \mathrm{H}\right\}$ NMR spectrum of compound $\mathbf{5 q}\left(100 \mathrm{MHz}, \mathrm{CDCl}_{3}\right)$. 


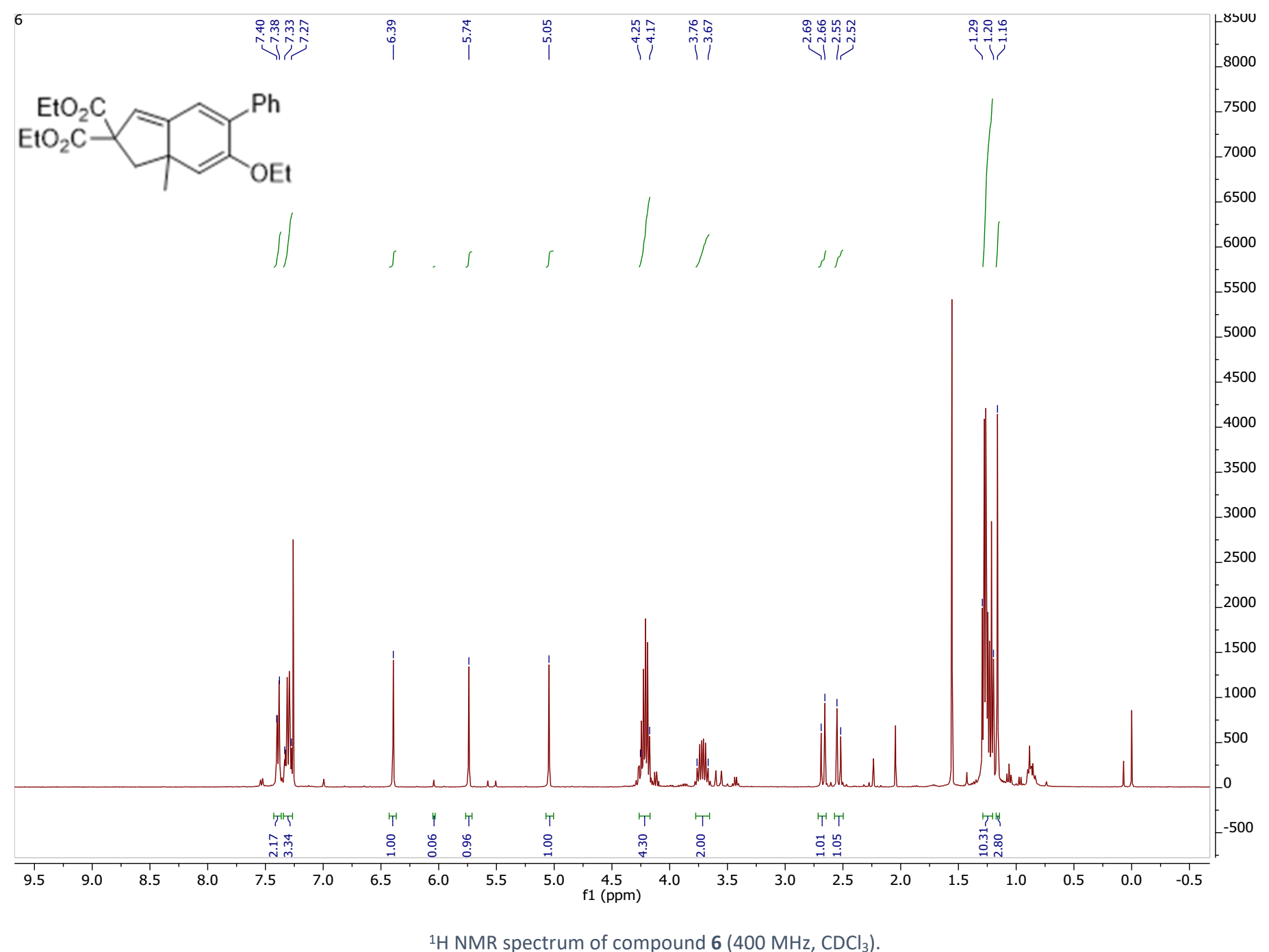




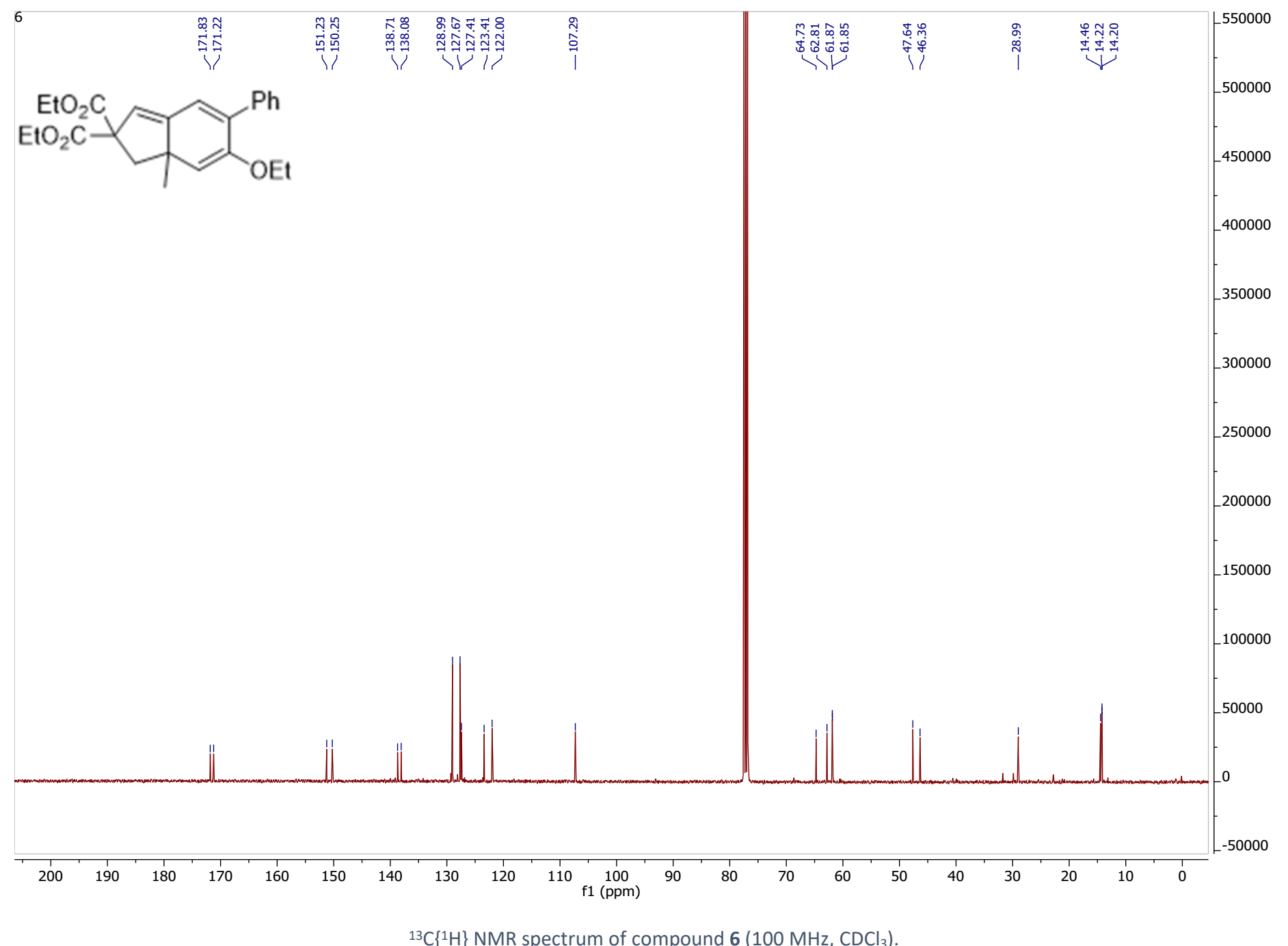

${ }^{13} \mathrm{C}\left\{{ }^{1} \mathrm{H}\right\} \mathrm{NMR}$ spectrum of compound $6\left(100 \mathrm{MHz}, \mathrm{CDCl}_{3}\right)$. 


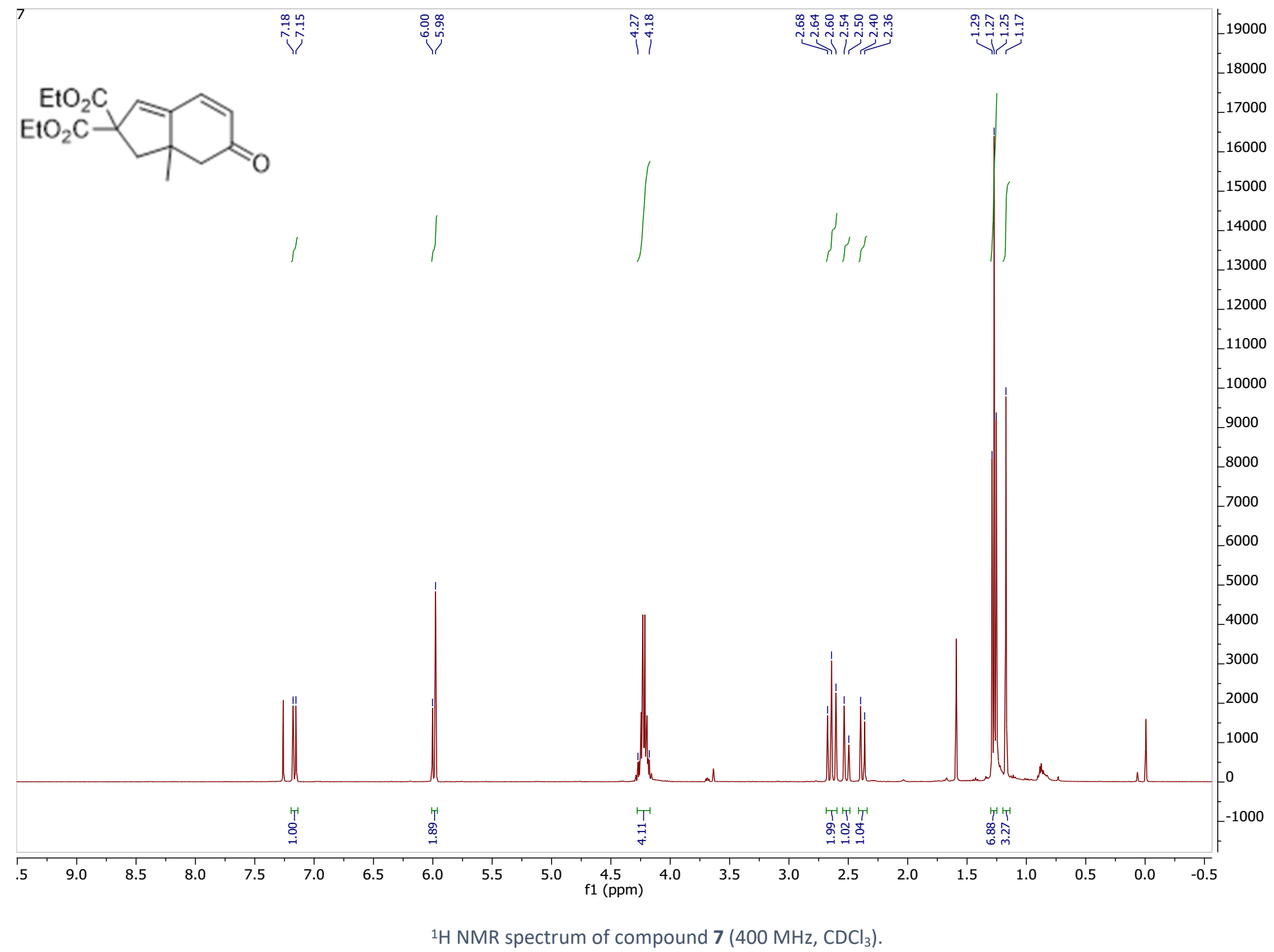




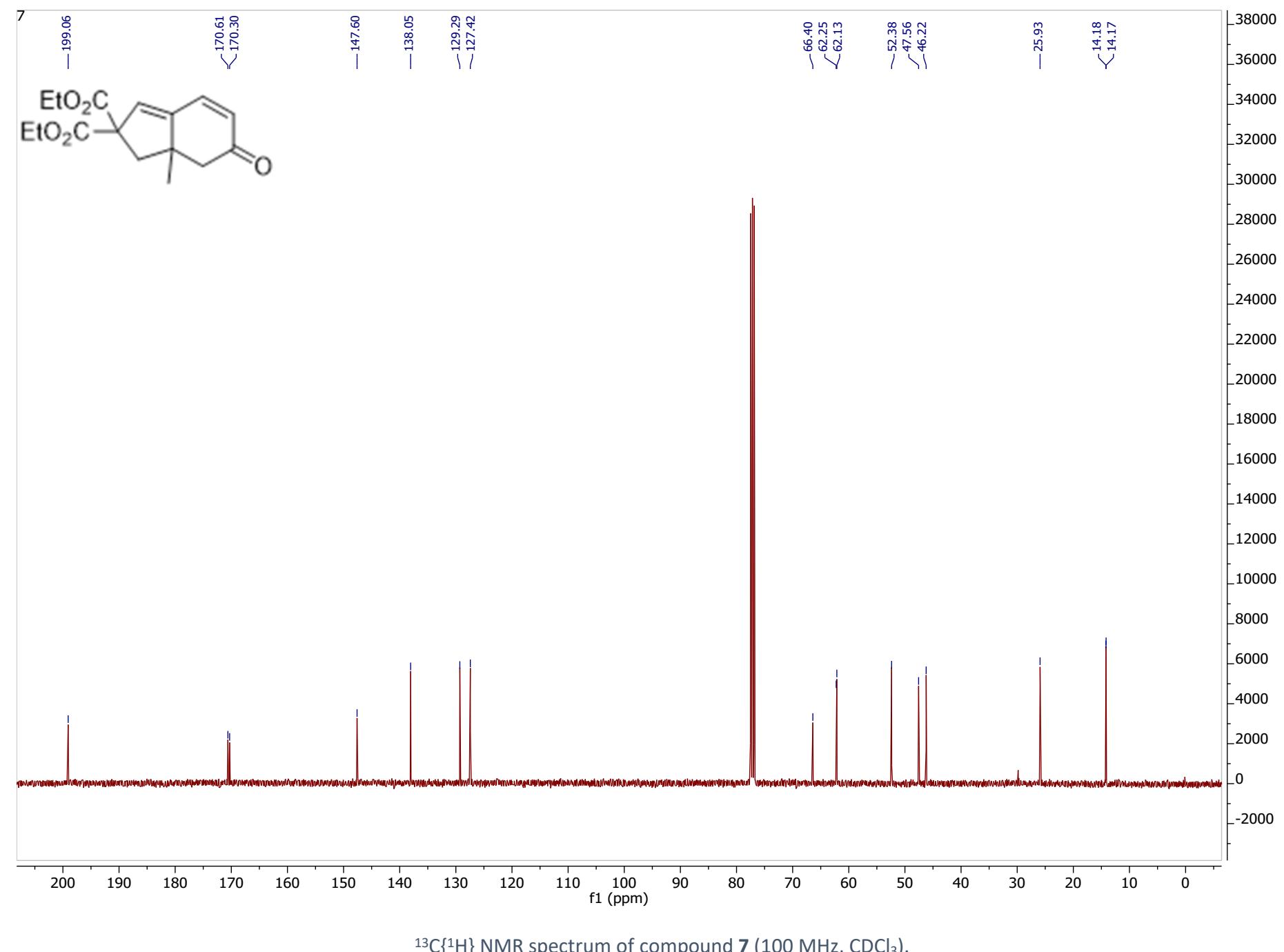

${ }^{13} \mathrm{C}\left\{{ }^{1} \mathrm{H}\right\}$ NMR spectrum of compound $7\left(100 \mathrm{MHz}, \mathrm{CDCl}_{3}\right)$. 


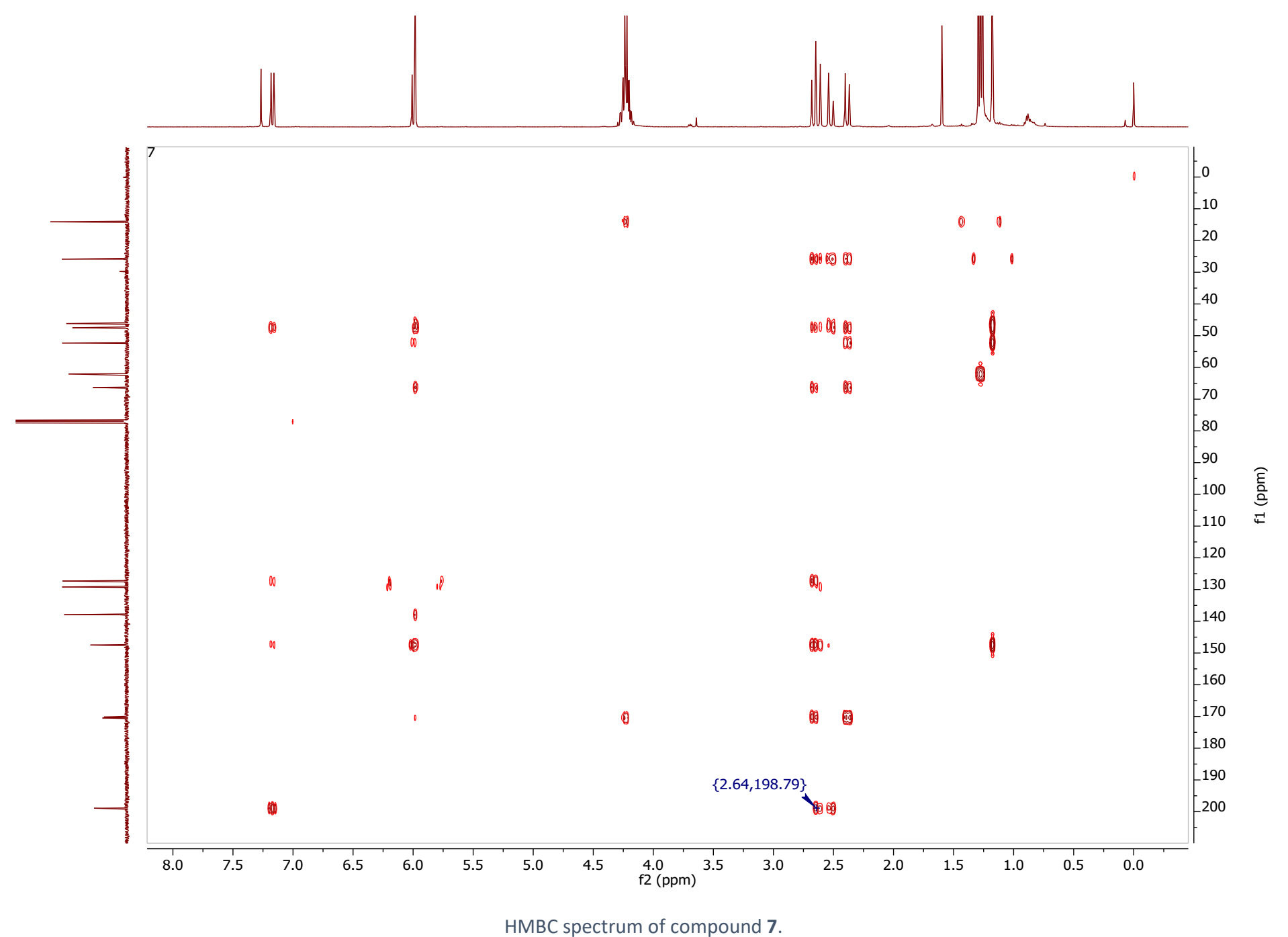




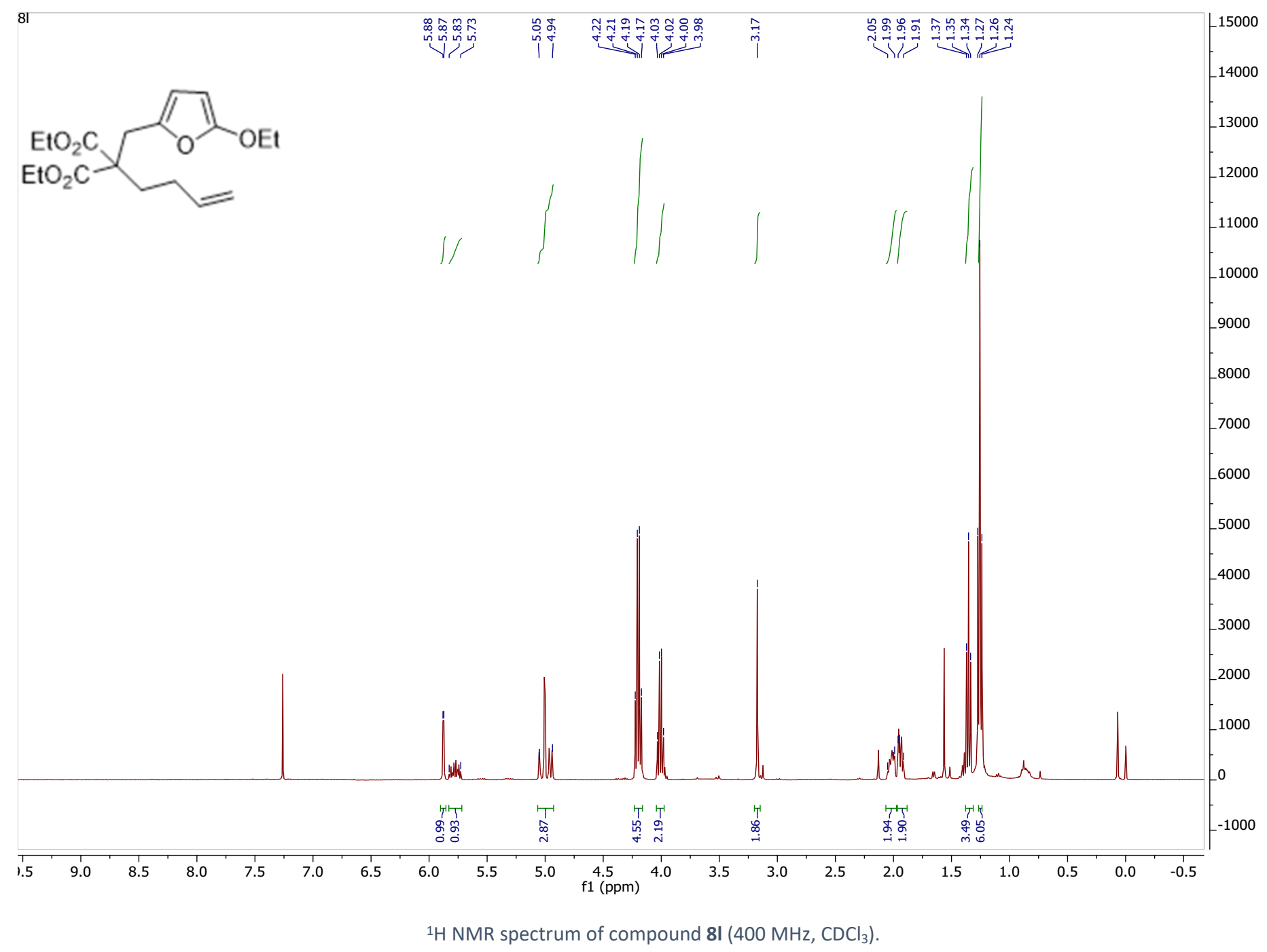



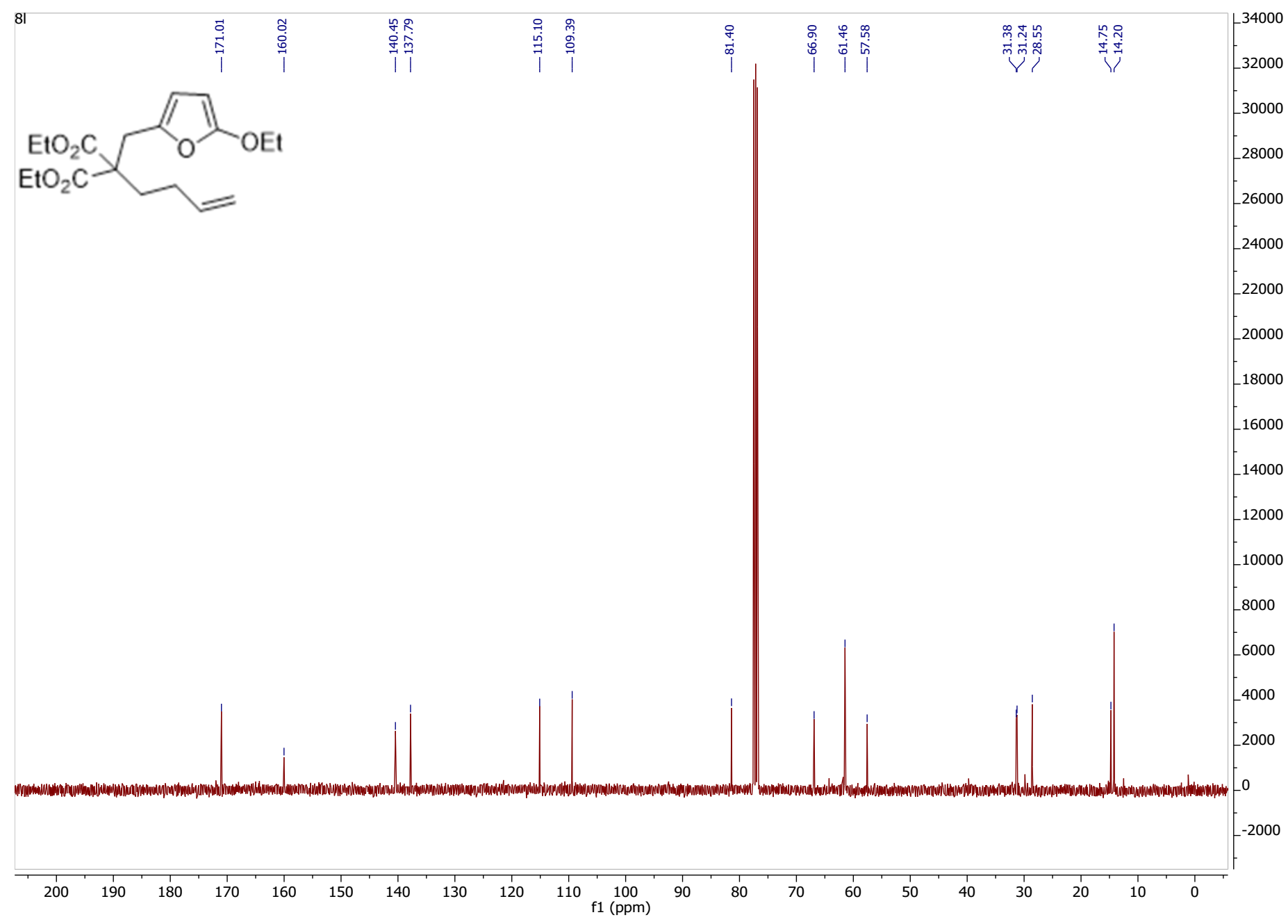

${ }^{13} \mathrm{C}\left\{{ }^{1} \mathrm{H}\right\}$ NMR spectrum of compound $8 \mathrm{l}\left(100 \mathrm{MHz}, \mathrm{CDCl}_{3}\right)$. 